\title{
Mothers' Accuracy and Bias in Predicting their Toddlers Performance on the Bayley Scales of Infant Development
}

\author{
Darcey N. Powell \\ West Virginia University
}

Follow this and additional works at: https://researchrepository.wvu.edu/etd

\section{Recommended Citation}

Powell, Darcey N., "Mothers' Accuracy and Bias in Predicting their Toddlers Performance on the Bayley Scales of Infant Development" (2011). Graduate Theses, Dissertations, and Problem Reports. 3345.

https://researchrepository.wvu.edu/etd/3345

This Thesis is protected by copyright and/or related rights. It has been brought to you by the The Research Repository @ WVU with permission from the rights-holder(s). You are free to use this Thesis in any way that is permitted by the copyright and related rights legislation that applies to your use. For other uses you must obtain permission from the rights-holder(s) directly, unless additional rights are indicated by a Creative Commons license in the record and/ or on the work itself. This Thesis has been accepted for inclusion in WVU Graduate Theses, Dissertations, and Problem Reports collection by an authorized administrator of The Research Repository @ WVU. For more information, please contact researchrepository@mail.wvu.edu. 
Mothers' Accuracy and Bias in Predicting their Toddlers Performance on the Bayley Scales of Infant Development

Darcey N. Powell

\author{
Thesis submitted to the \\ Eberly College of Arts and Sciences \\ at West Virginia University \\ in partial fulfillment of the requirements \\ for the degree of \\ Master of Science \\ in \\ Life-Span Developmental Psychology
}

\author{
Katherine Karraker, Ph.D., Chair \\ Amy Gentzler, Ph.D. \\ Priscilla Coleman, Ph.D.
}

Department of Psychology

Morgantown, WV

2011

Keywords: Maternal knowledge, maternal predictions, Bayley Scales of Infant Development, toddlers Copyright 2011 Darcey N. Powell 


\section{ABSTRACT \\ Mothers' Accuracy and Bias in Predicting their Toddlers Performance \\ on the Bayley Scales of Infant Development}

Darcey N. Powell

This study evaluated mothers' specific knowledge of their own toddlers' development. Mothers' predictions of their toddlers' performance on the Bayley Scales of Infant Development, Second Edition (BSID-II) were compared to their toddlers' performance on each task. In addition, mothers' accuracy in their predictions and toddlers' performance was compared to the toddlers' display of emotional behaviors during the assessment. Mothers $\left(N=68, M_{\text {age }}=31.31\right.$ years) with toddlers between the ages of 19 and 26 months ( $M_{\text {age }}=21.76$ months) completed demographic questionnaires, measures assessing their perceived parenting self-efficacy, their knowledge of developmental norms, and their expectation for their toddlers' performance on the BSID-II. Toddlers were administered the BSID-II, with their parent present. The administration was videotaped and toddlers' behavior during the assessment was later coded. Results indicated that mothers' predictions were associated with their toddlers' performance, but their predictions of performance varied between the mental and motor scales. In addition, mothers' biographical information was not associated with their accuracy on either the mental or the motor scale, or their toddlers' performance. Mothers' biases were associated with their toddlers' performance on the mental scale, but not the motor scale. Finally, mothers' ratings and the assessment administrator's ratings of toddlers' emotional behavior were associated with mothers' accuracy and their toddlers' performance. However, toddlers' display of emotional behavior was only modestly associated with their mothers' accuracy. These results suggest that mothers may take their children's typical behavior into consideration when predicting their performance, recognizing that the toddlers' emotional behavior during the assessment will likely affect their performance. These findings may be useful to the revision and development of assessments for young children and to practitioners who work with parents of young children. 


\section{ACKNOWLEDGEMENTS}

My sincere appreciation goes to all those that contributed to this project. I am extremely grateful for Dr. Katherine Karraker's guidance and support of my project, as well as her dedication to my professional and academic development. I am also appreciative of Dr. Priscilla Coleman for allowing me to use data she collected as a part of her dissertation for this project, as well as her comments and suggestions on this project. Additionally, I am thankful for the feedback provided by Dr. Amy Gentlzer. Finally, I am eternally grateful for my family's continuous support and encouragement while I strive to reach my goals. 
TABLE OF CONTENTS

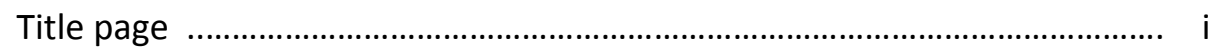

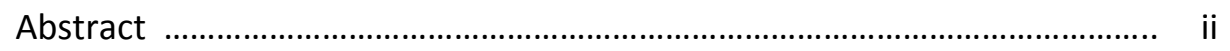

Acknowledgements ................................................................................ iii

Table of contents …............................................................................. iv

List of tables .............................................................................................

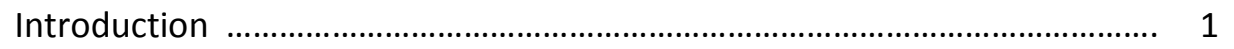

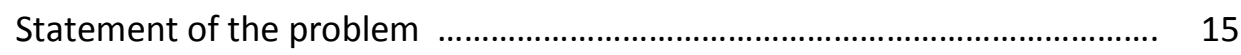

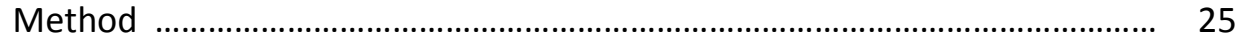

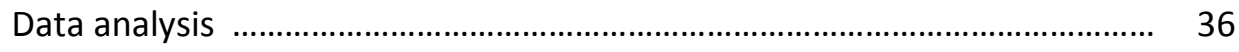

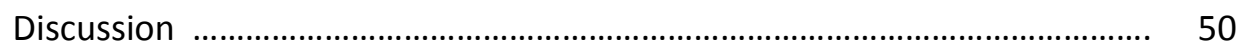

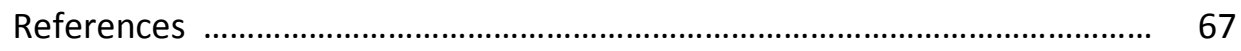

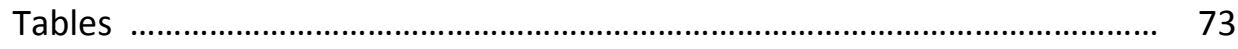

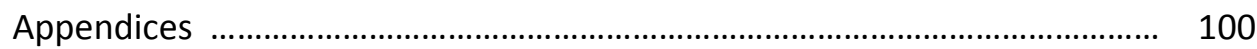




\section{LIST OF TABLES}

Table 1

Participant characteristics

Table 2

Additional participant characteristics

Table 3 75

How maternal accuracy and bias variables and toddlers' performance variables were created.

Table 4 76

Cohen's Kappas for the researcher's and research assistants' coding of toddlers' emotional behavior during the BSID-II

Table 5 77

Missing data from mothers' predictions of and toddlers performance on the BSID-II, reported by participant ID number

Table 6

Summary of demographic variables separated by sex of toddler

Table 7 80

Means for maternal accuracy and bias variables and toddler performance variables separated by sex of toddler

Table 8 81

Summary of toddlers' mood and emotional behavior variables separated by sex of toddler

Table 9 82

Correlations between maternal and toddler characteristics and mothers' 
accuracy and bias in predicting their toddlers' BSID-II performance

Table 10 85

Multiple regression analyses predicting mothers' accuracy on the mental scale from individual differences in mother and toddler characteristics

Table 11 87

Multiple regression analyses predicting mothers' accuracy on the motor scale from individual differences in mother and toddler characteristics

Table 12 89

Multiple regression analyses predicting mothers' overestimations on the mental scale from individual differences in mother and toddler characteristics

Table 13

Multiple regression analyses predicting mothers' overestimations on the motor scale from individual differences in mother and toddler characteristics

Table 14 93

Multiple regression analyses predicting mothers' underestimations on the mental scale from individual differences in mother and toddler characteristics

Table 15 95

Multiple regression analyses predicting mothers' underestimations on the motor scale from individual differences in mother and toddler characteristics

Table 16 97

Correlations between maternal and toddler characteristics and toddlers' performance on the BSID-II 
Mothers' Accuracy and Bias in Predicting Their Toddlers' Performance on the Bayley Scales of Infant Development

Research has shown that mothers who are familiar with child development norms and know the capabilities of their own children are likely to create more optimal child rearing settings than are mothers who know less about child development and what their children can do (Coleman et al., 2002; Hunt \& Paraskevopoulos, 1980; Morawska, Winter, \& Sanders, 2009; Reich, 2005). Greater knowledge of child development has also been associated with more positive child outcomes (Morawska et al., 2009). General knowledge of child development is related to, but is not the same as, specific knowledge about one's own child. Both types of knowledge are important when mothers predict their children's future behavior; mothers can draw on general knowledge of when children typically develop certain abilities and relate that information to what they know their children can do.

Mothers are providing an estimate of the abilities they believe their children have when they predict how their children will perform a task. Researchers can assess the accuracy of the mothers' predictions by asking their children to perform the tasks and evaluating how the children perform at a particular point in time. Accurate predictions suggest that mothers know their children's capabilities. At times there can be a systematic difference between what mothers believe their children can do and what their children do during an assessment. This bias arises when mothers routinely think their children cannot do something, but the children can - underestimations, or when mothers routinely think their children can do something, but the children cannot - overestimations. In addition, there may be instances when mothers know that their children are capable of performing a task but the children fail to perform the task, 
despite being able to, resulting in an outcome that appears to be an overestimation, but the error is due to the children and not the mothers.

Previous studies have found that mothers' characteristics and actions relate to their accuracy in predicting their children's capabilities and performance on developmental tasks (Coleman et al., 2002; Hunt \& Paraskevopoulos, 1980; Karraker \& Evans, 1996; Tamis-LeMonda, Chen, \& Bornstein, 1998). Although these studies have documented maternal inaccuracy, extant studies have not explored children's characteristics and behaviors during assessments that may contribute to this inaccuracy. Furthermore, researchers have not determined if maternal inaccuracy and bias is a result of maternal characteristics and behaviors, child characteristics and behaviors, or a combination of both.

Therefore, this study proposed three primary research goals: (a) to assess the accuracy of mothers' predictions of their children's performance, (b) to identify characteristics and behaviors, of both the mothers and their children, that are predictive of individual differences in mothers' accuracy, and (c) to identify characteristics and behaviors, of both the mothers and their children, that are associated with mothers' biased predictions of their children's performance (systematically predicting better or worse performance from their children relative to their children's abilities).

Data on mother-child dyads from a previous study investigating parenting self-efficacy and mother-child interaction (Coleman \& Karraker, 2000) were reexamined to address these research goals. Mothers in that study completed a series of questionnaires regarding demographic information (including information on their children's temperament and when the children had reached developmental milestones), parenting self-efficacy, child-rearing 
attitudes, knowledge of child development, and expectations for their children's performance on the Bayley II Scales of Infant Development (BSID-II). Their children were then administered the BSID-II. In this study, characteristics and behaviors of both the mothers and their children were examined as correlates of mothers' accuracy and bias in making their predictions. Videotapes of the BSID-II were coded to quantify the children's behavior during the assessment to determine behavioral correlates of maternal accuracy and bias.

The literature review below first covers the BSID-II and the use of maternal report by researchers, then addresses what is known about factors associated with (a) mothers' knowledge of child development and knowledge of their own children's abilities, (b) mothers' biases in reporting and predicting their own children's behaviors, and (c) mothers' and toddlers' characteristics and behaviors that relate to mothers' accuracy in predicting their toddlers' performance. Following a review of literature that relates to the goals of this study, the specific research questions and hypotheses evaluated are described.

\section{Bayley II Scales of Infant Development (BSID-II; Bayley, 1993)}

Unless otherwise noted all information in this section is from the Bayley Scales of Infant Development, Second Edition, manual (Bayley, 1993). Revised in 1993, the BSID-II consists of a mental, a motor, and a behavior rating scale. The BSID-II has been used in research and clinical settings and within the medical field to assess children's developmental abilities and to determine if children are possibly developmentally delayed or advanced. This measure has been validated for children between the ages of 1 and 42 months. The assessment takes about half an hour for children under the age of 15 months and up to an hour for children between 15 and 42 months. 
Flexible administration allows caregivers to encourage their children to complete a task or take short breaks when the children are tired or restless, which aids test administrators in capturing the children's fullest potential. However, there may be instances when even this flexible administration does not allow the administrator to accurately observe the children's capabilities. To reduce the number of distractions in the environment and gauge the children's true ability, the manual suggests conducting the assessment in a lab, rather than in the children's home. In addition, the developers discuss methods of handling stranger fear, a common obstacle in capturing the child's true ability when assessing children in this age range.

The mental scale includes tasks assessing children's memory, habituation, problem solving, number concepts, generalization, classification, vocalization, and social skills. The motor scale assesses children's gross and fine motor movements including rolling, crawling or creeping, sitting, standing, walking, running, jumping, prehension, use of writing instruments, and hand movements. Raw scores on the two scales are converted to index scores to create the Mental Development Index (MDI) and the Psychomotor Development Index (PDI), each with a mean of 100 and standard deviation of 15 . Research on the mental and motor scales of the BSID-II has found that approximately one-quarter of the variance in children's scores, two weeks later, are explained by their original scores, indicative of moderate stability (Harris, Megens, Backman, \& Hayes, 2005). The manual also offers evidence suggesting good inter-item reliability for the assessment as a whole and within the mental and motor scales. In addition, it gives evidence for predictive, discriminant, construct, content, and concurrent validity of the assessment. 
The Behavior Rating Scale (BRS) is completed by the administrator after the assessment has ended to evaluate the children's behavior during the assessment and includes: attention and arousal, orientation and engagement with the task, their caregiver, and the administrator, emotional regulation, and the quality of movements. The overall score, as well as the scores within each scale, are used to determine whether the children's behavior was within normal limits, questionable, or non-optimal for their age during the assessment. This scale has been shown to have the lowest test-retest reliability of the three scales, due to its focus on unstable traits such as mood. Research by Thompson, Wasserman, and Matula (1996) suggested that the BRS was most influenced by the child's motor performance and that scores tended to be more heterogeneous as the sample children's age increased.

While not an intelligence test or a test to predict future academic performance, the BSID-II does provide important information. During a single assessment, the administrator is able to provide a child's caregivers with an idea of the child's strengths and weaknesses across several developmental domains (Bayley, 2006). If conducted multiple times with a child, the administrator can chart the child's developmental progress as he or she ages or as a result of intervention (Bayley, 2006). In addition, this assessment has been used to determine if children are developing their mental and motor skills in line with previously normed standards (Black \& Matula, 2000).

The Bayley Scales of Infant Development have never taken maternal reports of children's capabilities into account when determining children's scores on the mental or motor scales. The manual for the second version does note though that before any decision is made about children's abilities or future, based on the BSID-II, other sources of information should be 
taken into consideration. These sources of information could include parental report, doctors' diagnoses, a more in-depth observation of the child's behavior, or other forms of assessment.

\section{Maternal Report}

Both advantages and disadvantages to using parents to report on their children's behavior or characteristics have been described (Seifer, 2005). This method tends to be less expensive and more time efficient than using trained observers. In addition, parents have had many interactions with their children, so they have a larger sample of behavior to base their judgments on than do trained observers, who may only spend an hour or two with the children and their parents (Coleman et al., 2002; Seifer, 2005; Saudino et al., 1998; Teti \& McGourty, 1996). In addition, there are times during children's days that researchers do not easily have access to, but that parents can report on, like bedtime or bath time. However, parents vary in education, experience, and training, which can lead to differential reports on behavior than would be given if trained observers were used. Also, parents typically see their children positively (Seifer, Sameroff, Dickstein, Schiller, \& Hayden, 2004); therefore, their positive biases may enter into their reports on behavior, giving the researcher an inaccurate picture of the children's actual behavior and characteristics.

Previous research by Teti and McGourty (1996) revealed that as trained observers spent more time with children, their ratings of children's temperament became more similar to mothers' ratings of their children's temperament. Therefore, it may not be the parent who is unreliable but rather the trained observer, who has not captured a representative sample of the children's behavior. Research also suggests that parents are most accurate when they are assessing current behaviors rather than prospective or retrospective behaviors (Saudino et al., 
1998). These authors also suggest that the combination of parental report and direct observation may assess children's ability better than either measure alone.

\section{Mothers' General Knowledge of Child Development}

Mothers tend to have two main types of knowledge about child development: general knowledge about child development, reflecting norms of development and typical behaviors of children, and specific knowledge about their children's characteristics, skills, and typical behaviors. This section focuses on mothers' general knowledge; the next focuses on mothers' specific knowledge. Much more is known about correlates of general knowledge than correlates of specific knowledge. Further research is needed to establish whether general knowledge, specific knowledge, or a combination of both predict optimal developmental outcomes for the child.

Previous research has suggested that having general knowledge of child development is not related to mothers' specific knowledge of their own children (Karraker \& Evans, 1996). Research by McGillicuddy-DeLisi (1982) suggests that mothers have complex belief systems in their knowledge of child development. How parents acquire this belief system is a combination of their own experiences as a child and a parent (McGillicuddy-DeLisi, 1982), as well as information from external sources such as classes, doctors, and books written by child professionals (Dichtelmiller et al., 1992; Reich, 2005).

In a study by Reich (2005) examining knowledge of developmental norms, parents and parents-to-be correctly indicated when developmental milestones occur approximately $65 \%$ of the time. However there can be great variability in adults' accuracy. Therefore, researchers have suggested that knowledge of child development may be multidimensional and domain 
specific (Tamis-Lemonda, Chen, \& Bornstein, 1998). For example, Tamis-Lemonda et al. found that mothers may know norms for language development but not know norms for play development.

Factors associated with mothers' knowledge of child development. Several studies have suggested that education may be the strongest predictor of maternal knowledge of child development, with higher education associated with greater knowledge (Hunt \& Paraskevopoulos, 1980; McGillicuddy-DeLisi, 1982; Morawska, Winter, \& Sanders, 2009; Reich, 2005). Further research demonstrated that older mothers knew more about child development norms than younger mothers (Dichtelmiller et al., 1992; Karraker \& Evans, 1996; McGillicuddyDeLisi, 1982; Reis, 1988). Reich (2005) found that Caucasian mothers knew more about child development than non-Caucasian mothers. However, one must take into consideration that different races prioritize certain behaviors and characteristics over others, which may relate to their differential levels of knowledge about child development (Benasich \& Brooks-Gunn, 1996; Tamis-LeMonda et al., 1998). Research has also suggested that parenting self-efficacy beliefs are associated with mothers' knowledge of child development (Coleman \& Karraker, 2003; Harty et al., 2006). Mothers with high levels of parenting self-efficacy tend to have more knowledge about child development.

Other research has revealed that mothers who reported a higher family income had more knowledge about child development (Morawska et al., 2009). Also, it has been found that mothers who work outside the home and have help caring for their children tend to know more about cognitive and physical development than those who do not work outside the home and have less assistance with child care (Hunt \& Paraskevopoulos, 1980; Reich, 2005). However, 
education may mediate the findings in both of these associations. Benasich and Brooks-Gunn (1996) though, reported that above and beyond socioeconomic status, aspects of the home environment, such as family make-up and amount of time spent with their own child, were associated with maternal knowledge of child development. These inconsistent findings, with regard to how the amount of time mothers spend with their children is associated with knowledge of child development, suggests that more research should be conducted in this area.

How knowledge of child development may affect child development. In the study by McGillicuddy-DeLisi (1982), described above, maternal knowledge of child development and child outcomes were not associated; whereas in other studies a significant association has been found. For example, Dichtelmiller et al. (1992) reported that mothers with above-average knowledge of child development had children who scored one standard deviation higher on the BSID than mothers with average or below-average knowledge of child development. Reis (1988) suggests that mothers' unrealistic expectations for when children acquire the skills to complete developmental norms may cause them to become frustrated that their children have not yet met these developmental milestones, potentially leading to harmful behaviors by the mothers. Along the same line of research, Reich (2005) cites several other studies that have linked greater knowledge of child development to lower levels of child maltreatment.

Why knowledge may be associated with child development. Although research has been inconsistent in finding significant associations between mothers' general knowledge of child development and children's developmental outcomes, one hypothesis has been posited when associations are significant. The match hypothesis states that bright mothers have bright children (Hunt \& Paraskevopoulos, 1980; Miller, 1986). Not only is intelligence passed on 
genetically, but mothers who have more knowledge about child development, in general, can create an environment that promotes their children's development, which in turn encourages the children to perform better on developmental assessments.

\section{Mothers' Specific Knowledge about Their Own Children}

Within a family, parents learn what their child can do through their own interactions with their child and by talking to the other parent about his or her interactions with the child (Dichtelmiller et al., 1992; McGillicuddy-DeLisi, 1982). Research has suggested that, like general knowledge of child development, specific knowledge may also be multidimensional and domain specific. This finding was evidenced in Miller's (1986) study where mothers were fairly accurate in estimating their children's ability to complete questions from the Stanford-Binet Intelligence Scales, but the mothers were only accurate at chance level on Piagetian questions. The time mothers spend with their children has also been suggested to be related to mothers' specific knowledge. All the mothers in McGillicuddy-DeLisi's (1982) study were their child's primary caregiver, thus spending more time with their child, and were more knowledgeable about their own children's abilities than the fathers in the study, who were not their children's primary caregivers. Therefore differences in mothers' specific knowledge may be a result of the amount of time spent with their children. Overall though, it is evident that several factors influence mothers' knowledge about their own children's abilities.

Mothers' accuracy and biases in reporting their children's behaviors. When studying children's characteristics and behaviors, often researchers turn to parents to report their children's behavior. Previous research on whether or not this is an accurate method has had mixed findings. Some research suggests that parents can accurately recognize their children's 
strengths and weaknesses (Harty, Alant, \& Uys, 2006). However, other studies have found that when parents are judging their own children's behaviors and characteristics there is a discrepancy between what parents report and what a trained observer reports (Seifer, 2005; Seifer, Sameroff, Dickstein, Schiller, \& Hayden, 2004; Teti \& McGourty, 1996). This inconsistency in the research suggests that there may be individual differences in mothers' accuracy.

Research by Seifer et al. (2004) suggests that parents can be reliable reporters of temperament for unfamiliar children, in that $74 \%$ of their ratings correlated at least 0.80 with trained observer ratings. However, parents are not reliable reporters of temperament, compared to trained observers, for their own children, with only 1 of the 112 ratings correlated at 0.80 or above with the trained observer ratings. Parents' ratings of their own children, and to a lesser extent ratings of unfamiliar children, were much more positive than the trained observers' ratings of the children.

\section{Mothers' accuracy in predicting their children's behaviors and associations with the} children's development. Hunt and Paraskevopoulos (1980) identified an association between the accuracy of a mother's predictions of performance, a measure of the mother's specific knowledge, and child performance; more than half of the variance in the child's performance was explained by the mother's predictions. Mothers who were less accurate in predicting their own children's behavior had children who performed less well on the BSID. Miller (1986) also found that the more accurate mothers had children who performed better on the BSID. 
Inaccurate predictions of child behavior can occur in two directions: mothers overestimate their children's performance when they expect that their children will be able to perform a task but they do not, and they underestimate their children's performance when they expect that their children will not be able to perform a task but they do. Although mothers often accurately predict their children's performance, when they err they tend to overestimate what their children can do (Hunt \& Paraskevopoulos, 1980; Miller, 1986; Reich, 2005). This finding suggests that mothers tend to see their children in a positive light and have high expectations of what their children can do. However, these overestimations of performance may frustrate children when they are unable to complete tasks that their mothers expect them to be able to complete. On the other hand, underestimations lead to child boredom because although their mothers believe they won't be able to complete the task, they do and are not challenged by it (as cited in Dichtelmiller, 1992), therefore producing a less challenging environment for those children. The issue of which are more detrimental to child development, overestimations or underestimations, is a debate within the literature (Hunt \& Paraskevopoulos, 1980; Price \& Gillingham, 1985). However, some researchers believe that overestimations may be good because they inspire children to enhance their abilities and strive toward higher levels of performance. In addition, mothers' overestimations of abilities may promote their use of scaffolding when presenting their children with a new type of activity. A reassessment of the Hunt and Paraskevopoulos's study (1980) scored over- and underestimations as a proportion of opportunities rather than simply counting the number of correct predictions, overestimations, and underestimations (Price \& Gillingham, 1985). Hunt and Paraskevopoulos reported that underestimations appeared to be less associated with 
children's developmental growth than overestimations; later, Price and Gillingham suggested that both underestimations and overestimations negatively correlated with intellectual development, but overestimations weren't negatively associated as initially reported. For both sets of authors, their determination of which was more negatively associated with child development was based on correlations between the direction of mothers' biasesunderestimations or overestimations, and the children's cognitive development. However, the researchers in both of these studies suggested that the ideal situation is when mothers know what their children are capable of and create an environment that promotes development (Hunt \& Paraskevopoulos, 1980; Price \& Gillingham, 1985).

Research by Miller (1986) revealed a pattern in mothers' errors in their knowledge of child development and of their own children: mothers tended to estimate overly early ages for beginning developmental abilities and estimate overly late ages for more advanced developmental abilities. This finding suggests that mothers may be accurate in reporting what their children can do currently, but have difficulty remembering the age at which their children were able to complete an early task and may be unsure of when their children will be able to do a later task. Mothers were also more knowledgeable about developmental norms that occurred around the age of their children and were less accurate for earlier and later developmental norms. This finding that accuracy of knowledge about developmental norms is influenced by the age of the child was supported by Tamis-LeMonda et al. (1998). They found that the mothers of older children in their study estimated that early developmental abilities happened later than did mothers of younger children. 
In addition, the children of mothers who were more likely to overestimate their own children's performance, in relation to their predictions of average children's performance, scored higher on the BSID than children of mothers whose predictions for their own children were similar to their predictions for average children (Miller, 1986). However, research by Karraker and Evans (1996) found only a trend between children's performance on the BSID and mothers' inaccurate predictions of their children's performance, suggesting that mothers' expectations of children's performance may not influence their behavior or the children's outcome. Taken together, research is inconsistent concerning whether mothers with greater knowledge of their own children's development and higher expectations are more likely to create an environment that fosters their children's growing abilities and promotes development (Reich, 2005).

\section{External Factors Interfering with Mothers' Accuracy in Predicting Their Children's Behavior}

As mentioned above, it is plausible that mothers may be correct in their predictions of their children's performance based on the children's abilities, but their children fail to perform the task due to other factors. These interferences may be due to child characteristics and behavioral styles, maternal behaviors, or environmental factors. The effect of children's characteristics and behavior on their performance during assessments has often been dismissed as error variance with a perfunctory statement within the limitations section of articles.

Early research evaluating children's performance on developmental assessments, such as the BSID-II, questioned whether test administers are measuring ability or compliance when assessing young children. For example, one such study reported that young children may be 
more likely to maximize their performance in a testing environment when they are better at learning tasks on their own than when they are less able to learn tasks on their own (Hrncir, Seller, \& West, 1985). Earlier research by Seegmiller and King (1975) revealed that children's sociability was less predictive of performance on the mental scale of the Bayley Scales of Infant Development, First Edition, (BSID-I) than was the children's responsiveness to the objects presented to them. In addition, these researchers reported that the social and emotional behaviors of the children did not significantly influence their performance on the motor scale on the BSID-I.

Previous research has coded maternal behavior during the BSID-II as competence inhibiting or competence promoting and found an association between maternal behaviors and child scores (Coleman et al., 2002). Mothers who engaged in more competence inhibiting behaviors had children who scored lower on the MDI than mothers who engaged in more competence promoting behaviors. The current study took a deeper look at the mother-child interaction to determine if the children's behavior contributed to maternal inaccuracy in predictions of performance. The environment the assessment is given in, the personality of the test administrator, and other factors may also interfere with the children's performance. However, as only one administrator gave the BSID-II to all the children and the assessment always took place in one of two laboratories, investigating environmental factors was not possible in the current study.

\section{Statement of the Problem}

This study assessed whether or not particular toddler attributes, as well as maternal attributes, were associated with differences in mothers' ability to predict their toddlers' 
performance and their toddlers' actual performance on the BSID-II. This study links two bodies of research, research on developmental assessments and research on maternal accuracy and bias in predicting their children's behaviors. Linking these two areas of research may aid in the development of future assessments or revision of current assessments, and contribute to understanding of how maternal knowledge and biased predictions may relate to child development.

The purpose of this study was to assess mother and toddler correlates of mothers' accuracy in predicting toddlers' performance on the BSID-II. Because performance is an estimate of the children's capabilities, investigating mothers' ability to correctly identify which tasks their toddler will or will not complete gives insight into mothers' specific knowledge of what their children can do and their general knowledge of child development. There are also instances when mothers do know what their children are capable of doing but their children refuse to complete the related tasks, causing inaccurate maternal predictions. Therefore, this study had three primary research goals: (a) to assess the accuracy of mothers' predictions of their toddlers' performance, (b) to identify maternal characteristics and toddler characteristics and behaviors that are predictive of individual differences in mothers' accuracy, and (c) to identify maternal characteristics and toddler characteristics and behaviors that are associated with mothers' biased predictions of their toddlers' performance (systematically predicting better or worse performance from their toddler relative to their toddlers' actual performance). Questionnaire data from mothers in a previous study assessing maternal self-efficacy were analyzed and video recordings of their toddlers during the BSID-II were coded to identify behavioral correlates of maternal accuracy and inaccuracy. 


\section{Research Question 1: How Accurately do Mothers, on Average, Predict Their Toddlers' Performance?}

Hypothesis 1a: Mothers' predictions of their toddlers' performance will be strongly positively correlated with their toddlers' actual performance on the BSID-II.

Rationale: Previous research has found that mothers are relatively accurate reporters of their children's behavior and abilities (Harty, Alant, \& Uys, 2006; Reich, 2005; Saudino et al., 1998; Tamis-LeMonda et al., 1998; Teti \& McGourty, 1996). Many of the behaviors assessed by the BSID-II should be familiar to mothers and, because they know their toddlers, mothers should be able to reflect back and remember whether or not they have seen their toddlers engage in these or similar behaviors.

Hypothesis 1b: Mothers will, on average, predict that their toddlers will pass more tasks than the toddlers will pass.

Rationale. In general, mothers have favorable opinions and optimism about their children and their abilities. Therefore it is expected that mothers will be more likely to overestimate than to underestimate their toddlers' performance. This expectation has been observed in several previous studies (Hunt \& Paraskevopoulos, 1980; Karraker \& Evans, 1996; Miller, 1986; Reich, 2005). A key component of their inaccurate predictions is that mothers tend to think of their children optimistically and therefore are more likely to affirm their children's ability than to indicate that their children may not be able to complete a task. 
Hypothesis 1c: Mothers will, on average, be more accurate on the motor scale than on the mental scale.

Rationale. Research by Tamis-LeMonda et al. (1998) found that mothers were more accurate in their expectations for tasks that they were more likely to have seen. Therefore, although mothers may be familiar with tasks on the mental scale, they are more likely to have seen their toddlers engage in the types of behaviors assessed on the motor scale, and thus be more accurate on the motor scale.

Research Question 2: What Factors are Related to Individual Differences in Mothers' Accuracy in Predicting Toddlers' BSID-II Performance?

Hypothesis 2a: Mothers who know more about child development will be more accurate than mothers who know less about child development.

Rationale. Possessing knowledge about child development norms and when toddlers typically pass developmental milestones will allow mothers to make informed guesses about those behaviors that they may not have witnessed their toddlers carry out.

Hypothesis $\mathbf{2 b}$ : Mothers with more education will be more accurate than mothers with less education.

Rationale. This association is anticipated due to the positive correlation previously found between education and knowledge of child development (Reich, 2005; Tamis-LeMonda et al., 1998). In addition, Hunt and Paraskevopoulos (1980) found that mothers with more 
education made fewer overestimation errors in predicting their children's performance than mothers with less education.

Hypothesis 2c: Mothers who provide more care for and spend more time with their toddlers will be more accurate than mothers who provide less care for and spend less time with their toddlers.

Rationale. The quantity of time mothers spend with their toddlers may increase the opportunities for the mothers to see their toddlers engage in the behaviors assessed by the BSID-II. Therefore, those who provide primary care for their children may be more likely to witness their toddlers demonstrate a skill (McGillicuddy-DeLisi, 1982) similar to those evaluated during the BSID-II than mothers who are not able to spend as much time with their toddlers.

Hypothesis 2d: Mothers with higher parenting self-efficacy will be more accurate than mothers with lower parenting self-efficacy.

Rationale. Greater parenting self-efficacy has been linked with mothers being more confident in the mothering role, being more knowledgeable of child development, and creating more appropriate experiences for their children than mothers with less parenting self-efficacy (Coleman \& Karraker, 2003). Therefore, mothers with higher parenting self-efficacy may have greater knowledge of child development and what their children are capable of doing, resulting in greater accuracy than mothers with lower parenting self-efficacy.

Hypothesis 2e: Multiparous mothers will be more accurate than primiparous mothers. 
Rationale. General knowledge of child development is gained from raising children (Dichtelmiller, 1992; Reich, 2005). Therefore, mothers who have additional children are expected to be more accurate than mothers who have only one child.

Hypothesis 2f: Older mothers will be more accurate than younger mothers.

Rationale. Previous studies have suggested that older mothers tend to have more education and know more about child development (Dichtelmiller, 1992; Karraker \& Evans, 1996). They are, therefore, anticipated to be more accurate in their predictions than younger mothers.

\section{Research Question 3: What Maternal Factors are Related to Individual Differences in Toddlers' Performance on the BSID-II?}

Hypothesis 3a: Toddlers whose mothers have greater knowledge about child development will pass more tasks on both the mental and motor scales than toddlers whose mothers have less knowledge about child development.

Rationale. Previous research by Dichtelmiller et al. (1992) found that low birth weight 8month-old infants whose mothers had above-average knowledge of child development scored one standard deviation higher on both the MDI and PDI than similar infants whose mothers had average or below-average knowledge of child development. Therefore, it is expected that this relation may persist into toddlerhood and be generalizable to all children, regardless of birth weight. Additional research on this topic has revealed that more knowledgeable mothers create more appropriate environments for toddlers' emerging abilities than do mothers with less 
knowledge of child development (Benasich \& Brooks-Gunn, 1996), potentially leading to better toddler performance.

Hypothesis 3b: Mothers who overestimate their toddlers' performance relatively more than other mothers and underestimate their toddlers' performance relatively less than other mothers will have toddlers who score higher on the BSID-II.

Rationale. Mothers who expect better performance from their toddlers are more likely than other mothers to create an atmosphere that aids their toddlers in developing to their greatest potential. Prince and Gillingham (1985) recalculated data initially collected by Hunt and Paraskevopoulos (1981) by accounting for overestimations and underestimations as a proportion of opportunities, rather than using the unadjusted frequency of overestimations and underestimations. Price and Gillingham found that overestimations of children's ability by parents were not as strongly negatively correlated with children's development as previously indicated by Hunt and Paraskevopoulos. In addition, underestimations of children's ability were also negatively correlated with children's development, leading Price and Gillingham to believe that it should no longer be considered optimal for children if their parents underestimate what they can do.

Research Question 4: What Toddler Characteristics and Behaviors are Associated With Reduced Maternal Accuracy?

Hypothesis 4a: Toddlers who show more signs of negative emotional behavior during the BSID-II will have mothers who are less accurate. 
Rationale. Although the mothers of those toddlers who display signs of negative mood may know their children's capabilities, toddlers' mood may hinder the toddlers' completion of tasks, resulting in fewer accurate predictions.

Hypothesis 4b: Mothers who rate their toddlers as more difficult in temperament will be less accurate.

Rationale. Toddlers rated by their mothers as more difficult may be less likely to follow the prompts of either the test administrator or their mothers than toddlers rated as easier, therefore leading to inaccurate predictions in their skills by their mothers, even if the mothers have witnessed their children engaging in such activities before.

Hypothesis 4c: Mothers whose toddlers are rated as more socially engaged by the test administrator on the Behavior Rating Scale will be more accurate.

Hypothesis 4d: Mothers whose toddlers are rated as more adaptable by the test administrator on the Behavior Rating Scale will be more accurate.

Rationale. The toddlers' ages at the time of this study coincide with the occurrence of stranger fear. Lamb, Garn, and Keating $(1981 ; 1982)$ found that sociability, operationalized as responsiveness to the administrator and mother, was associated with better performance on the mental and motor scales of the BSID. Therefore, it is expected that toddlers who are less adaptable to new environments and less sociable around strangers will perform less well than they are capable of performing, resulting in more inaccurate predictions by their mothers. 
Hypothesis 4e: Mothers whose toddlers are rated more negatively by the test administrator on the Behavior Rating Scale will be less accurate.

Rationale. Those toddlers rated less positively by the administrator are more likely to have not completed the tasks during the BSID-II than those rated more positively, resulting in inaccuracy by the mother. Toddlers who are more task oriented, who are more engaged, and who display better emotion regulation are more likely to interact with the administrator and participate in the tasks they are capable of, when prompted; resulting in greater accuracy among these mothers than among mothers of toddlers who are less oriented, who are less engaged, or who display poorer emotional regulation.

Hypothesis 4f: Toddlers who awoke more frequently during the previous night will have mothers who are less accurate.

Rationale. Those toddlers who had more fragmented sleep the previous night will be more likely to display a negative mood during the BSID-II, resulting in inaccuracies by their mothers because their toddlers refuse to engage in the tasks prompted by the test administrator and their mothers.

Research Question 5: Does the Combination of Toddler Emotional Behavior and Maternal Pass Predictions During the BISD-II Predict Maternal Pass Predictions and Toddler Performance Better Than Either Measure Alone?

Hypothesis 5a: Although both toddlers' negative emotional behavior and maternal pass predictions will independently predict BSID-II performance, the combination of these 
two variables will significantly increase the prediction of toddlers' performance on the BSID-II than either variable alone.

Hypothesis 5b: Although both toddlers' negative emotional behavior and toddlers' performance will predict maternal pass predictions, the combination of these two variables will account for more variability in mothers' pass predictions than either variable alone.

Rationale. Previous reports of research in this area have often included recognition of the child's mood as a variable affecting a child's score in the limitations section of the discussion. In addition, mood may have a significant effect on mothers' inaccurate expectations of their children's capabilities. A negative mood can make even the most sociable toddler withdrawn and uninterested in appealing tasks. Therefore, it is expected that the combination of the toddlers' mood and their mothers' pass predictions will account for more variance than either alone when predicting toddlers' BSID-II performance; and the combination of toddlers' mood and performance will account for more variance than either alone when predicting mothers' pass predictions.

Exploratory Questions. Although answers to these questions are not directly addressed by prior research, they may further understanding of the processes being studied, and will be explored as part of this study. Answers to these questions will help to describe the nature of the data and the relations among maternal predictions and other variables.

Question 6a: Will mothers' ratings of their toddlers' mood be associated with mothers' accuracy in predicting performance? 
Question 6b: Will mother and toddler characteristics be related to mothers' accuracy and bias in predicting their toddlers' BSID-II performance?

Question 6c: Will mothers be better able to predict their children's performance on some tasks than others?

Question 6d: Will mothers be more likely to overestimate or underestimate their children's performance on some tasks than others?

Question 6e: How much variance do mother and toddler characteristics account for in explaining mothers' accuracy and bias?

Question 6f: How strongly correlated are mother and toddler characteristics?

Question 6g: Are there significant interactions between mother and toddler characteristics when predicting maternal accuracy and bias?

Question 6h: How do high-scoring infants differ from low-scoring infants?

Question 6i: What are alternative methods for calculating accuracy and bias, and how do they affect the results?

\section{Method}

This study tested the hypotheses using data previously collected by Priscilla Coleman (Coleman, 1999; Coleman et al., 2002). Information about the participants in the study and the materials that were used is summarized below, based on Coleman (1999) and Coleman et al. 
(2002). Additional data were obtained by coding toddlers' emotional behavior from videotapes of the BSID-II administrations included in the study.

\section{Participants}

Sixty-eight mother-toddler dyads participated in this study, conducted in Harrisonburg, Virginia $(n=42)$, and Sewanee, Tennessee $(n=26)$. Initially, participants were recruited from birth announcements in the local newspapers of the two areas. Advertisements were also placed in doctors' offices, daycare facilities, retail stores, and elementary schools.

Independent samples $t$-tests and chi-square difference tests were conducted to compare the participants who participated at the two sites and no significant differences between the two groups emerged for mothers' age, children's age, mothers' parity, mothers' race, mothers' education, mothers' marital status, families' income, or child care arrangements (see Tables 1 and 2). There was, however, a significant difference between the two groups for employment status: in Harrisonburg, Virginia, more mothers were employed, at least part-time, than in Sewanee, Tennessee, where more mothers were unemployed.

Mothers who participated in the study were between the ages of 20 and 44 years and their toddlers were between the ages of 19 and 26 months. The families' average annual income ranged from $\$ 11,000$ to over $\$ 100,000$ with the majority between $\$ 21,000$ and $\$ 60,000$, indicative of middle class. A majority of mothers were multiparous (66.2\%); 30 had two children, 12 had three children, 2 had four children, and 1 had six children. The remaining 23 mothers were primiparous (33.8\%). Almost all of the mothers were married, 60 for the first 
time $(88.2 \%)$ and 7 for the second time (10.3\%); one mother reported her marital status as single (1.5\%).

\section{Materials}

Demographic Questionnaire. See Appendix A. Mothers were asked to report basic background information: age, number of children, ethnicity, education level, marital status, annual income, employment status, child care arrangements and prior experience with children. Mothers were also asked about their child's toilet training, age of first words, and age of first walking.

Maternal Efficacy Questionnaire (MEQ: Teti and Gelfand, 1991). The MEQ (see Appendix B) contains ten 4-point items. Nine items assess the mothers' self-efficacy beliefs with regard to an aspect of infant/toddler care, while the last item gauges their general perceived competence for being a mother. Mothers answered each item on a 4-point scale: 1 represented not good at all and 4 represented very good. The mean score across the 9 items was used to obtain a total maternal self-efficacy score; higher scores imply stronger self-efficacy beliefs. Teti and Gelfand reported Chronbach's alpha to be .86 and reported concurrent validity as shown by its strong correlation with scores from the Parenting Stress Index sense of competence subscale. For this sample, the MEQ had moderate internal consistency with a Chronbach's alpha of .61.

Infant Characteristics Questionnaire (ICQ: Bates, Freeland, and Lounsbury (1979). The ICQ (see Appendix C) has 32 7-point items. Each item assesses parents' perceptions of their toddlers' temperament, including soothability, consistency, reactivity, adaptability, and persistence. Scores are summed across all items and higher scores imply more difficult 
temperament. Bates et al. (1979) reported moderate internal consistency for the ICQ in the studies the authors reviewed, Chronbach's alphas of .39-.79, and appropriate test-retest reliability for the measure, .47-.70. For this sample, the ICQ had excellent internal consistency with a Chronbach's alpha of .89.

Developmental Milestones Survey - Revised. This survey is modeled after the Developmental Milestones Survey (DMS) part of the larger Maternal Developmental Expectations and Childrearing Attitudes Survey (Field, 1981; as cited by Karraker \& Evans, 1996). The DMS-Revised (see Appendix D) was created to assess mothers' knowledge about the age of acquisition of eight milestones that most children achieve between 18 and 32 months of age. Respondents were asked to indicate the age at which they think an average child attains each milestone. Only participants in Harrisonburg completed this measure.

Sleep and Mood Questionnaire. This questionnaire (see Appendix E) was created to assess the child's typical sleep patterns, as well as how often the child woke the previous night and if the child had napped during the day of the assessment. It also asked about the mother's sleep, the child's health, and the child's mood and behavior. The first half of this questionnaire was completed by mothers prior to administration of the BSID-II, and the other half after the BSID-II was administered. Only those participants in Sewanee completed this measure.

Bayley Expectations Questionnaire. This questionnaire was developed to examine mothers' ability to predict their toddlers' abilities. Three forms were created (see Appendix F), each matching the item set of BSID-II tasks administered to toddlers at each of the ages of 17- 
19, 20-22, and 23-25 months. Mothers indicated whether or not they thought their child would pass each task.

Bayley II Scales of Infant Development. Revised in 1993, the Bayley Scales of Infant Development, Second Edition (BSID-II), assess the developmental status of children between the ages of 1 and 42 months. The BSID-II is composed of three scales - the mental, motor, and behavior rating scales. The mental and motor scales examine the child's performance within the two domains with age-appropriate tasks. These age-appropriate tasks are divided into item sets. Each set contains tasks that range from those that, on average, $90 \%$ of children in a particular age range pass to those that, on average, $15 \%$ of children in that age range pass. During a typical administration of the BSID-II, if a child does not complete 5 or more items on the mental scale or 4 or more items on the motor scale within the age-appropriate item set, the basal rule states that the administrator should administer tasks from the previous item set. In addition, if the child completes all but 3 or fewer tasks on the mental scale or all but 2 or fewer tasks on the motor scale within the age-appropriate item set, the ceiling rule states that the administrator should administer tasks from the next item set as well. In this study, toddlers were administered only the mental and motor tasks within the item sets specified for their chronological age. Additional tasks prior to or beyond the selected item set were not administered. Therefore, there may have been some instances in which the basal rule would have required that the toddler be administered tasks from an earlier item set, or in which the ceiling rule would have required that the toddler be administered tasks beyond the item set. This procedure was used so that a specific version of the Bayley Expectations Questionnaire could be administered to each mother based on the age of her toddler. 
Upon completion of the assessment, the administrator completed the BRS to identify any issues regarding the validity of the assessment, such as negative mood displayed by the toddler or refusal to engage in tasks. The first two questions of the BRS were asked of the mothers to determine whether their child behaved typically during the assessment and how they would classify their children's mood, then the administrator completed the rest of the questions. The overall score and the scale scores are used to classify children as being within normal limits, questionable, or non-optimal with respect to their behavior during the BSID-II.

\section{Procedure}

After expressing interest in participating, mother-toddler dyads were scheduled for a 2hour visit to the laboratory. Two weeks prior to their scheduled visit, the mothers were sent the questionnaires to complete and return by mail. Upon arrival to the laboratory, the mothers were asked to complete the Bayley Expectations Questionnaire and then the toddlers were administered the BSID-II, by Coleman, while on their mother's lap. The age-appropriate item sets for both the mental and motor scales were administered, taking, on average, 45 minutes to complete. After administration of the BSID-II had ended, the administrator (Coleman) completed the BRS. Mother-toddler dyads also then completed the Crowell procedure; data from this procedure were not used in the present investigation. For more information see Coleman (1999) or Coleman and Karraker (2003). Upon completion of the study, mothers were thanked and children received either an age-appropriate toy or article of clothing.

Coding of BSID-II. The principal investigator coded all 68 videos prior to any examination of the maternal expectation or other questionnaire data. A coding form was created (see 
Appendix G) so coders could fill in what tasks they coded and whether or not the toddlers displayed each emotional behavior during each task and during inter-task times. See Appendix $\mathrm{H}$ for a description of the codes. Only the toddlers' emotional behavior during the mental scale and portions of the motor scale that included fine motor tasks could be coded as gross motor tasks were conducted off-camera. See Appendix I for task names and descriptions.

Research assistants were trained by coding two videos with the researcher and each incidence of toddlers' emotional behavior that should be coded was discussed. The research assistants then coded the same videos for a few weeks to check their reliability. After each video completed, the researcher met with the assistants together to discuss where they were discrepant from each other or the researcher. After the research assistants became consistent in recognizing toddlers' emotional behaviors, they began coding separate videos. Typically, each assistant reviewed one subject per week, but no more than two. Overall, the research assistants coded 21 videos.

The researcher's reliability was checked initially by another researcher who had previous experience coding videos and emotional behaviors. For the remaining coding, the researcher's reliability was compared to her researcher assistants. Cohen's Kappas, based on the research assistants, for each quantified emotional behavior during the BSID-II are presented in Table 4. For the assessment overall, Kappas ranged from .44 to .80. According to Byrt (1996), Tseveral previous statisticians have acknowledged that Kappas between .41 and .60 are typically considered "moderate" or "fair," while Kappas between .61 and .80 are typically considered "good." 


\section{Mothers' accuracy and bias in predicting toddlers' performance on the BSID-II.}

Toddlers' performance on each task of the BSID-II was compared to their mothers' predictions.

See Table 3. Maternal accuracy in predicting performance was based on cells $A$ and $D$, overestimations were indicated by cell $\mathrm{C}$, and underestimations by cell B.

\section{Variables}

The following is a list of variables created for the analyses. Each description includes how a variable was calculated.

Maternal accuracy and bias variables. The following variables were multiplied by 100 and reported as percentages. Alternative methods for calculating accuracy and bias variables will be considered and differences between the methods will be noted under exploratory questions and analyses.

Mental accuracy. Mental accuracy was calculated as the number of mental tasks predicted correctly $(A+D)$ divided by the number of mental tasks administered $(A+B+C+D)$.

Motor accuracy. Motor accuracy was calculated as the number of motor tasks the mothers predicted correctly $(A+D)$ divided by the number of motor tasks administered $(A+B+C+D)$.

Maternal bias. The following variables were calculated for the mental and motor scales separately. 
Pass predictions. Pass predictions were calculated as the number of tasks predicted to pass $(A+C)$ divided by the tasks administered $(A+B+C+D)$.

Fail predictions. Fail predictions were calculated as the number of tasks predicted to fail $(B+D)$ divided by the tasks administered $(A+B+C+D)$.

Overestimation. Overestimation of performance, when mothers predicted that their toddlers would pass a task but the toddlers did not, was calculated as the number of tasks overestimated $(C)$ divided by the number of opportunities for the mothers to overestimate $(C+D)$.

Underestimation. Underestimation of performance, when mothers predicted that their toddlers would not pass a task but the toddlers did, was calculated as the number of tasks underestimated (B) divided by the number of opportunities for the mothers to underestimate $(A+B)$.

Toddler performance variables. The following variables were multiplied by 100 and reported as percentages.

Mental performance. Mental performance was calculated as the number of tasks passed $(A+B)$ divided by the number of mental tasks administered $(A+B+C+D)$.

Motor performance. Motor performance was calculated as the number of tasks passed $(A+B)$ divided by the number of motor tasks administered $(A+B+C+D)$.

Maternal characteristics. 
Time with toddler. Mothers indicated the type of childcare their child received. Toddlers in full-time care, 21 to 40 hours of care, by a non-maternal caregiver, either in-home or at a center, were categorized as spending the least amount of time with their mothers, "low time with toddler." Toddlers in part-time care, 20 or fewer hours of care, by a nonmaternal caregiver, either in-home or at a center, or toddlers in full-time maternal care were categorized as spending more time with their mothers, "high time with toddler."

Knowledge of child development. Correct answers were calculated as the number of questions answered within 1 month of the developmental norm, on either side. Higher scores are indicative of greater knowledge.

Maternal self-efficacy. Mothers answered each item of the MEQ on a 4-point scale. This variable was formed by calculating the mean rating on the 9 specific items on this scale. Higher scores are indicative of higher perceived parenting self-efficacy.

BSID-II coding of toddlers' emotional behavior. Each emotional behavior (see Appendix $\mathrm{H}$ ) was coded as present if a toddler displayed that behavior at least once during each administration of a BSID-II task. If a particular task was administered more than once, emotional behavior was coded during each administration. Then, the number of task administrations during which the behavior was shown was divided by the total number of task administrations and multiplied by 100 to create and report percentages. Many of the gross motor tasks were not videotaped so toddlers' emotional behavior was not separately coded for the mental and motor scales.

\section{Toddler characteristics.}


Administrator's rating of toddlers' mood and behavior. The test administrator's rating of toddlers' mood and behavior during the assessment was determined from the overall raw score of the Behavior Rating Scale (BRS). The administrator indicated how positive and negative the toddlers were, how sociable, how adaptable, how interested, how cooperative, how persistent, and so forth. Toddlers were rated for each item on a 5point scale: 1 represented less positive behavior and 5 represented more positive behavior for each item. Scores are calculated by summing the administrator's rating of each item, applicable to the child's age, not including the mothers' rating on the first two items. Higher scores are indicative of a more positive emotional behavior during the assessment.

Mothers' rating of toddlers' mood. As a part of the study in Sewanee, mothers rated their toddlers' mood that day prior to the administration of the BSID-II on a 5-point scale from much happier than usual to much more irritable than usual. After administration of the BSID-II, these mothers were again asked to rate their toddlers' mood during the BSID-II administration using the same scale. Higher ratings on both questions are indicative of a more negative mood.

Mothers' rating of toddlers' behavior. Mothers in Sewanee were asked, after administration of the BSID-II, how typical their toddlers' behavior was during the assessment. In addition, at both locations, after the BSID-II was administered, and as a part of the BRS, mothers were asked how typical their toddlers' behavior was during the 
assessment. Answers to both behavior questions ranged on 4-point scale from very atypical to very typical.

Mothers' rating of toddlers' performance. Mothers in Sewanee were asked, after administration of the BSID-II, whether they thought their toddlers performed as well as they could have. In addition, at both locations, after the BSID-II was administered, and as a part of the BRS, mothers were asked whether the assessment adequately captured their toddlers' abilities. Answers to these performance questions ranged on a 4-point scale from the assessment being a poor indicator of the toddler's optimal performance to the assessment being an excellent indicator of the toddler's optimal performance.

Toddlers' temperamental difficulty. Toddlers' overall temperamental difficulty was calculated as the mean rating their mothers gave on the items of the IBQ. Mothers answered each question on a 7-point scale. Higher scores are indicative of a more difficult temperament.

Fragmented sleep. Mothers in Sewanee reported the number of times the mothers were aware that their toddlers had awoken during the previous night.

\section{Data Analysis}

Prior to conducting any analyses on the hypotheses, preliminary analyses were conducted. There were no missing demographic data for the sample tested in Harrisonburg, but one mother did not report her age and four did not report their income in the Sewanee sample. Only mothers in Harrisonburg completed the DMS, and no data were missing. In addition, only 
mothers in Sewanee answered questions about their toddlers' mood, sleep, and behavior before and after the BSID-II, and none of their data were missing. Nine mothers from the Harrisonburg sample did not complete all of the ICQ while only one mother from Sewanee did not complete all of the ICQ. Four mothers from each sample did not answer the first two questions on the BRS regarding whether the toddlers' behavior during the BSID-II was comparable to their typical behavior and whether the toddlers' performance during the BSID-II was indicative of their abilities. Ten toddlers were not videotaped while being assessed on the BSID-II: two in Harrisonburg and eight in Sewanee.

Toddlers were more likely to have missing data from their performance on the BSID-II than mothers were to have missing data from their predictions. See table 5 for the specific number of missing items for both mothers' predictions and toddlers' performance. All calculated variables for which mothers did not answer the questions or toddlers did not complete the tasks, and coded variables for which toddlers were not videotaped were coded as missing and not included in the analyses.

The administrator's scoring of the BRS overall was both negatively skewed and leptokurtic. Therefore, total scores for the BRS were reflected and log transformed. This transformation rectified both distribution issues. Toddlers' performance on the motor scales was also negatively skewed and leptokurtic. Therefore, the variable created to assess toddlers' performance on the motor scale was reflected and log transformed. This transformation rectified both distribution issues. Mothers' marital status was both positively skewed and leptokurtic. However, marital status was not included in any of the research question analyses 
so the variable was not transformed. Mothers' proportion of underestimated mental tasks was positively skewed. However, because results associated with maternal underestimations on the mental scale were the same regardless of whether the variable was transformed or not, the untransformed variable was used in all analyses. Although analyses were conducted with the transformed variables noted above, means are provided below for the untransformed rather than the transformed variables.

Differences between male and female toddlers on the demographic variables are reported in Table 6 . The mothers of the male toddlers were significantly older and had significantly more education than the mothers of the female toddlers. Differences between male and female toddlers in the maternal accuracy and bias variables, as well as toddler performance, are reported in Table 7. There were no significant differences in these variables between male and female toddlers. Differences between male and female toddlers in the variables assessing toddlers' mood and emotional behavior are reported in Table 8. Female toddlers expressed more positive vocalizations than male toddlers during the BSID-II.

\section{Research question 1: How Accurately do Mothers, on Average, Predict Their Toddlers' Performance?}

Hypothesis 1a: Mothers' predictions of their toddlers' performance will be strongly positively correlated with their toddlers' actual performance on the BSID-II. Maternal pass predictions were significantly correlated with toddlers' performance on the mental, but not the motor, scale, $r(68)=.65, p<.001$, and $r(60)=.01, p=.949$, respectively. The more tasks the 
mothers predicted that their child would pass on the mental scale, the more tasks their toddler passed on that scale.

Hypothesis 1b: Mothers will, on average, predict that their toddlers will pass more tasks than the toddlers will pass. Mothers predicted that their toddlers would pass significantly more tasks on the mental scale $(M=73 \%)$ than their toddlers actually passed $(M=67 \%), t(67)=$ $2.99, p=.004$. However, toddlers passed significantly more tasks on the motor scale $(M=73 \%)$ than their mothers predicted they would $(M=69 \%), t(59)=20.50, p<.001$.

Hypothesis 1c: Mothers will, on average, be more accurate on the motor scale than on the mental scale. Mothers were no more accurate on the mental scale $(M=71 \%)$ than on the motor scale $(M=68 \%), t(63)=1.14, p=.259$.

Research Question 2: What Factors are Related to Individual Differences in Mothers' Accuracy in Predicting Toddlers' BSID-II Performance?

Hypothesis 2a: Mothers who know more about child development will be more accurate than mothers who know less about child development. Mothers' knowledge about child development was not associated with maternal accuracy on either the mental or the motor scale, $r(42)=.04, p=.784$, and $r(38)=.23, p=.159$, respectively.

Hypothesis $\mathbf{2 b}$ : Mothers with more education will be more accurate than mothers with less education. Years of education was not significantly correlated with maternal accuracy on either the mental or motor scale, $r(68)=.07, p=.578$, and $r(64)=.08, p=.539$, respectively. 
Hypothesis 2c: Mothers who provide more care for and spend more time with their toddlers will be more accurate than mothers who provide less care for and spend less time with their toddlers. Mothers who spent more time with their toddlers ( $M=72 \%$ ) were no more accurate in their predictions on the mental scale than mothers who spent less time with their toddlers $(M=69 \%), t(66)=.83, p=.408$. However, mothers who spent less time with their toddlers $(M=75 \%)$ were more accurate in their predictions of their toddlers' performance on the motor scale than mothers who spent more time with their toddlers $(M=63 \%), t(62)=3.00$, $p=.004$

Hypothesis 2d: Mothers with higher parenting self-efficacy will be more accurate than mothers with lower parenting self-efficacy. Maternal self-efficacy was not significantly correlated with maternal accuracy on either the mental or motor scale, $r(68)=.19, p=.130$, and $r(64)=.16, p=.201$, respectively.

Hypothesis 2e: Multiparous mothers will be more accurate than primiparous mothers. Accuracy of primiparous $(M=69 \%)$ and multiparous $(M=71 \%)$ mothers did not differ on the mental scale, $t(66)=.45, p=.654$. In addition, primiparous $(M=72 \%)$ and multiparous $(M=$ $72 \%)$ mothers did not differ in accuracy on the motor scale either, $t(62)=.41, p=.685$.

Hypothesis 2f: Older mothers will be more accurate than younger mothers. Mothers' age was not significantly correlated with mothers' accuracy on either the mental or motor scale, $r(67)=.09, p=.497$, and $r(63)=-.11, p=.408$, respectively.

Research Question 3: What Maternal Factors are Related to Individual Differences in Toddlers' Performance on the BSID-II? 
Hypothesis 3a: Toddlers whose mothers have greater knowledge about child development will pass more tasks on both the mental and motor scales than toddlers whose mothers have less knowledge about child development. Mothers' knowledge of child development was not associated with their toddlers' performance on the mental or motor scale, $r(42)=-.05, p=.754$, and $r(38)=-.08, p=.633$, respectively.

Hypothesis 3b: Mothers who overestimate their toddlers' performance relatively more than other mothers and underestimate their toddlers' performance relatively less than other mothers will have toddlers who score higher on the BSID-II. Mothers' overestimations and underestimations were significantly associated with toddlers' performance on the mental scale, $r(66)=.36, p=.003$, and $r(68)=-.34, p=.004$, respectively. Mothers' overestimations and underestimations were not significantly associated with toddlers' performance on the motor scale, $r(55)=-.03, p=.829$, and $r(59)=.03, p=.828$, respectively.

\section{Research Question 4: What Toddler Characteristics and Behaviors are Associated With}

\section{Reduced Maternal Accuracy?}

Hypothesis 4a: Toddlers who show more signs of negative emotional behavior during the BSID-II will have mothers who are less accurate. Mothers were less accurate in their predictions on the mental scale when their toddlers expressed less positive vocalizations during the assessment and engaged in more off-task behavior, $r(58)=.41 p=.002$, and $r(58)=-.30, p=$ .022, respectively. Toddlers' positive and negative facial expressions, negative and other vocalizations, reaching, refusing, and escape behaviors were not significantly associated with 
mothers' predictions on the mental scale. None of the quantified emotional behaviors were significantly associated with mothers' predictions on the motor scale.

Hypothesis 4b: Mothers who rate their toddlers as more difficult in temperament will be less accurate. Mothers' ratings of their toddlers' temperament were not significantly correlated with their accuracy on either the mental or motor scale, $r(58)=-.19, p=.163$, and $r(54)=-.12, p=.405$, respectively.

Hypothesis 4c: Mothers whose toddlers are rated as more socially engaged by the test administrator on the Behavior Rating Scale will be more accurate. Sociability was not significantly correlated with maternal accuracy on either the mental or motor scale, $r(68)=.19$, $p=.114$, and $r(64)=-.06, p=.668$, respectively.

Hypothesis 4d: Mothers whose toddlers are rated as more adaptable by the test administrator on the Behavior Rating Scale will be more accurate. Adaptability was not significantly correlated with maternal accuracy on either the mental or motor scale, $r(68)=.07$, $p=.549$, and $r(64)=.06, p=.659$, respectively.

Hypothesis 4e: Mothers whose toddlers are rated more negatively by the test administrator on the Behavior Rating Scale will be less accurate. Administrator's overall rating of mood and behavior (BRS total score) was significantly associated with maternal accuracy on the mental scale, $r(68)=-.40, p=.001$. Administrator's overall rating of mood and behavior was not significantly associated with maternal accuracy on the motor scale, $r(64)=.00, p=.995$. Mothers were less accurate on the mental scale when their toddlers were rated more negatively by the administrator on the BRS. 
Hypothesis 4f: Toddlers who awoke more frequently during the previous night will have mothers who are less accurate. Toddlers' previous night's waking frequency was not significantly correlated with maternal accuracy on either the mental or motor scale, $r(26)=.30$, $p=.138$ and $r(26)=-.05, p=.881$, respectively.

Research question 5: Does the Combination of Toddler Emotional Behavior and Maternal Pass Predictions During the BISD-II Predict Maternal Pass Predictions and Toddler Performance Better Than Either Measure Alone?

Hypothesis 5a: Although both toddlers' negative emotional behavior and maternal pass predictions will independently predict BSID-II performance, the combination of these two variables will significantly increase the prediction of performance than either variable alone. Step-wise multiple regressions were conducted to analyze this hypothesis. Quantified emotional behaviors indicative of negative mood (i.e. negative facial expressions, negative vocalizations, refusals, and escapes) and maternal pass predictions were entered in separate steps. For the mental scale, $R^{2}$ change was significant in the second step when toddlers' negative emotional behaviors were entered first, Adjusted $R^{2}=.50, F$ change $(1,52)=32.27, p<$ .001 , but was not significant when maternal pass predictions were entered first, $F$ change (4, 52) $=2.17, p=.085$.

For the motor scale, $R^{2}$ change was not significant in the second step when either toddlers' negative emotional behaviors were entered first, Adjusted $R^{2}=.10, F$ change $(1,44)=$ $.16, p=.695$, or when maternal pass predictions were entered first, $F$ change $(4,44)=2.57, p=$ .051. Therefore, the hypothesis was not supported for either the mental or the motor scale. 
Hypothesis 5b: Although both toddlers' negative emotional behavior and toddlers' performance will predict maternal pass predictions, the combination of these two variables will account for more variability in mothers' predictions than either variable alone. Step-wise multiple regressions were conducted to analyze this hypothesis. Quantified emotional behaviors indicative of negative mood (i.e. negative facial expressions, negative vocalizations, refusals, and escapes) and toddler performance were entered in separate steps. For the mental

scale, $R^{2}$ change was significant in the second step when toddlers' negative emotional behaviors were entered first, Adjusted $R^{2}=.43, F$ change $(1,52)=32.27, p<.001$, but not when toddler performance was entered first, $F$ change $(4,52)=.25, p=.91$. For the motor scale, $R^{2}$ change was not significant in the second step when either toddlers' negative emotional behaviors were entered first, Adjusted $R^{2}=-.05, F$ change $(1,44)=.16, p=.695$, or when toddler performance was entered first, $F$ change $(4,44)=.72, p=.586$. Therefore, this hypothesis was not supported for either the mental or motor scale.

Exploratory Questions. Although answers to these questions are not directly addressed by prior research, they may further understanding of the processes being studied, and were therefore explored as part of this study. Answers to these questions helped to describe the nature of the data and the relations among maternal predictions and other variables.

\section{Question 6a: Will mothers' ratings of their toddlers' mood be associated with} mothers' accuracy in predicting performance? Maternal ratings of toddler mood, both before and as a part of the BRS after the assessment, were significantly correlated with maternal accuracy on the mental scale, $r(26)=-.69, p<.001$, and $r(26)=-.62, p=.001$, respectively. 
Maternal ratings of toddler mood, both before and after the assessment, were not significantly associated with maternal accuracy on the motor scale, $r(26)=.19, p=.355$, and $r(26)=-.11, p=$ .588 , respectively. Mothers were more accurate in their predictions when they rated their toddlers as being in a happier mood, both prior to and after completing the BSID-II, on the mental scale but not the motor scale.

\section{Question 6b: Will mother and toddler characteristics be related to mothers' accuracy} and bias in predicting their toddlers' BSID-II performance? See Table 9 for associations between maternal and toddler characteristics and mothers' accuracy and bias in predicting their toddlers' performance.

Mothers were more accurate on the mental scale when they reported their toddlers had not recently been ill and were not currently ill, when they stated that their toddlers were in a happier mood (both before and after administration), and when they stated that their toddlers' behavior was very typical and an excellent indicator of their toddlers' abilities. In addition, mothers were more accurate on the mental scale when the test administrator rated their toddlers as more interested, showing more initiative and enthusiasm, being more fearful, paying better attention and persisting, being more cooperative, acting more hyperactive, and being more soothe-able. However, the test administrator's overall rating of toddlers' mood and behavior was negatively associated with mothers' accuracy on the mental scale.

Mothers were more likely to overestimate their toddlers' performance on the mental scale when they rated their toddlers' performance as being an excellent indicator of their abilities and stated that their toddlers' behavior was very typical of their usual behavior. In 
addition, mothers were more likely to overestimate on the mental scale when the test administrator rated the toddler as expressing more negative affect, but also when the test administrator rated the toddler as paying better attention, persisting on tasks longer, and being more cooperative.

Mothers were more likely to underestimate their toddlers' performance on the mental scale when their toddler had more fragmented sleep the night before or was currently ill, and when the mothers reported lower self-efficacy. They were also more likely to underestimate on the mental scale when they rated their toddlers' mood as happier mood before and after the BSID-II, rated their toddlers' behavior as very typical, and stated that their toddlers' performance was an excellent indicator of their toddlers' abilities. In addition, mothers were more likely to underestimate when the test administrator rated their toddler as displaying a greater amount of both positive and negative affect, being more interested, showing more initiative and enthusiasm, being more oriented to the task at hand, being more socially engaged, paying more attention, persisting longer, being cooperative, acting more hyperactive, and being more soothe-able. Finally, mothers were also more likely to underestimate their toddlers' performance on the mental scale when toddlers engaged in fewer negative facial expressions, negative vocalizations, refusals, escapes, and off-task.

None of the variables were significantly associated with higher accuracy or greater number of underestimations on the motor scale. However, mothers were more likely to overestimate their toddlers' performance on the motor scale if they were young, had less education, and reported lower levels of parenting self-efficacy. 


\section{Question 6c: Will mothers be better able to predict their toddlers' performance on}

some tasks than others? This exploratory question has not yet been analyzed due to the difficulty of assessing mothers' accuracy in predicting their toddlers' performance for individual tasks.

\section{Question 6d: Will mothers be more likely to overestimate or underestimate their} children's performance on some tasks than others? This exploratory question has not yet been analyzed due to the challenges of creating variables that assess mothers' bias in predicting their toddlers' performance for individual tasks.

Question 6e: How much variance do mother and toddler characteristics account for in explaining mothers' accuracy and bias? Linear regressions were conducted for each set of variables predicting mothers' accuracy and bias in estimating how their toddlers would perform on both the mental and motor scale. See Tables 10 - 15.

Demographic variables (toddlers' age, mothers' age, mothers' parity, mothers' education, mothers' time with toddler, mothers' reported maternal self-efficacy, mothers' knowledge of child development, and mothers' rating of their toddlers' difficulty) did not account for a significant amount of variance in explaining individual differences in mothers' accuracy on the mental scale. However, the demographic variables did account for a significant amount of variance in explaining individual differences in mothers' accuracy on the motor scale, and mothers' overestimations on the mental scale and the motor scale. These variables did not account for a significant amount of variance in mothers' underestimations on the mental or the motor scale. 
Maternal and administrator ratings of mood and behavior (maternal mood rating before and during the BSID-II, maternal rating of child behavior before and during the BSID-II, maternal rating of child behavior before and during the BSID-II, and administrator's overall mood rating from the BRS) did not account for a significant amount of variance in explaining individual differences in mothers' accuracy on the mental scale or mothers' overestimations on the mental scale. These variables did not account for a significant amount of variance in mothers' underestimations on the mental or the motor scale. However, they did account for a significant amount of variance in explaining individual differences in mothers' accuracy and mothers' overestimations on the motor scale.

The researcher's coding of toddlers' emotional behavior (positive and negative facial expressions, positive, negative, and other vocalizations, reaches, refusals, escapes, and off-task behavior) accounted for a significant amount of variance in explaining individual differences in mothers' accuracy on the mental scale. However, the researcher's coding of toddlers' emotional behavior did not account for a significant amount of variance in explaining individual differences in mothers' accuracy on the motor scale, or mothers' overestimations on the mental scale or motor scale. These variables also did not account for a significant amount of variance in mothers' underestimations on the mental or the motor scale.

\section{Question 6f: How strongly correlated are mother and toddler characteristics? Only}

mothers' perceived self-efficacy was associated with any of the toddler characteristic variables; mothers who rated themselves as having higher levels of maternal self-efficacy had toddlers 
who engaged in more negative facial expressions and more refusals, $r(58)=.27 . p=.038$, and $r(58)=.47, p<.001$, respectively

\section{Question 6g: Are there significant interactions between mother and toddler}

characteristics when predicting maternal accuracy and bias? This exploratory question has not yet been analyzed due to the large number of potential interactions.

\section{Question 6h: Will mother and toddler characteristics be related to toddlers'}

performance? See Table 16 for associations between maternal and toddler characteristics and toddlers' performance on the mental and motor scales of the BSID-II.

Toddlers performed better on the mental scale when they were not currently ill, when their mothers rated their mood less positively before and after the assessment, and when their mothers rated their behavior as very typical and the toddlers' performance as an excellent indicator of abilities. Toddlers also performed better when the test administrator rated them as displaying greater amounts of positive and negative affect, being interested in the tasks, showing initiative, being enthusiastic, being more oriented to the tasks, engaging socially, paying more attention, being more persistent, being more cooperative, behaving more hyperactively, and being more soothe-able. However, the test administrator's overall rating of the toddlers' mood and behavior was negatively associated with performance. Finally, toddlers also performed better on the mental scale when they engaged in fewer negative facial expressions and vocalizations, positive vocalizations, refusals, escapes, and off-task behavior.

Toddlers performed better on the motor scale when their mothers rated their behavior as less typical and performance as a poorer indicator of their abilities. They also performed 
better on the motor scale when the test administrator rated them as less interested, displaying less initiative, being less enthused, displaying less negative affect, paying less attention, being less persistent, and being not as cooperative. However, the test administrator's overall score was positively associated with their performance on the mental scale. Finally, toddlers also performed better on the motor scale when they displayed more negative facial expressions and vocalizations, reaches, and refusals.

\section{Question 6i: What are alternative methods for calculating accuracy and bias, and how}

do they affect the results? Due to the association between maternal accuracy and toddler performance, the methods used to calculate maternal accuracy are inflated in this study. Base rates, the proportion of times mothers are accurate by chance alone, should be taken into consideration when calculating accuracy to reduce inflation. Therefore, maternal accuracy will be calculated using Cohen's Kappa in future analyses. These calculations and analyses have not yet been conducted. However, more difficult is the calculation of maternal biases using Kappa. Additional methods are under consideration and will be conducted if deemed appropriate.

\section{Discussion}

\section{Summary of Findings}

The purpose of this study was to assess how maternal characteristics and toddlers' emotional behavior impacted toddlers' performance and mothers' accuracy and bias in predicting how their toddler would perform on the Bayley Scales of Infant Development-II. As expected, mothers' predictions of performance and their toddlers' performance were significantly associated on mental scale. Contrary to expectations though, mothers' predictions 
of performance and their toddlers' performance was not significantly association on the motor scale. Thus, mothers who predicted that their toddler would pass more tasks had toddlers who did pass more tasks on the mental scale but not the motor scale. In addition, mothers predicted that their toddlers would pass more tasks on the mental scale than their toddlers passed, but on the motor scale toddlers passed more tasks than their mothers predicted them to pass. However, mothers were no more accurate in predicting their toddlers' performance on one scale over the other.

Contrary to what was expected, many of mothers' characteristics were unrelated to their accuracy in predicting their toddlers' performance. Some hypotheses about maternal characteristics being associated with toddlers' performance were supported and others were not. Mothers' biases were associated with their toddlers' performance on the mental scale mothers who underestimated their toddlers' performance relatively less than other mothers and overestimated their toddlers' performance relatively more than other mothers had toddlers who passed more tasks. However, contrary to expectations, mothers' biases were not associated with their toddlers' performance on the motor scale and mothers' knowledge about child development was not associated with their toddlers' performance on either scale.

Hypotheses about toddler characteristics being associated with maternal accuracy were largely supported for the mental scale and unsupported for the motor scale. Two of the nine emotional behaviors were associated with increased maternal accuracy on the mental scalegreater number of positive vocalizations during the assessment and less engagement in off-task behavior. None of the emotional behaviors were significantly associated with mothers' 
accuracy in predicting toddler performance on the motor scale. Although only the mothers in Sewanee answered questions about their toddlers' mood, both before and after the assessment, those mothers who rated their toddlers as more irritable were also less accurate on the mental scale; this finding was not supported for mothers' accuracy on the motor scale. In addition, the test administrator's overall rating of mood and behavior was negatively associated with mothers' accuracy on the mental scale and not significantly associated with mothers' accuracy on the motor scale. Contrary to expectations though, mothers' ratings of child difficulty, the administrator's rating sociability or adaptability during the assessment, and toddlers' sleep fragmentation during the previous night were not associated with mothers' accuracy on either the mental or motor scale.

Variability in toddlers' performance on the mental scale was better accounted for mothers' pass predictions than by the combination of pass predictions and toddlers' negative emotional behavior. In addition, variability in mothers' pass predictions for the mental scale, was better explained by toddlers' performance than by the combination of toddlers' performance and their negative emotional behaviors. These variables did not significantly explain the variability in toddlers' performance or mothers' pass predictions on the motor scale.

\section{Mothers' Accuracy in Predicting Toddlers' Performance}

In general, mothers' pass predictions were highly correlated with toddlers' performance on the mental scale. Mothers who predicted that their toddlers would pass more tasks overall had toddlers who passed more tasks on the mental, while mothers who predicted that their toddlers would pass fewer tasks had toddlers who passed fewer tasks on the mental scales. This 
finding is in line with previous research on mothers' knowledge of their children's abilities, suggesting that they are relatively accurate reporters and estimators of their children's abilities (Harty, Alant, \& Uys, 2006; Hunt \& Paraskevopoulos, 1980; Miller, 1986). However, while that research focused solely on cognitive skills, such as those assessed on the mental scale of the BSID-II, this study suggest this finding does not extend to psychomotor skills, such as those assessed on the motor scale of the BSID-II, as well.

In line with previous research on maternal bias (Hunt \& Paraskevopoulos, 1980; Karraker \& Evans, 1996; Miller, 1986; Reich, 2005), when predicting performance on cognitive tasks, mothers in this study predicted that their toddlers would pass more tasks than their toddlers actually passed on the mental scale. However, toddlers' passed more tasks on the motor scale than their mothers' predicted. Mothers' tendency to not overestimate their toddlers' performance on the motor scale may be because, as Tamis-LeMonda et al. (1998) found, mothers are generally more accurate when predicting tasks that they have seen their child previously engage in. Tasks on the motor scale include standing, walking, throwing a ball, kicking a ball, climbing up and down stairs, and so forth. All of these are tasks that the mothers have likely seen their toddlers attempt in the past. However, tasks on the mental scale include some tasks they may have seen their toddlers attempt in the past, such as stacking blocks, completing puzzles, and naming objects, but also tasks they may not have seen their toddlers' attempt in the past, such as placing pegs in a pegboard, matching colors, or using tools to obtain a desired toy. Therefore, mothers may have been more likely to predict their toddlers would be able to complete tasks that which they were less familiar with. However, although the mothers may have seen their toddler attempt more of the tasks on the motor scale, they were 
not more accurate in their predictions on the motor scale than on the mental scale. Exploratory analyses revealed a possible explanation for why there was no difference in maternal accuracy between the two scales. Mothers predicted that their toddlers would pass more of the tasks on the mental scale $(74 \%)$ than the motor scale $(70 \%)$, however toddlers passed more tasks on the motor scale $(74 \%)$ than the mental scale $(68 \%)$, resulting in mothers being accurate approximately $70 \%$ of the time on both scales.

Mothers were relatively accurate predictors of their toddlers' performance and, in general, toddlers performed relatively well on both scales. However, the number of tasks correctly predicted by mothers and the number of tasks correctly performed by toddlers are associated, even if maternal predictions and toddlers' performance are random. Thus, toddlers who performed less well on either scale hampered their mothers' opportunities to be accurate in their predictions, while toddlers who performed well increased their mothers' opportunities to be accurate. Therefore, rather than calculating mothers' accuracy as a proportion of opportunities, future research should consider calculating Kappa values to better characterize maternal accuracy.

\section{Maternal Characteristics That Relate to Their Accuracy}

A majority of the previous studies assessing relations between mothers' knowledge and several demographic characteristics has focused on general knowledge of general child development (e.g. Dichtelmiller, 1992; Hunt \& Paraskevopoulos, 1980; McGillicuddy-DeLisi, 1982; Reich, 2005; Tamis-LeMonda et al., 1998), rather than mothers' knowledge of their own children's development (e.g. Coleman \& Karraker, 2003; Karraker \& Evans, 1996). The lack of 
significant results in the current study may have been a function of very little variability in these mothers' age, parity, education, knowledge of child development, and parenting self-efficacy scores. In general, mothers were in their mid-twenties to mid-thirties, had one to three children, had completed at least high school, if not college and a master's program, answered fewer than half of the Developmental Milestones Survey questions correctly, and reported high levels of parenting self-efficacy. The finding that mothers who provide less care to, and thus spend less time with, their toddlers were not less knowledgeable about their own toddlers' capabilities than the mothers who provide more care to, and thus spend more time with, their toddlers was unexpected but encouraging. This finding, in particular, suggests that the quality of the time a mother spends with her child may be more important than the quantity in influencing her knowledge about what her child is capable of doing.

\section{Maternal Characteristics That Relate to Their Toddlers' Performance}

In contrast to what has been reported in other studies (Benasich \& Brooks-Gunn, 1996; Dichtelmiller et al., 1992), mothers' general knowledge of child development was not associated with their toddlers' performance on the either the mental scale or the motor scale. As suggested previously, the non-significant finding may be due to very little variability in mothers' general knowledge of child development, with no mothers answering more than 4 items correctly and most only answering between 1 and 3 of the 8 questions on the DMS correctly. Children often reach developmental norms at different times, so mothers may have been less able to accurately estimate when children typically develop these skills because they were basing their estimate on when they believed their toddler had, or will, meet these 
milestones. In addition, the limited range within which the mothers were scored as accurate may have been too stringent.

However, similar to what Price and Gillingham (1985) found when they reanalyzed Hunt and Paraskevopoulos's (1980) findings, mothers who overestimated more frequently than other mothers had toddlers who passed more tasks on the mental scale. In addition, mothers who underestimated more frequently than other mothers had toddlers who passed fewer tasks on the mental scale. Thus, in line with Price and Gillingham's conclusions, maternal underestimations of toddlers' cognitive abilities may not facilitate toddlers' emerging abilities, and thus performance, while overestimations may facilitate toddlers' abilities, and thus performance. Mothers who believe that their toddlers can engage in more complex cognitive tasks may present them with more opportunities to work on developing their skills. A study by Pratt and colleagues (1988) found that most parents were likely to use a scaffolding-like approach when presenting new and more complex tasks, and those who did not had young children who performed less well on subsequent attempts. Mothers who don't believe their toddlers are yet able to engage in more complex tasks may not present them with the opportunity to try those tasks, and therefore the mothers can end up stifling their toddlers' development rather than encouraging it. It may also be that mothers who see their toddlers engage in tasks that they perceive to be cognitively complex for their toddlers' developmental age may anticipate that their toddler can complete other cognitively complex tasks, possibly overestimating their capabilities. Mothers who witness their toddlers engaging only in tasks that they think are below their toddlers' developmental age may anticipate that their toddlers 
would not be able to complete cognitively complex tasks, thus underestimating their capabilities.

It was anticipated that the previous finding of maternal biases being associated with mental development would translate to psychomotor development; however maternal biased predictions were not significantly associated with toddlers' motor performance in our sample. Some cultures believe that psychomotor development does not need to be focused on the same way that cognitive development needs to be, under the expectation that children will develop motor skills regardless of reinforcement or practice, while other cultures believe that both should be focused on (Berk, 2010). In support of the cultures who believe psychomotor skills develop naturally, research has found that although certain waking and sleeping positions may slightly delay the development of new psychomotor abilities, they still develop (Majnemer \& Barr, 2005). Therefore, it may be that children's cognitive development is more dependent on the interactions they have with adults, whereas their physical development may be less dependent on these interactions.

\section{Toddler Characteristics That Relate to Maternal Accuracy}

Findings from this study suggest that toddlers' emotional behavior, quantified by the researcher and rated by their mothers, affects mothers' accuracy in predicting cognitive performance, but does not affect mothers' accuracy in predicting psychomotor performance. Although very few studies have assessed mothers' knowledge of their own children's development, these findings suggest that children's mood should be considered when interpreting maternal accuracy and inaccuracy, especially on assessments that measure 
cognitive skills. In addition, this study suggests that mood specifically, a dynamic attribute, should be assessed rather than temperament, a stable trait, as toddlers' mood, as rated by their mothers, significantly impacted maternal accuracy but toddlers' temperament, as rated by their mothers, did not. A possible explanation for why maternal accuracy was not impacted by toddlers' negative emotional behavior may be because there were very few instances of some of these behaviors, particularly refusals, escapes, negative facial expressions, and negative vocalizations. In addition, reliability for coding refusals and negative facial expressions was lower than it was for the other codes. Finally, mothers may have taken into consideration the way their toddler typically responds to new requests when predicting how they would perform on each task, thus reducing the association between toddlers' negative emotional behavior and maternal accuracy.

In line with findings reported above, the administrator's rating of the toddler's mood was associated with maternal accuracy on the mental scale, but not the motor scale. As already discussed, toddlers' emotional behavior impacted their mothers' accuracy on the mental scale, but this emotional behavior was not captured in the administrator's completion of items related to positive and negative affect or frustration in the Behavior Rating Scale. Exploratory analyses also revealed that mothers' ratings of their toddlers' mood after the assessment were not significantly associated with the administrator's rating of the toddlers' mood. This finding suggests the mothers and the administrator may have been recalling different portions of the assessment when they reported the toddlers' mood. It may be that incidences of negative emotional behavior were more salient to the mother when assessing their toddler's mood or that the administrator and mother were basing their report on different standards. The 
administrator may have compared each toddler to an extremely uncooperative and unhappy toddler while the mothers compared their toddler to an extremely cooperative and happy toddler. Exploratory analyses did find that some individual items from the administrator's completion of the BRS were associated with maternal accuracy on the mental scale. However, these associations were not significant for the motor scale.

Therefore, it is the researcher's belief that inclusion of caregiver ratings of positive and negative affect, as well as fearfulness, enthusiasm, and cooperativeness, in the Bayley Scales of Infant Development, Third Edition (BSID-III), is justified. In the BSID-II, only two questions were asked of the mothers as a part of the BRS: whether their toddler behaved as usual and whether the assessment accurately captured their toddlers' abilities. The rest of the BRS was completed by the administrator, rating the toddlers' behavior and emotionality during the assessment. In the BSID-III, the same thirteen questions are asked of both the child's caregiver and of the administrator. These questions ask the caregiver how the child behaves and reacts typically and the administrator how the child behaved and reacted during the assessment. Therefore, discrepancies between the two can be easily examined. Future studies should examine whether mothers' ratings or administrator's ratings of the children's mood and behavior on the BSID-III is more predictive of toddlers' performance and maternal accuracy in predicting performance. Such information would help practitioners decide how to weight the information from that section in relation to the toddlers' performance when examining their developmental progress.

Because neither the mothers' ratings of their toddlers' mood or the administrator's ratings on the BRS were significantly associated with maternal accuracy on the motor scale, it is 
conceivable that the caregiver ratings and administrator ratings at the end of the BSID-II, and possibly the BSID-III, may not be capturing how toddlers' emotional behavior impacts their performance on the motor scale, and thus their mothers' accuracy. Negative emotional behavior may impact toddler performance on the cognitive scale more than the motor scale given that during the cognitive scale the children are expected to complete each task sitting at the table with their parents while during the parts of the motor scale they are able to be up and moving about. Rather than sitting, pointing to objects in pictures, completing puzzles, or naming objects, they are showing how they can walk backwards or sideways, kick a ball, and hop. In addition, for toddlers, there are more tasks on the motor scale that can be incidentally observed than on the cognitive scale, like running, climbing stairs, and grasping tasks. For the fine motor portion of the motor scale, there are several abilities that can be assessed while allowing the child to draw - such as whether they hold the paper down, how they hold the crayon and pencil, and how well they draw lines and circles, whereas on the cognitive scale, many of the abilities are assessed with individual tasks. Therefore, this study supports Seegmiller and King's (1975) finding that the motor scale may be less affected by aspects of toddlers' emotional behavior than the mental scale.

Some, but not all, of the toddler emotional behavior variables were associated with the toddlers' performance on the scales. For the same reasons listed above, toddlers' emotional behavior may differentially affect their performance on the mental and motor scales. Exploratory analyses revealed that toddlers' emotional behavior explained more of the variance in their performance on the mental scale than in performance on the motor scale. In addition, the non-significant associations between toddlers' performance and the emotional variables 
may have been because the toddlers' emotional behavior often varied greatly between tasks. Therefore, a more comprehensive picture of how their behavior impacts their performance and maternal accuracy may have been obtained by analyzing at the task level rather than averaging their overall behavior during the entire assessment.

Contrary to expectations, the number of times the toddlers awoke the night before was not associated with mothers' accuracy on either scale. Exploratory analyses revealed that the toddlers who woke up more during the previous night were also the toddlers who had taken more naps during the day of the assessment, possibly negating the impact of their previous night's fragmented sleep. Exploratory analyses also revealed that maternal accuracy in predicting performance on the mental scale was impacted if the toddler had recently been ill or was currently ill. Additional exploratory analyses revealed that mothers who reported that their toddlers were currently ill were not only less accurate but that their toddlers also performed less well, compared to those who reported their toddler was not currently ill. Neither of these findings extended to the motor scale though, suggesting that when toddlers are ill, it affects them more on cognitive tasks than psychomotor tasks. Their illness may have affected their affect, their attention, and their enthusiasm. As noted above, toddlers mobility during the assessment varies much more on the motor scale (e.g. running, climbing) than it does on the mental scale (e.g. sitting). Therefore, the ability to move around more during the motor scale may have distracted toddlers from feeling ill and made them more likely to follow the administrator's requests. However, there was not a significant difference in any of the coded emotional behaviors between toddlers who were currently ill and those who were not. 


\section{Cumulative Effect of Variables on Toddler Performance and Maternal Accuracy}

More variability in toddlers' performance on the mental scale was explained by their mothers' predictions that they would pass more tasks, than by toddlers' engagement in less negative emotional behaviors (e.g. negative facial expressions, negative vocalizations, refusals, and escapes). In line with this finding, previous research (Coleman et al., 2002; Hunt \& Paraskevopoulos, 1980; Morawska, Winter, \& Sanders, 2009; Reich, 2005) has reported that mothers who know more about their children's capabilities may be more likely to create environments that encourage those skills and promote the development of more advanced skills.

Toddlers' negative emotional behaviors and mothers' pass predictions were not predictive of toddlers' performance on the motor scale. Toddlers' negative emotional behavior during the motor scale was not directly assessed and because toddlers' mood varied between tasks, it is likely that it also varied between scales, potentially explaining why it was predictive for the mental scale but not the motor scale. In addition, toddlers performed better, overall, on the motor scale than the mental scale so it may be that performance on the motor scale is more resistant to emotional and behavioral influences and thus may be a better representation of the toddlers' abilities.

Toddlers' performance explained variability in maternal pass predictions for the mental scale significantly better than toddlers' emotional behavior. The combination of toddlers' emotional behavior and their performance did not, however, significantly increase the prediction of mothers' pass predictions on the motor scale. As stated previously, mothers may 
have taken their toddlers' current mood and typical behavior into consideration when they made their predictions. Doing so would negate the impact of the toddlers' emotional behavior during the assessment and lessen the impact of their performance on the mothers' predictions.

\section{Limitations and Future Directions}

One major limitation of this study, as mentioned previously, was that toddlers were not videotaped for all of the motor scale. Therefore, their quantified emotional behavior is based primarily on tasks from the mental scale. Future studies should also record toddlers' emotional behavior while completing tasks on the motor scale to determine if doing so better predicts their performance or their mothers' accuracy on that scale. In addition, additional analyses should assess the degree to which toddlers' emotional behavior varied between tasks to evaluate whether this variability impacted their performance, and mothers' accuracy, or if their emotional behavior impacted their performance on some tasks more than others.

Another limitation of this study was that some of the measures were only completed by participants at one or the other of the locations. Had all participants completed all measures, there may have been more power to find significant results. In addition, alternative ways of calculating mothers' general knowledge of child development and specific knowledge of their own child's development should be addressed. Mothers' accuracy for when children achieve particular milestones can be addressed by counting the number of milestones they correctly estimated the age for, by considering how far from the correct age mothers were, or by counting the number of milestones they estimated correctly within a fixed time frame. Future 
analyses should address how each of these methods of calculation impacts the results of the study.

Due to the number of analyses conducted on this data set, the results should be interpreted with caution. When too many analyses are conducted with a small sample size, power is affected. This reduction in power can contribute to Type I error, or an increase in significant findings based on chance alone (Howell, 2007). Future research should recruit for a larger sample size if similar analyses are to be conducted.

As highlighted earlier, there has been a valid debate in the literature as to how mothers' specific knowledge of their child's development should be calculated. Even the method used in this study is inflated due to the inevitable association between the number of tasks toddlers successfully complete and the number of tasks correctly predicted by their mothers. Therefore, future studies should reduce this inflation by taking into account chance agreement by using Cohen's Kappa to calculate maternal accuracy. However, maternal bias - overestimations and underestimations, also may be subject to effects of base rates, and thus another approach may need to be considered to appropriately assess them.

An additional suggestion for future research concerns the homogeneity of and limited variability within this sample. A more heterogeneous sample of mothers should be sought, varying in age, education, income, perceived parenting self-efficacy, and knowledge of child development. Additional studies should be conducted with both younger infants and older toddlers to determine whether these findings are limited to children in this age range or if they are generalizable to other age groups. 
In general, hypotheses about mothers' predictions of their toddlers' performance on the Bayley Scales of Infant Development, Second Edition, were largely supported for the mental scale, but less so for the motor scale. Mothers were relatively knowledgeable about what their toddlers are able to do, but were more likely to overestimate their toddlers' capabilities on the mental scale than the motor scale. Toddlers' emotional behavior was also much more likely to impact the toddlers' performance on the mental scale than the motor scale, resulting in higher inaccuracies in their mothers' predictions; whereas toddlers' performance on the motor scale was less likely to be impacted by toddlers' emotional behavior, other toddler characteristics, or characteristics of their mothers.

Understanding how mothers' predictions relate to their toddlers' performance may be important in the development and revision of developmental assessments. Infant and toddler behavior is variable and therefore any snapshot of their behavior by a researcher may be incomplete and may be enhanced by a maternal report of children's expected behaviors. Further, it is important to determine how children's emotional behavior can affect performance to improve the validity of developmental assessments. The current study enhances our knowledge about individual differences in mothers' predictions of their children's behaviors and how their biases may be related to parenting. These findings may be useful to individuals working directly with parents to educate them on how to promote their child's development. If Price and Gillingman (1985) were correct in their findings that overestimation of abilities by parents can advance their children's development and that underestimation of abilities can hinder their children's development, targeting parents who underestimate their children's cognitive and psychomotor abilities will be an important avenue for promoting the 
development of children. However, when encouraging parents to introduce more developmentally difficult tasks to their children, parents should also be reminded to select tasks that are within the children's zone of proximal development. Previous research has reported that extreme and unrealistic expectations of child development are risk factors for child abuse (Dukewich, Borkowski, \& Whitman, 1996). Therefore, scaffolding techniques and the "contingent-shift rule" for facilitating development and performance must also be encouraged when suggesting to parents that they give their children tasks slightly outside of their current developmental ability (Carr \& Pike, 2011; Pratt, Kerig, Cowan, \& Cowan, 1988).

Although additional studies will be needed to verify this study's findings, the findings suggest that mothers are relatively accurate in predicting how their toddlers will perform on tasks within a developmental assessment. In addition, the findings suggest that mothers may take their toddlers' emotional behavior and usual reaction to new individuals and environments into consideration when predicting how they will perform, as the toddlers' emotional behavior was associated with their performance but not their mothers' accuracy. Finally, this study suggests that the BSID-II motor scale may be more resistant to the impact of toddlers' emotional behavior than the mental scale. The motor scale may therefore provide a more accurate depiction than the mental scale of toddlers' actual abilities. 


\section{References}

Baltes, P. B., Reese, H. W., \& Nesselroade, J. R. (1988). Selected issues in developmental assessment. Introduction to research methods: Life-span developmental psychology (pp 156-166). Hillsdale, NJ: Lawrence Erlbaum Associates.

Bates, J. E., Freeland, C. A., \& Lounsbury, M. L. (1979). Measurement of infant difficultness. Child Development, 50, 784-803.

Bayley, N. (1993). Bayley Scales of Infant Development Manual (2 ${ }^{\text {nd }}$ ed.). San Antonio, TX: The Psychological Corporation.

Bayley, N. (2006). Bayley Scales of Infant Development: Administration Manual (3 ${ }^{\text {rd }}$ ed.). San Antonio, TX: NCS Pearson, Inc.

Benasich, A. A. \& Brooks-Gunn, J. (1996). Maternal attitudes and knowledge of child-rearing: associations with family and child outcomes. Child Development, 67, 1186-1205.

Berk, L. E. (2010). Exploring Lifespan Development (2 ${ }^{\text {nd }}$ ed.). Boston, MA: Pearson Education, Inc.

Black, M. M. \& Matula, K. (2000). Essentials of Bayley Scales of Infant Development-II Assessment. New York, NY: Wiley.

Byrt. T. (1996). How good is that agreement? Epidemiology, 7, 561.

Carr, A. \& Pike, A. (2011). Maternal scaffolding behavior: Links with parenting style and maternal education. Developmental Psychology, doi: 10.1037/a0025888. 
Coleman, P. K. (1999). Maternal self-efficacy beliefs as predictors of parenting competence and toddlers' emotional, social, and cognitive development (Doctoral Dissertation, West Virginia University, 1998). Dissertation Abstracts International, 60, 2981.

Coleman, P. K., Trent, A., Bryan, S., King, B., Rogers, N., \& Nazir, M. (2002). Parenting behavior, mothers' self-efficacy beliefs, and toddler performance on the Bayley Scales of Infant Development. Early Child Development and Care, 172, 123-149.

Coleman, P. K. \& Karraker, K. H. (2003). Maternal self-efficacy beliefs, competence in parenting, and toddlers' behavior and developmental status. Infant Mental Health Journal, 24, 126148.

Dichtelmiller, M, Meisels, S. J., Plunkett, J. W., Bozynski, M. E. A., \& Mangelsdorf, S. C. (1992). The relationship of parental knowledge to the development of extremely low birth weight infants. Journal of Early Intervention, 16, 210-220.

Dukewich, T. L., Borkowski, J. G., \& Whitman, T. L. (1996). Adolescent mothers and child abuse potential: An evaluation of risk factors. Child Abuse \& Neglect, 20, 1031-1047.

Harris, S. R., Megens, A. M., Backman, C.L., \& Hayes, V. E. (2005). Stability of the Bayley II Scales of Infant Development in a sample of low-risk and high-risk infants. Developmental Medicine and Child Neurology, 47, 820-823.

Harty, M., Alant, E., \& Uys, C. J. E. (2006). Maternal self-efficacy and maternal perception of child language competence in pre-school children with a communication disability. Child: Care, Health, and Development, 33, 144-154. 
Howell, D. C. (2007). Statistical Methods for Psychology, $6^{\text {th }}$ Edition. Belmont, CA: Thomson Wadsworth.

Hrncir, E. J., Speller, G. M., \& West, M. (1985). What are we testing? Developmental Psychology, $21,226-232$.

Hunt, J. M. \& Paraskevopoulos, J. (1980) Children's psychological development as a function of the inaccuracy of their mothers' knowledge of their abilities. The Journal of Genetic Psychology, 136, 285-298.

Karraker, K. H. \& Evans, S. L. (1996). Adolescent mothers' knowledge of child development and expectations for their own infants. Journal of Youth and Adolescence, 25, 651-666.

Lamb, M. E., Garn, S. M., \& Keating, M. T. (1981). Correlations between sociability and cognitive performance among eight-month-olds. Child Development, 52, 711-713.

Lamb, M. E., Garn, S. M., \& Keating, M. T. (1982). Correlations between sociability and motor performance in 8-month-olds. Infant Behavior and Development, 5, 97-101.

Majnemer, A. \& Barr, R. G. (2005). Influence of supine sleep positioning on early motor milestone acquisition. Developmental Medicine \& Child Neurology, 47, 370-376.

Matheny Jr., A. P., Wilson, R. S., \& Nuss, S. M. (1984). Toddler temperament: stability across settings and over ages. Child Development, 55, 1200-1211.

McGillicuddy-DeLisi, A. V. (1982). Parental beliefs about developmental processes. Human Development, 25, 192-200. 
Miller, S. A. (1986). Parents' beliefs about their children's cognitive abilities. Developmental Psychology, 22, 276-284.

Morawska, A., Winter, L., \& Sanders, M. R. (2009). Parenting knowledge and its role in the prediction of dysfunctional parenting and disruptive child behavior. Child: Care, Health, and Development, 35, 217-226.

Pratt, M. W., Kerig, P., Cowan, P. A., \& Cowan, C. P. (1988). Mothers and fathers teaching 3year-olds: Authoritative parenting and adult scaffolding of young children's learning. Developmental Psychology, 24, 832-839.

Price, G. G. \& Gillingham, M. G. (1985). Effect of mothers' overestimations and underestimations of their children's intellectual ability: A reanalysis of Hunt and Paraskevopoulos. The Journal of Genetic Psychology, 146, 477-481.

Reich, S. (2005). What do mothers know? Maternal knowledge of child development. Infant Mental Health Journal, 26, 143-156.

Reis, J. (1988). Child-rearing expectations and developmental knowledge according to maternal age and parity. Infant Mental Health Journal, 9, 287-304.

Saudino, K. J., Dale, P. S., Oliver, B., Petrill, S. A., Richardson, V., Rutter, M., Simonoff, E., Stevenson, J., \& Plomin, R. (1998). The validity of parent-based assessment of the cognitive abilities of 2-year-olds. British Journal of Developmental Psychology, 16, 349363. 
Seegmiller, B. R. \& King, W. L. (1975). Relations between behavioral characteristics of infants, their mothers' behaviors, and performance on the Bayley mental and motor scales. The Journal of Psychology, 90, 99-111.

Seifer, R. (2005). Who should collect our data: parents or trained observers? In D. M. Teti (Ed.), Handbook of Research Methods in Developmental Psychology (pp. 123-137). Malden, MA: Blackwell Publishing.

Seifer, R., Sameroff, A., Dickstein, S., Schiller, M., \& Hayden, L. C. (2004). Your own children are special: clues to the sources of reporting bias in temperament assessments. Infant Behavior and Development, 27, 323-341.

Spruyt, K., Aitken, R. J., So, K., Charlton, M., Adamson, T. M., \& Horne, R. S. C. (2008) Relationship between sleep/wake patterns, temperament, and overall development in term infants over the first year of life. Early Human Development, 84, 289-296.

Tamis-LeMonda, C. S., Chen, L. A., \& Bornstein, M. H. (1998) Mothers' knowledge about children's play and language development: Short-term stability and interrelations. Developmental Psychology, 34, 115-124.

Teti, D. M. \& Gelfand, D. M. (1991). Behavioral competence among mothers of infants in the first year: The mediational role of maternal self-efficacy. Child Development, 62, 918929. 
Teti, D. M. \& McGourty, S. (1996). Using mothers versus trained observers in assessing children's secure base behavior: theoretical and methodological considerations. Child Development, 67, 597-605.

Thompson, B., Wasserman, J. D., \& Matula, K. (1996). The factor structure of the behavior rating scale of the Bayley Scales of Infant Development II. Educational and Psychological Measurement, 56, 460-474. 
Table 1

Participant Characteristics

\begin{tabular}{|c|c|c|c|c|c|c|c|}
\hline \multirow[b]{2}{*}{ Measure } & \multicolumn{2}{|c|}{$\frac{\text { Harrisonburg, VA }}{(\mathrm{N}=42)}$} & \multicolumn{2}{|c|}{$\frac{\text { Sewanee, TN }}{(N=26)}$} & \multirow[b]{2}{*}{$t$} & \multirow[b]{2}{*}{$d f$} & \multirow[b]{2}{*}{$p$} \\
\hline & $M$ & $S D$ & $M$ & $S D$ & & & \\
\hline $\begin{array}{l}\text { Mothers' age } \\
\text { (years) }\end{array}$ & 31.64 & 4.21 & 30.76 & 5.18 & .76 & 65 & .45 \\
\hline $\begin{array}{l}\text { Toddlers' age } \\
\text { (months) }\end{array}$ & 21.50 & 1.57 & 22.19 & 2.30 & -1.48 & 66 & .14 \\
\hline $\begin{array}{l}\text { Mothers' education } \\
\text { (years) }\end{array}$ & 15.05 & 2.39 & 14.92 & 2.26 & .21 & 66 & .83 \\
\hline Families' income & 4.79 & 1.91 & 4.64 & 2.19 & .28 & 62 & .78 \\
\hline MEQ & 3.34 & .25 & 3.46 & .28 & -1.83 & 66 & .07 \\
\hline ICQ & 3.15 & .55 & 3.08 & .56 & .43 & 56 & .67 \\
\hline
\end{tabular}


Table 2

Additional participant characteristics

\begin{tabular}{|c|c|c|c|c|c|}
\hline Measure & $\frac{\text { Harrisonburg, VA }}{(N=42)}$ & $\frac{\text { Sewanee, TN }}{(N=26)}$ & $\chi^{2}$ & $d f$ & $\begin{array}{c}\text { Fisher's } \\
\text { Exact } \\
\text { Test }\end{array}$ \\
\hline Toddlers' sex & & & .65 & 1 & \\
\hline Boys & 22 & 11 & & & \\
\hline Girls & 20 & 15 & & & \\
\hline Mothers' parity & & & .41 & 1 & \\
\hline Primiparous & 13 & 10 & & & \\
\hline Multiparous & 29 & 16 & & & \\
\hline Mothers' race & & & & & .622 \\
\hline Caucasian & 41 & 25 & & & \\
\hline Other & 1 & 1 & & & \\
\hline Marital status & & & & & .382 \\
\hline Married & 42 & 25 & & & \\
\hline Single & 0 & 1 & & & \\
\hline Employment status & & & $6.40 *$ & 2 & \\
\hline Unemployed & 12 & 15 & & & \\
\hline Employed part-time & 9 & 5 & & & \\
\hline Employed full-time & 31 & 6 & & & \\
\hline Childcare arrangement & & & .90 & 2 & \\
\hline Nonmaternal & 17 & 11 & & & \\
\hline Maternal full-time & 10 & 10 & & & \\
\hline Maternal part-time & 5 & 5 & & & \\
\hline
\end{tabular}

Note. Fisher's Exact Test statistic was used for mothers' race and marital status because two cells in each had less than five individuals in them. Chi-square is not an appropriate statistic to use in those cases. ${ }^{*} p<.05$ 
Table 3

How maternal accuracy and bias variables and toddlers' performance variables were created.

\begin{tabular}{ccc}
\hline \multirow{2}{*}{ Toddler performance } & \multicolumn{2}{c}{ Maternal prediction } \\
& Pass & Fail \\
\hline Pass & Correct prediction $(\mathrm{A})$ & Underestimation (B) \\
Fail & Overestimation $(\mathrm{C})$ & Correct prediction (D) \\
\hline
\end{tabular}

Note: Maternal pass predictions were calculated as $(A+C) /(A+B+C+D)$. Maternal accuracy was calculated as $(A+D) /(A+B+C+D)$. Maternal overestimations were calculated as $(C) /(C+D)$. Maternal underestimations were calculated as $(B) /(A+B)$. Toddler performance was calculated as $(A+B) /(A+B+C+D)$. 
Table 4

Cohen's Kappa for the researcher's and research assistants' coding of toddlers' emotional behavior during the BSID-II

\begin{tabular}{lccc}
\hline Emotional behavior & During task & Inter-task time & Overall \\
\hline Positive facial expressions & .65 & .51 & .63 \\
Negative facial expressions & .54 & .41 & .49 \\
Positive vocalizations & .59 & .72 & .63 \\
Negative vocalizations & .66 & .59 & .63 \\
Other vocalizations & .74 & .71 & .74 \\
Reaching & .44 & .41 & .42 \\
Refusing & .76 & & .76 \\
Escaping & .80 & .61 & .76 \\
Off-task behaviors & .60 & .50 & .68 \\
\hline
\end{tabular}

Note. Kappa statistic could not be calculated for refusing during inter-task time because there were no instances when the research assistants indicated that the toddlers were refusing task related materials during the inter-task times. 
Table 5

Missing data from mothers' predictions of and toddlers performance on the BSID-II, reported by participant ID number.

\begin{tabular}{|c|c|c|c|c|}
\hline ID number & $\begin{array}{l}\text { Mother's missing } \\
\text { - mental scale }\end{array}$ & $\begin{array}{c}\text { Toddler's missing } \\
\text { - mental scale }\end{array}$ & $\begin{array}{l}\text { Mother's missing } \\
\text { - motor scale }\end{array}$ & $\begin{array}{c}\text { Toddler's missing } \\
\text { - motor scale }\end{array}$ \\
\hline 101 & 9 & 8 & 4 & 6 \\
\hline 102 & 0 & 4 & 1 & 1 \\
\hline 104 & 0 & 3 & 1 & 1 \\
\hline 105 & 0 & 5 & 0 & 1 \\
\hline 106 & 0 & 4 & 0 & 1 \\
\hline 107 & 0 & 3 & 0 & 1 \\
\hline 108 & 0 & 1 & 0 & 1 \\
\hline 109 & 0 & 3 & 0 & 1 \\
\hline 110 & 0 & 3 & 0 & 0 \\
\hline 111 & 2 & 5 & 5 & 0 \\
\hline 112 & 0 & 6 & 0 & 1 \\
\hline 113 & 0 & 1 & 0 & 2 \\
\hline 114 & 1 & 2 & 0 & 0 \\
\hline 115 & 0 & 3 & 0 & 0 \\
\hline 116 & 0 & 3 & 1 & 1 \\
\hline 117 & 1 & 3 & 0 & 1 \\
\hline 118 & 2 & 5 & 0 & 6 \\
\hline 119 & 0 & 4 & 0 & 0 \\
\hline 120 & 0 & 4 & 0 & 13 \\
\hline 121 & 0 & 3 & 0 & 0 \\
\hline 122 & 0 & 3 & 0 & 0 \\
\hline 123 & 0 & 3 & 0 & 0 \\
\hline 124 & 1 & 5 & 0 & 0 \\
\hline 125 & 0 & 3 & 0 & 16 \\
\hline 126 & 0 & 3 & 0 & 18 \\
\hline 127 & 0 & 4 & 16 & 0 \\
\hline 128 & 0 & 4 & 0 & 0 \\
\hline 129 & 0 & 4 & 0 & 1 \\
\hline 130 & 0 & 4 & 0 & 0 \\
\hline 131 & 1 & 5 & 0 & 0 \\
\hline 132 & 0 & 4 & 0 & 0 \\
\hline 133 & 0 & 4 & 8 & 0 \\
\hline 134 & 0 & 4 & 0 & 0 \\
\hline 135 & 0 & 5 & 0 & 1 \\
\hline 136 & 6 & 4 & 0 & 0 \\
\hline 137 & 0 & 4 & 0 & 0 \\
\hline 138 & 0 & 4 & 0 & 0 \\
\hline
\end{tabular}




\begin{tabular}{|c|c|c|c|c|}
\hline 139 & 8 & 10 & 4 & 4 \\
\hline 140 & 0 & 4 & 0 & 0 \\
\hline 141 & 0 & 4 & 0 & 0 \\
\hline 142 & 0 & 4 & 0 & 1 \\
\hline 143 & 0 & 3 & 0 & 0 \\
\hline 201 & 17 & 1 & 0 & 1 \\
\hline 202 & 7 & 4 & 1 & 1 \\
\hline 203 & 0 & 3 & 0 & 1 \\
\hline 204 & 1 & 7 & 0 & 1 \\
\hline 205 & 1 & 7 & 0 & 0 \\
\hline 206 & 7 & 4 & 0 & 1 \\
\hline 207 & 8 & 5 & 0 & 2 \\
\hline 210 & 3 & 7 & 0 & 1 \\
\hline 211 & 2 & 6 & 1 & 0 \\
\hline 212 & 0 & 3 & 0 & 0 \\
\hline 213 & 2 & 6 & 0 & 0 \\
\hline 214 & 7 & 2 & 4 & 0 \\
\hline 215 & 1 & 7 & 0 & 1 \\
\hline 216 & 1 & 7 & 1 & 1 \\
\hline 217 & 2 & 6 & 0 & 0 \\
\hline 218 & 0 & 3 & 0 & 0 \\
\hline 219 & 1 & 7 & 1 & 1 \\
\hline 220 & 1 & 7 & 0 & 0 \\
\hline 221 & 0 & 3 & 0 & 0 \\
\hline 222 & 1 & 3 & 0 & 0 \\
\hline 223 & 6 & 20 & 4 & 3 \\
\hline 225 & 2 & 3 & 0 & 0 \\
\hline 226 & 1 & 7 & 0 & 0 \\
\hline 227 & 7 & 2 & 0 & 1 \\
\hline 228 & 7 & 4 & 0 & 2 \\
\hline 229 & 7 & 2 & 0 & 1 \\
\hline
\end{tabular}


Table 6

Summary of demographic variables separated by sex of toddler

\begin{tabular}{lcccccccccc}
\hline Variable & \multicolumn{7}{c}{ Boys } & \multicolumn{7}{c}{ Girls } & & & \\
\cline { 2 - 8 } & $N$ & $M$ & $s d$ & $N$ & $M$ & $s d$ & $t$ & $d f$ & $p$ \\
\hline $\begin{array}{l}\text { Toddlers' age } \\
\text { (months) }\end{array}$ & 33 & 21.79 & 1.78 & 35 & 21.74 & 2.02 & .10 & 66 & .923 \\
$\begin{array}{l}\text { Mothers' age } \\
\text { (years) }\end{array}$ & 32 & 32.56 & 4.82 & 35 & 30.17 & 4.08 & $2.20^{*}$ & 65 & .032 \\
$\begin{array}{l}\text { Mothers' education } \\
\text { (years) }\end{array}$ & 33 & 15.58 & 2.29 & 35 & 14.46 & 2.25 & $2.03^{*}$ & 66 & .046 \\
$\begin{array}{l}\text { Mothers' knowledge } \\
\text { of child development }\end{array}$ & 22 & 1.86 & 1.04 & 20 & 1.95 & 1.32 & -.24 & 40 & .814 \\
$\begin{array}{l}\text { Mothers' parenting } \\
\text { self-efficacy }\end{array}$ & 33 & 3.38 & .28 & 35 & 3.38 & .26 & .04 & 66 & .965 \\
\hline
\end{tabular}

$* p<.05$ 
Table 7

Means for maternal accuracy and bias variables and toddler performance variables separated by sex of toddler

\begin{tabular}{|c|c|c|c|c|c|c|c|c|c|}
\hline \multirow{2}{*}{ Variable } & \multicolumn{3}{|c|}{ Boys } & \multicolumn{3}{|c|}{ Girls } & \multirow[b]{2}{*}{$t$} & \multirow[b]{2}{*}{$d f$} & \multirow[b]{2}{*}{$p$} \\
\hline & $N$ & $M \%$ & $s d \%$ & $N$ & $M \%$ & $s d \%$ & & & \\
\hline $\begin{array}{l}\text { Maternal pass } \\
\text { prediction: mental }\end{array}$ & 33 & 71 & 16 & 35 & 76 & 14 & -1.37 & 66 & .175 \\
\hline $\begin{array}{l}\text { Maternal pass } \\
\text { predictions: motor }\end{array}$ & 31 & 66 & 21 & 33 & 73 & 22 & -1.40 & 62 & .176 \\
\hline $\begin{array}{l}\text { Maternal accuracy: } \\
\text { mental }\end{array}$ & 33 & 70 & 13 & 35 & 72 & 14 & -.64 & 66 & .522 \\
\hline $\begin{array}{l}\text { Maternal accuracy: } \\
\text { motor }\end{array}$ & 29 & 71 & 15 & 35 & 66 & 16 & 1.09 & 62 & .281 \\
\hline $\begin{array}{l}\text { Maternal over- } \\
\text { estimations: mental }\end{array}$ & 33 & 56 & 25 & 33 & 64 & 25 & -1.35 & 64 & .181 \\
\hline $\begin{array}{l}\text { Maternal over- } \\
\text { estimations: motor }\end{array}$ & 30 & 48 & 36 & 29 & 61 & 33 & -1.40 & 57 & .168 \\
\hline $\begin{array}{l}\text { Maternal under- } \\
\text { estimations: mental }\end{array}$ & 33 & 21 & 16 & 35 & 17 & 13 & 1.05 & 66 & .298 \\
\hline $\begin{array}{l}\text { Maternal under- } \\
\text { estimations: motor } \\
\text { Toddler }\end{array}$ & 31 & 28 & 23 & 32 & 20 & 17 & 1.41 & 61 & .165 \\
\hline $\begin{array}{l}\text { performance: } \\
\text { mental } \\
\text { Toddler }\end{array}$ & 33 & 64 & 24 & 35 & 70 & 22 & -1.17 & 66 & .246 \\
\hline $\begin{array}{l}\text { performance: } \\
\text { motor }\end{array}$ & 29 & 73 & 21 & 35 & 74 & 20 & .32 & 62 & .746 \\
\hline
\end{tabular}

Note: Means for toddlers' performance on the motor scale reported here are based on the original scale rather than after the variable was reflected and transformed. 
Table 8

Summary of toddlers' mood and emotional behavior variables separated by sex of toddler

\begin{tabular}{|c|c|c|c|c|c|c|c|c|c|}
\hline \multirow{2}{*}{ Variable } & \multicolumn{3}{|c|}{ Boys } & \multicolumn{3}{|c|}{ Girls } & \multirow[b]{2}{*}{$t$} & \multirow[b]{2}{*}{$d f$} & \multirow[b]{2}{*}{$p$} \\
\hline & $N$ & $M$ & $s d$ & $N$ & $M$ & $s d$ & & & \\
\hline BRS: sociability & 33 & 4.64 & .60 & 35 & 4.54 & .61 & .64 & 66 & .528 \\
\hline BRS: adaptability & 33 & 4.67 & .54 & 35 & 4.49 & .66 & 1.24 & 66 & .221 \\
\hline Overall BRS score & 33 & 121.76 & 7.72 & 35 & 120.86 & 9.04 & .44 & 66 & .661 \\
\hline $\begin{array}{l}\text { Mothers' rating of } \\
\text { toddlers' difficulty }\end{array}$ & 26 & 2.98 & .59 & 32 & 3.24 & .49 & -1.83 & 56 & .072 \\
\hline $\begin{array}{l}\text { Positive facial } \\
\text { expressions }\end{array}$ & 29 & $27 \%$ & $21 \%$ & 29 & $23 \%$ & $18 \%$ & .70 & 56 & .489 \\
\hline $\begin{array}{l}\text { Negative facial } \\
\text { expressions }\end{array}$ & 29 & $2 \%$ & $3 \%$ & 29 & $4 \%$ & $10 \%$ & -.95 & 56 & .348 \\
\hline $\begin{array}{l}\text { Positive } \\
\text { vocalizations }\end{array}$ & 29 & $6 \%$ & $6 \%$ & 29 & $13 \%$ & $13 \%$ & $-2.39 *$ & 56 & .020 \\
\hline $\begin{array}{l}\text { Negative } \\
\text { vocalizations }\end{array}$ & 29 & $10 \%$ & $13 \%$ & 29 & $13 \%$ & $16 \%$ & -.60 & 56 & .552 \\
\hline Other vocalizations & 29 & $54 \%$ & $19 \%$ & 29 & $52 \%$ & $19 \%$ & .32 & 56 & .748 \\
\hline Reaches & 29 & $20 \%$ & $12 \%$ & 29 & $23 \%$ & $11 \%$ & -.93 & 56 & .356 \\
\hline Refusals & 29 & $4 \%$ & $5 \%$ & 29 & $4 \%$ & $6 \%$ & .11 & 56 & .912 \\
\hline Escapes & 29 & $9 \%$ & $10 \%$ & 29 & $7 \%$ & $9 \%$ & .81 & 56 & .424 \\
\hline Off-task behaviors & 29 & $21 \%$ & $13 \%$ & 29 & $19 \%$ & $11 \%$ & .74 & 56 & .465 \\
\hline
\end{tabular}

Note: Individual items on the BRS are answered on a scale of 1 to 5 . Overall BRS scores can range from 30 to 150. In this sample they ranged from 93 to 130. Overall BRS score means reported here are based on the original scale rather than after the variable was reflected and transformed. ${ }^{*} p<.05$ 
Table 9

Correlations between maternal and toddler characteristics and mothers' accuracy and bias in predicting their toddlers' BSID-II performance

\begin{tabular}{|c|c|c|c|c|c|c|}
\hline Characteristics & $\begin{array}{l}\text { Mental } \\
\text { accuracy }\end{array}$ & $\begin{array}{c}\text { Motor } \\
\text { accuracy }\end{array}$ & $\begin{array}{l}\text { Mental } \\
\text { overest. }\end{array}$ & $\begin{array}{c}\text { Motor } \\
\text { overest. }\end{array}$ & $\begin{array}{c}\text { Mental } \\
\text { underest. }\end{array}$ & $\begin{array}{c}\text { Motor } \\
\text { underest. }\end{array}$ \\
\hline Toddlers' age & .22 & -.01 & -.10 & -.11 & -.02 & .04 \\
\hline $\begin{array}{l}\text { Toddlers' } \\
\text { fragmented sleep }\end{array}$ & .30 & -.05 & -.03 & .22 & $.40^{*}$ & -.20 \\
\hline Toddlers napped & -.02 & .06 & -.14 & .27 & .28 & -.17 \\
\hline $\begin{array}{l}\text { Toddlers previously } \\
\text { ill }\end{array}$ & $.46^{*}$ & .20 & -.01 & -.13 & .36 & .15 \\
\hline $\begin{array}{l}\text { Toddlers currently } \\
\text { ill }\end{array}$ & $.39 *$ & -.20 & .03 & .30 & $.44^{*}$ & -.36 \\
\hline Mothers' age & .09 & -.11 & -.21 & $-.31 *$ & .06 & .23 \\
\hline Mothers' education & .07 & .03 & .06 & -.14 & -.09 & .08 \\
\hline $\begin{array}{l}\text { Mothers parenting } \\
\text { self-efficacy } \\
\text { Mothers' }\end{array}$ & .19 & .16 & .17 & $-.25^{*}$ & $-.25 *$ & -.20 \\
\hline $\begin{array}{l}\text { knowledge of child } \\
\text { development }\end{array}$ & .04 & .23 & -.25 & .03 & -.05 & -.15 \\
\hline $\begin{array}{l}\text { Mothers' rating of } \\
\text { toddler difficulty }\end{array}$ & -.19 & -.12 & -.12 & .25 & -.20 & -.14 \\
\hline $\begin{array}{l}\text { Mothers' rating of } \\
\text { toddlers' mood } \\
\text { (before BSID-II) }\end{array}$ & $-.69 * * *$ & .19 & -.30 & .19 & $-.60 * *$ & .23 \\
\hline $\begin{array}{l}\text { Mothers' rating of } \\
\text { toddlers' behavior } \\
\text { (after BSID-II) }\end{array}$ & $.67 * * *$ & .16 & .35 & -.08 & $.59 * *$ & -.22 \\
\hline $\begin{array}{l}\text { Mothers' rating of } \\
\text { toddlers' mood } \\
\text { (after BSID-II) }\end{array}$ & $-.62 * *$ & -.11 & -.38 & .31 & $-.65 * * *$ & .15 \\
\hline $\begin{array}{l}\text { Mothers' rating of } \\
\text { toddlers' } \\
\text { performance (after } \\
\text { BSID-II) }\end{array}$ & .64 & .22 & $.45^{*}$ & -.10 & $.79 * * *$ & -.21 \\
\hline $\begin{array}{l}\text { Mothers' rating of } \\
\text { toddlers' behavior } \\
\text { (BRS) }\end{array}$ & $.37 * *$ & -.01 & $.27^{*}$ & -.07 & $.58 * * *$ & -.16 \\
\hline $\begin{array}{l}\text { Mothers' rating of } \\
\text { toddlers' } \\
\text { performance (BRS) }\end{array}$ & $.37^{* *}$ & .06 & $.30 *$ & -.12 & $.66 * * *$ & -.07 \\
\hline
\end{tabular}


Administrator's rating: positive

.22

.22

.18

.08

$.45^{* * *} \quad-.06$

affect

Administrator's rating: interest

Administrator's

rating: initiative

Administrator's rating: exploration

Administrator's rating: enthusiasm

Administrator's rating: fearfulness

Administrator's rating: orientation

Administrator's rating: social engagement Administrator's rating: negative affect

Administrator's rating:

hypersensitivity Administrator's rating: adaptability

Administrator's rating: attention

Administrator's rating: persistence Administrator's rating: frustration

Administrator's rating: cooperation

Administrator's rating: hyperactivity Administrator's rating: sootheability

Administrator's rating of mood: BRS total score

Positive facial expressions

\begin{tabular}{|c|c|c|c|c|c|}
\hline $.39 * *$ & .00 & .19 & -.15 & $.55^{* * *}$ & .01 \\
\hline $.42 * * *$ & .03 & .21 & -.21 & $.60 * * *$ & .07 \\
\hline .22 & .13 & .07 & -.09 & .18 & .02 \\
\hline $.42 * * *$ & .07 & .19 & -.17 & $.62 * * *$ & .06 \\
\hline $.32 * *$ & -.03 & -.18 & -.07 & .11 & -.01 \\
\hline .11 & -.06 & .13 & -.09 & $.28^{*}$ & -.02 \\
\hline .19 & -.06 & .10 & -.02 & $.25 *$ & -.08 \\
\hline .21 & .21 & $.33^{* *}$ & .06 & $.37 * *$ & -.13 \\
\hline .06 & .01 & -.01 & & .13 & .15 \\
\hline .07 & .06 & .22 & -.08 & .20 & .01 \\
\hline $.36 * *$ & .07 & $.27^{*}$ & -.12 & $.57 * * *$ & .00 \\
\hline $.42 * * *$ & .06 & $.26^{*}$ & -.15 & $.61^{* * *}$ & .07 \\
\hline .08 & -.20 & .03 & .14 & .21 & -.23 \\
\hline $.28^{*}$ & .10 & $.30 *$ & -.03 & $.50 * * *$ & -.15 \\
\hline $.32 * *$ & -.011 & -.09 & .08 & $.25^{*}$ & -.13 \\
\hline $.29 *$ & .18 & .14 & -.07 & $.44^{* * *}$ & -.03 \\
\hline$-.40 * *$ & .00 & $-.25^{*}$ & .10 & .13 & .02 \\
\hline .02 & -.07 & .04 & -.22 & .04 & -.05 \\
\hline
\end{tabular}




\begin{tabular}{|c|c|c|c|c|c|c|}
\hline $\begin{array}{l}\text { Negative facial } \\
\text { expressions }\end{array}$ & -.22 & -.24 & -.12 & -.09 & $-.29 *$ & -.06 \\
\hline $\begin{array}{l}\text { Positive } \\
\text { vocalizations }\end{array}$ & $.41^{* *}$ & -.01 & .13 & -.24 & $.37 * *$ & .12 \\
\hline $\begin{array}{l}\text { Negative } \\
\text { vocalizations }\end{array}$ & -.17 & -.01 & -.15 & -.09 & $-.32 *$ & .04 \\
\hline Other vocalizations & .16 & .18 & .04 & .05 & .21 & -.10 \\
\hline Reaches & .06 & -.17 & -.16 & .10 & -.17 & -.03 \\
\hline Refusals & -.20 & -.08 & -.13 & .03 & $-.34 * *$ & .00 \\
\hline Escapes & -.13 & .06 & -.26 & .20 & $-.34 *$ & .01 \\
\hline Off-task behavior & $-.30 *$ & .11 & -.11 & .28 & $-.31^{*}$ & -.11 \\
\hline
\end{tabular}


Table 10

Multiple regression analyses predicting mothers' accuracy on the mental scale from individual differences in mother and toddler characteristics

\begin{tabular}{|c|c|c|c|c|c|}
\hline Variables & b & $\begin{array}{c}\text { Adjusted } \\
R^{2} \\
\end{array}$ & $\begin{array}{c}F \\
\text { change }\end{array}$ & $\mathrm{df}$ & $p$ \\
\hline Demographics & & -.28 & .15 & 8,23 & .995 \\
\hline Toddlers' age & .005 & & & & \\
\hline Mothers' age & -.086 & & & & \\
\hline Mothers' parity & .054 & & & & \\
\hline Mothers' education & .154 & & & & \\
\hline $\begin{array}{l}\text { Mothers' time with } \\
\text { toddler }\end{array}$ & .153 & & & & \\
\hline $\begin{array}{l}\text { Mothers' parenting } \\
\text { self-efficacy }\end{array}$ & .102 & & & & \\
\hline $\begin{array}{l}\text { Mothers' knowledge } \\
\text { of child development }\end{array}$ & .021 & & & & \\
\hline $\begin{array}{l}\text { Mothers' rating of } \\
\text { infant difficulty }\end{array}$ & -.002 & & & & \\
\hline $\begin{array}{l}\text { Ratings of mood and } \\
\text { behavior }\end{array}$ & & .35 & 2.63 & 7,14 & .059 \\
\hline $\begin{array}{l}\text { Administrator's } \\
\text { overall rating }\end{array}$ & -.32 & & & & \\
\hline $\begin{array}{l}\text { Mothers' mood rating } \\
\text { before BSID-II }\end{array}$ & -.54 & & & & \\
\hline $\begin{array}{l}\text { Mothers' rating of } \\
\text { toddlers' behavior }\end{array}$ & -.45 & & & & \\
\hline $\begin{array}{l}\text { Mothers' mood rating } \\
\text { after BSID-II }\end{array}$ & .26 & & & & \\
\hline $\begin{array}{l}\text { Mothers' rating of } \\
\text { toddlers' performance }\end{array}$ & .07 & & & & \\
\hline $\begin{array}{l}\text { Mothers' BRS rating } \\
\text { of behavior }\end{array}$ & .66 & & & & \\
\hline $\begin{array}{l}\text { Mothers' BRS rating } \\
\text { of performance }\end{array}$ & .04 & & & & \\
\hline Emotional behaviors & & $.18^{*}$ & $2.36 *$ & 9,48 & .027 \\
\hline $\begin{array}{l}\text { Positive facial } \\
\text { expressions }\end{array}$ & $-.32 *$ & & & & \\
\hline $\begin{array}{l}\text { Negative facial } \\
\text { expressions }\end{array}$ & -.18 & & & & \\
\hline Positive vocalizations & $.44^{* *}$ & & & & \\
\hline Negative vocalizations & -.02 & & & & \\
\hline Other vocalizations & .09 & & & & \\
\hline
\end{tabular}


Reaches $\quad .08$

Refusals $\quad .05$

Escapes $\quad .03$

Off-task behaviors $\quad-.27$

Note: Each panel represents a separate model. Administrator's overall rating variable reported here is based on the reflected and transformed variable. ${ }^{*} p<.05, * * p<.01$ 


\section{Table 11}

Multiple regression analyses predicting mothers' accuracy on the motor scale from individual differences in mother and toddler characteristics

\begin{tabular}{|c|c|c|c|c|c|}
\hline Variables & 8 & $\begin{array}{c}\text { Adjusted } \\
R^{2} \\
\end{array}$ & $\begin{array}{c}F \\
\text { change }\end{array}$ & $d f$ & $p$ \\
\hline Demographics & & $.32 *$ & 2.61 & 8,19 & .041 \\
\hline Toddlers' age & -.093 & & & & \\
\hline Mothers' age & -.42 & & & & \\
\hline Mothers' parity & .06 & & & & \\
\hline Mothers' education & .02 & & & & \\
\hline $\begin{array}{l}\text { Mothers' time with } \\
\text { toddler }\end{array}$ & $-.52 * *$ & & & & \\
\hline $\begin{array}{l}\text { Mothers' parenting } \\
\text { self-efficacy }\end{array}$ & -.14 & & & & \\
\hline $\begin{array}{l}\text { Mothers' knowledge } \\
\text { of child development }\end{array}$ & .14 & & & & \\
\hline $\begin{array}{l}\text { Mothers' rating of } \\
\text { infant difficulty }\end{array}$ & .08 & & & & \\
\hline $\begin{array}{l}\text { Ratings of mood and } \\
\text { behavior }\end{array}$ & & $.43^{*}$ & 3.34 & 7,14 & .029 \\
\hline $\begin{array}{l}\text { Administrator's } \\
\text { overall rating }\end{array}$ & -.06 & & & & \\
\hline $\begin{array}{l}\text { Mothers' mood rating } \\
\text { before BSID-II }\end{array}$ & $1.29 * *$ & & & & \\
\hline $\begin{array}{l}\text { Mothers' rating of } \\
\text { toddlers' behavior }\end{array}$ & 1.55 & & & & \\
\hline $\begin{array}{l}\text { Mothers' mood rating } \\
\text { after BSID-II }\end{array}$ & $-1.43^{* *}$ & & & & \\
\hline $\begin{array}{l}\text { Mothers' rating of } \\
\text { toddlers' performance }\end{array}$ & -.69 & & & & \\
\hline $\begin{array}{l}\text { Mothers' BRS rating } \\
\text { of behavior }\end{array}$ & -1.76 & & & & \\
\hline $\begin{array}{l}\text { Mothers' BRS rating } \\
\text { of performance }\end{array}$ & 1.22 & & & & \\
\hline Emotional behaviors & & .00 & .99 & 9,44 & .466 \\
\hline $\begin{array}{l}\text { Positive facial } \\
\text { expressions }\end{array}$ & -.07 & & & & \\
\hline $\begin{array}{l}\text { Negative facial } \\
\text { expressions }\end{array}$ & -.42 & & & & \\
\hline Positive vocalizations & -.04 & & & & \\
\hline Negative vocalizations & .26 & & & & \\
\hline Other vocalizations & .24 & & & & \\
\hline
\end{tabular}


Reaches $\quad-.21$

Refusals $\quad .14$

Escapes $\quad-.08$

Off-task behaviors $\quad .01$

Note: Each panel represents a separate model. Administrator's overall rating variable reported

here is based on the reflected and transformed variable. ${ }^{* *} p<.01$ 
Table 12

Multiple regression analyses predicting mothers' overestimations on the mental scale from individual differences in mother and toddler characteristics

\begin{tabular}{|c|c|c|c|c|c|}
\hline Variables & B & $\begin{array}{c}\text { Adjusted } \\
R^{2} \\
\end{array}$ & $\begin{array}{c}F \\
\text { change }\end{array}$ & $d f$ & $p$ \\
\hline Demographics & & .25 & 2.30 & 8,23 & .056 \\
\hline Toddlers' age & .31 & & & & \\
\hline Mothers' age & $-.87 * *$ & & & & \\
\hline Mothers' parity & .07 & & & & \\
\hline Mothers' education & $.71^{*}$ & & & & \\
\hline $\begin{array}{l}\text { Mothers' time with } \\
\text { toddler }\end{array}$ & -.14 & & & & \\
\hline $\begin{array}{l}\text { Mothers' parenting } \\
\text { self-efficacy }\end{array}$ & .18 & & & & \\
\hline $\begin{array}{l}\text { Mothers' knowledge } \\
\text { of child development }\end{array}$ & -.26 & & & & \\
\hline $\begin{array}{l}\text { Mothers' rating of } \\
\text { infant difficulty }\end{array}$ & -.33 & & & & \\
\hline $\begin{array}{l}\text { Ratings of mood and } \\
\text { behavior }\end{array}$ & & $.44^{*}$ & 3.12 & 7,12 & .040 \\
\hline $\begin{array}{l}\text { Administrator's } \\
\text { overall rating }\end{array}$ & -.10 & & & & \\
\hline $\begin{array}{l}\text { Mothers' mood rating } \\
\text { before BSID-II }\end{array}$ & .45 & & & & \\
\hline $\begin{array}{l}\text { Mothers' rating of } \\
\text { toddlers' behavior }\end{array}$ & $2.12 *$ & & & & \\
\hline $\begin{array}{l}\text { Mothers' mood rating } \\
\text { after BSID-II }\end{array}$ & -.80 & & & & \\
\hline $\begin{array}{l}\text { Mothers' rating of } \\
\text { toddlers' performance }\end{array}$ & -.20 & & & & \\
\hline $\begin{array}{l}\text { Mothers' BRS rating } \\
\text { of behavior }\end{array}$ & $-2.34 *$ & & & & \\
\hline $\begin{array}{l}\text { Mothers' BRS rating } \\
\text { of performance }\end{array}$ & .60 & & & & \\
\hline Emotional behaviors & & -.05 & .71 & 9,46 & .695 \\
\hline $\begin{array}{l}\text { Positive facial } \\
\text { expressions }\end{array}$ & .00 & & & & \\
\hline $\begin{array}{l}\text { Negative facial } \\
\text { expressions }\end{array}$ & .00 & & & & \\
\hline Positive vocalizations & .00 & & & & \\
\hline Negative vocalizations & .01 & & & & \\
\hline Other vocalizations & .10 & & & & \\
\hline
\end{tabular}


Reaches $\quad-.19$

Refusals $\quad-.12$

Escapes $\quad-.27$

Off-task behaviors $\quad-.04$

Note: Each panel represents a separate model. Administrator's overall rating variable reported here is based on the reflected and transformed variable. ${ }^{*} p<.05, * * p<.01$ 
Table 13

Multiple regression analyses predicting mothers' overestimations on the motor scale from individual differences in mother and toddler characteristics

\begin{tabular}{|c|c|c|c|c|c|}
\hline Variables & $B$ & $\begin{array}{c}\text { Adjusted } \\
R^{2} \\
\end{array}$ & $\begin{array}{c}F \\
\text { change }\end{array}$ & $d f$ & $p$ \\
\hline Demographics & & -.11 & .68 & 8,18 & .701 \\
\hline Toddlers' age & -.32 & & & & \\
\hline Mothers' age & -.21 & & & & \\
\hline Mothers' parity & -.14 & & & & \\
\hline Mothers' education & .11 & & & & \\
\hline $\begin{array}{l}\text { Mothers' time with } \\
\text { toddler }\end{array}$ & -.18 & & & & \\
\hline $\begin{array}{l}\text { Mothers' parenting } \\
\text { self-efficacy }\end{array}$ & -.02 & & & & \\
\hline $\begin{array}{l}\text { Mothers' knowledge } \\
\text { of child development }\end{array}$ & -.09 & & & & \\
\hline $\begin{array}{l}\text { Mothers' rating of } \\
\text { infant difficulty }\end{array}$ & .12 & & & & \\
\hline $\begin{array}{l}\text { Ratings of mood and } \\
\text { behavior }\end{array}$ & & .02 & 1.06 & 7,12 & .442 \\
\hline $\begin{array}{l}\text { Administrator's } \\
\text { overall rating }\end{array}$ & -.37 & & & & \\
\hline $\begin{array}{l}\text { Mothers' mood rating } \\
\text { before BSID-II }\end{array}$ & -.83 & & & & \\
\hline $\begin{array}{l}\text { Mothers' rating of } \\
\text { toddlers' behavior }\end{array}$ & -.62 & & & & \\
\hline $\begin{array}{l}\text { Mothers' mood rating } \\
\text { after BSID-II }\end{array}$ & 1.34 & & & & \\
\hline $\begin{array}{l}\text { Mothers' rating of } \\
\text { toddlers' performance }\end{array}$ & -.11 & & & & \\
\hline $\begin{array}{l}\text { Mothers' BRS rating } \\
\text { of behavior }\end{array}$ & .70 & & & & \\
\hline $\begin{array}{l}\text { Mothers' BRS rating } \\
\text { of performance }\end{array}$ & .06 & & & & \\
\hline Emotional behaviors & & .04 & 1.21 & 9,41 & .314 \\
\hline $\begin{array}{l}\text { Positive facial } \\
\text { expressions }\end{array}$ & -.23 & & & & \\
\hline $\begin{array}{l}\text { Negative facial } \\
\text { expressions }\end{array}$ & -.01 & & & & \\
\hline Positive vocalizations & -.06 & & & & \\
\hline Negative vocalizations & -.33 & & & & \\
\hline Other vocalizations & .03 & & & & \\
\hline
\end{tabular}


Reaches $\quad .17$

Refusals $\quad .20$

Escapes $\quad .19$

Off-task behaviors $\quad .20$

Note: Each panel represents a separate model. Administrator's overall rating variable reported here is based on the reflected and transformed variable. 
Table 14

Multiple regression analyses predicting mothers' underestimations on the mental scale from individual differences in mother and toddler characteristics

\begin{tabular}{|c|c|c|c|c|c|}
\hline Variables & 8 & $\begin{array}{c}\text { Adjusted } \\
R^{2}\end{array}$ & $\begin{array}{c}F \\
\text { change }\end{array}$ & df & $p$ \\
\hline Demographics & & .03 & 1.11 & 8,23 & .391 \\
\hline Toddlers' age & -.21 & & & & \\
\hline Mothers' age & .48 & & & & \\
\hline Mothers' parity & -.27 & & & & \\
\hline Mothers' education & -.59 & & & & \\
\hline $\begin{array}{l}\text { Mothers' time with } \\
\text { toddler }\end{array}$ & -.33 & & & & \\
\hline $\begin{array}{l}\text { Mothers' parenting } \\
\text { self-efficacy }\end{array}$ & -.32 & & & & \\
\hline $\begin{array}{l}\text { Mothers' knowledge } \\
\text { of child development }\end{array}$ & .01 & & & & \\
\hline $\begin{array}{l}\text { Mothers' rating of } \\
\text { infant difficulty }\end{array}$ & .33 & & & & \\
\hline $\begin{array}{l}\text { Ratings of mood and } \\
\text { behavior }\end{array}$ & & .15 & 1.52 & 7,14 & .237 \\
\hline $\begin{array}{l}\text { Administrator's } \\
\text { overall rating }\end{array}$ & .47 & & & & \\
\hline $\begin{array}{l}\text { Mothers' mood rating } \\
\text { before BSID-II }\end{array}$ & .48 & & & & \\
\hline $\begin{array}{l}\text { Mothers' rating of } \\
\text { toddlers' behavior }\end{array}$ & -.75 & & & & \\
\hline $\begin{array}{l}\text { Mothers' mood rating } \\
\text { after BSID-II }\end{array}$ & .01 & & & & \\
\hline $\begin{array}{l}\text { Mothers' rating of } \\
\text { toddlers' performance }\end{array}$ & .38 & & & & \\
\hline $\begin{array}{l}\text { Mothers' BRS rating } \\
\text { of behavior }\end{array}$ & .79 & & & & \\
\hline $\begin{array}{l}\text { Mothers' BRS rating } \\
\text { of performance }\end{array}$ & -.28 & & & & \\
\hline Emotional behaviors & & .11 & .65 & 9,48 & .745 \\
\hline $\begin{array}{l}\text { Positive facial } \\
\text { expressions }\end{array}$ & .18 & & & & \\
\hline $\begin{array}{l}\text { Negative facial } \\
\text { expressions }\end{array}$ & .10 & & & & \\
\hline Positive vocalizations & -.23 & & & & \\
\hline Negative vocalizations & -.16 & & & & \\
\hline Other vocalizations & -.10 & & & & \\
\hline
\end{tabular}


Reaches $\quad .03$

Refusals $\quad-.04$

Escapes $\quad .14$

Off-task behaviors $\quad .13$

Note: Each panel represents a separate model. Administrator's overall rating variable reported here is based on the reflected and transformed variable. 
Table 15

Multiple regression analyses predicting mothers' underestimations on the motor scale from individual differences in mother and toddler characteristics

\begin{tabular}{|c|c|c|c|c|c|}
\hline Variables & $B$ & $\begin{array}{c}\text { Adjusted } \\
R^{2} \\
\end{array}$ & $\begin{array}{c}F \\
\text { change }\end{array}$ & $d f$ & $p$ \\
\hline Demographics & & -.17 & .50 & 8,19 & .840 \\
\hline Toddlers' age & .11 & & & & \\
\hline Mothers' age & .14 & & & & \\
\hline Mothers' parity & .01 & & & & \\
\hline Mothers' education & -.34 & & & & \\
\hline $\begin{array}{l}\text { Mothers' time with } \\
\text { toddler }\end{array}$ & -.14 & & & & \\
\hline $\begin{array}{l}\text { Mothers' parenting } \\
\text { self-efficacy }\end{array}$ & -.31 & & & & \\
\hline $\begin{array}{l}\text { Mothers' knowledge } \\
\text { of child development }\end{array}$ & -.11 & & & & \\
\hline $\begin{array}{l}\text { Mothers' rating of } \\
\text { infant difficulty }\end{array}$ & .01 & & & & \\
\hline $\begin{array}{l}\text { Ratings of mood and } \\
\text { behavior }\end{array}$ & & -.16 & .60 & 7,14 & .748 \\
\hline $\begin{array}{l}\text { Administrator's } \\
\text { overall rating }\end{array}$ & .22 & & & & \\
\hline $\begin{array}{l}\text { Mothers' mood rating } \\
\text { before BSID-II }\end{array}$ & .50 & & & & \\
\hline $\begin{array}{l}\text { Mothers' rating of } \\
\text { toddlers' behavior }\end{array}$ & 1.02 & & & & \\
\hline $\begin{array}{l}\text { Mothers' mood rating } \\
\text { after BSID-II }\end{array}$ & -.66 & & & & \\
\hline $\begin{array}{l}\text { Mothers' rating of } \\
\text { toddlers' performance }\end{array}$ & -.19 & & & & \\
\hline $\begin{array}{l}\text { Mothers' BRS rating } \\
\text { of behavior }\end{array}$ & -1.29 & & & & \\
\hline $\begin{array}{l}\text { Mothers' BRS rating } \\
\text { of performance }\end{array}$ & .18 & & & & \\
\hline Emotional behaviors & & -.12 & .39 & 9,43 & .932 \\
\hline $\begin{array}{l}\text { Positive facial } \\
\text { expressions }\end{array}$ & -.10 & & & & \\
\hline $\begin{array}{l}\text { Negative facial } \\
\text { expressions }\end{array}$ & -.22 & & & & \\
\hline Positive vocalizations & .21 & & & & \\
\hline Negative vocalizations & .15 & & & & \\
\hline Other vocalizations & -.17 & & & & \\
\hline
\end{tabular}


Reaches $\quad .05$

Refusals $\quad .07$

Escapes $\quad .08$

Off-task behaviors $\quad-.10$

Note: Each panel represents a separate model. Administrator's overall rating variable reported here is based on the reflected and transformed variable. 
Table 16

Correlations between maternal and toddler characteristics and toddlers' performance on the BSID-II

\begin{tabular}{|c|c|c|}
\hline Characteristics & $\begin{array}{c}\text { Mental } \\
\text { performance }\end{array}$ & $\begin{array}{c}\text { Motor } \\
\text { performance }\end{array}$ \\
\hline Toddlers' age & -.10 & .21 \\
\hline $\begin{array}{l}\text { Toddlers' fragmented } \\
\text { sleep }\end{array}$ & $.40 *$ & -.08 \\
\hline Toddlers napped & .28 & -.05 \\
\hline Toddlers previously ill & .36 & -.29 \\
\hline Toddlers currently ill & $.44^{*}$ & -.23 \\
\hline Mothers' age & -.10 & .08 \\
\hline Mothers' education & .04 & -.14 \\
\hline $\begin{array}{l}\text { Mothers parenting } \\
\text { self-efficacy }\end{array}$ & -.01 & -.03 \\
\hline $\begin{array}{l}\text { Mothers' knowledge } \\
\text { of child development }\end{array}$ & -.05 & -.08 \\
\hline $\begin{array}{l}\text { Mothers' rating of } \\
\text { toddler difficulty }\end{array}$ & -.20 & .12 \\
\hline $\begin{array}{l}\text { Mothers' rating of } \\
\text { toddlers' mood } \\
\text { (before BSID-II) }\end{array}$ & $-.60 * *$ & .15 \\
\hline $\begin{array}{l}\text { Mothers' rating of } \\
\text { toddlers' behavior } \\
\text { (after BSID-II) }\end{array}$ & $.59 * *$ & -.23 \\
\hline $\begin{array}{l}\text { Mothers' rating of } \\
\text { toddlers' mood (after } \\
\text { BSID-II) }\end{array}$ & $-.65 * * *$ & .38 \\
\hline $\begin{array}{l}\text { Mothers' rating of } \\
\text { toddlers' } \\
\text { performance (after } \\
\text { BSID-II) }\end{array}$ & $.79 * * *$ & $-.46^{*}$ \\
\hline $\begin{array}{l}\text { Mothers' rating of } \\
\text { toddlers' behavior } \\
\text { (BRS) }\end{array}$ & $.58 * * *$ & $-.50 * *$ \\
\hline $\begin{array}{l}\text { Mothers' rating of } \\
\text { toddlers' } \\
\text { performance (BRS) }\end{array}$ & $.66 * * *$ & $-.57 * * *$ \\
\hline $\begin{array}{l}\text { Administrator's } \\
\text { rating: positive affect }\end{array}$ & $.45^{* * *}$ & $-.39 * *$ \\
\hline
\end{tabular}


Administrator's

rating: energy

Administrator's

$\begin{array}{ll}.55^{* * *} & -.34^{* *} \\ .60^{* * *} & -.33^{* *} \\ .18 & -.22 \\ .62 * * * & -.40^{* *} \\ .11 & -.13 \\ .28 * & -.15 \\ .25 * & -.18 \\ .37^{* *} & -.26 *\end{array}$

rating: interest

Administrator's

rating: initiative

Administrator's

rating: exploration

Administrator's

rating: enthusiasm

Administrator's

rating: fearfulness

Administrator's

rating: orientation

Administrator's

rating: social

engagement

Administrator's

rating: negative

affect

Administrator's

rating:

.13

$-.05$

hypersensitivity

Administrator's

rating: adaptability

.20

$-.17$

Administrator's

rating: attention

$.57 * * *$

$-.37 * *$

Administrator's

rating: persistence

$.61 * * * \quad-.31 *$

Administrator's

rating: frustration

.21

$-.09$

Administrator's

rating: cooperation

$.50 * * *$

$-.33 * *$

Administrator's

rating: hyperactivity

$.25^{*}$

$-.08$

Administrator's

rating: soothe-ability

$\begin{array}{ll}.44 * * * & -.22\end{array}$

Administrator's rating

of mood: BRS total

$-.54 * * *$

score

Positive facial

expressions

.04

$-.18$

Negative facial

expressions 


\begin{tabular}{lll} 
Positive vocalizations & $-.34^{* *}$ & -.24 \\
Negative & $-.32^{*}$ & $.28^{*}$ \\
vocalizations & .21 & -.12 \\
Other vocalizations & -.17 & $.31^{*}$ \\
Reaches & $-.34^{* *}$ & $.38^{* *}$ \\
Refusals & $-.34^{*}$ & .09 \\
Escapes & $-.31^{*}$ & .11 \\
Off-task behavior & & \\
\hline
\end{tabular}

Note: Associations between motor performance and maternal and toddlers' characteristics reported here are based on the reflected and transformed variable. Associations between administrator's rating of mood: BRS overall and toddlers' performance variables reported here are based on the reflected and transformed variable. ${ }^{*} p<.05$, $* * p<.01, * * * p<.001$ 


\section{Appendix A}

\section{Demographic Questionnaire}

1. What is your current age?

2. How many children do you have?

What are their ages?

3. What is the highest grade in school or year in college that you have completed?

What degrees have you earned?

4. What is your current marital status?

If married, is your current marriage your first?

5. Please circle your race below.

Black White Other

6. Please circle your current employment status.

Unemployed Employed Part-Time Employed Full-Time

7. What is your annual total household gross income?

8. Please circle the response that best describes the extent of your past experience with children other than your own.

None Very Little Moderate Amount Very Much

9. What is your child's date of birth?

10. What is your child's current age in months?

11. Please circle your child's gender.

Male Female

12. Please circle your child's current weekly care arrangement.

Full-time care (21-40 hrs.) in center daycare

Full-time care (21-40 hrs.) in provider's home

Full-time (21-40 hrs.) non-maternal care in home

Full-time maternal care

Part-time (20 hours or less) center care

Part-time (20 hours or less) in provider's home

Part-time (20 hours or less) non-maternal care 
13. Please describe your child's daily care arrangement since birth in detail below.

14. At what age did your child first walk without help?

15. Has your child begun toilet training?

If so, at what age?

16. When did your child speak his/her first meaningful word?

17. Please circle your child's current sleeping arrangement.

Sleeps alone in his/her own bed or crib all night

Sleeps part of the night alone and part of the night with me

Sleeps in my bed all night

Sleeps part of the night alone and part of the night with a sibling

Sleeps with a sibling all night long

18. Does your child use a blanket, pacifier, or other security object?

Yes No

If yes, what is it?

19. Please give your current address and telephone number to enable us to contact you if needed during the study.

Address:

Telephone number: 


\section{Appendix B}

\section{Maternal Self-Efficacy Scale}

We want to ask you some questions about yourself and your baby. We are trying to get a general idea of how you usually handle different situations with your baby. We realize that no one is always effective or always ineffective. We all do better in some situations than in others. So we would like to have you think about some situations that all mothers encounter.

1. When your baby is upset, fussy or crying, how good are you at soothing him or her?

1

not good at all
2

not good enough
3

good enough
4

very good

2. How good are you at understanding what your baby wants or needs? For example, do you know when your baby needs to be changed or wants to be fed?

1

I do not

understand

my baby
2

I understand

my baby some

of the time
3

\begin{abstract}
I understand
\end{abstract}
my baby most

of the time
4

I understand

my baby all

of the time

3. How good are you at making your baby understand what you what him/her to do? For example. If you want your baby to eat dinner or play quietly, how good are you at making him or her do that?

1

not good at all
2

not good enough
3

good enough
4

very good

4. How good are you at getting your baby to pay attention to you? For example, when you want your baby to look at you, how good are you at making him or her do it?

1

not good at all
2

not good enough
3

good enough
4

very good

5. How good are you at getting your baby to have fun with you? For example, how good are you at getting your baby to smile and laugh with you?

1

not good at all
2

not good enough
3

good enough
4 very good

6. How good are you at knowing what activities your baby will enjoy? For example, how good are you at knowing what games and toys your baby will like to play with? 
1

2

3

4

not good at all not good enough good enough very good

7. How good are you at keeping your baby occupied when you need to do housework? For example, how good are you at finding things for the baby to do when you need to do the dishes?

$12 \quad 3 \quad 4$

not good at all not good enough good enough very good

8. How good do you feel you are at feeding, changing, and bathing your baby?

$1 \quad 2 \quad 3 \quad 4$

not good at all not good enough good enough very good

9. How good are you at getting your baby to show off for visitors? For example, how good are you at making your baby smile or laugh for people who visit?

$1 \quad 2 \quad 3 \quad 4$

not good at all not good enough good enough very good

10. In general, how good a mother do you feel you are?

1

not good at all
2

3 not good enough good enough very good

4 


\section{Appendix C}

\section{Infant Characteristics Questionnaire}

On the following questions please circle the number that is most typical of your child. "About average" means how you think the typical child would be scored

1. How easy or difficult is it for you to calm or soothe your child when he/she is upset?

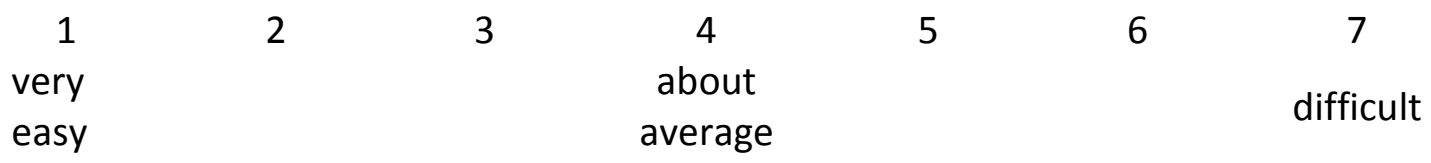

2. How consistent is your child in sticking to his/her sleeping routine?

$\begin{array}{lccccc}1 & 2 & 3 & 4 & 5 & 6\end{array}$

3. How consistent is your child to sticking to his/her eating routine?

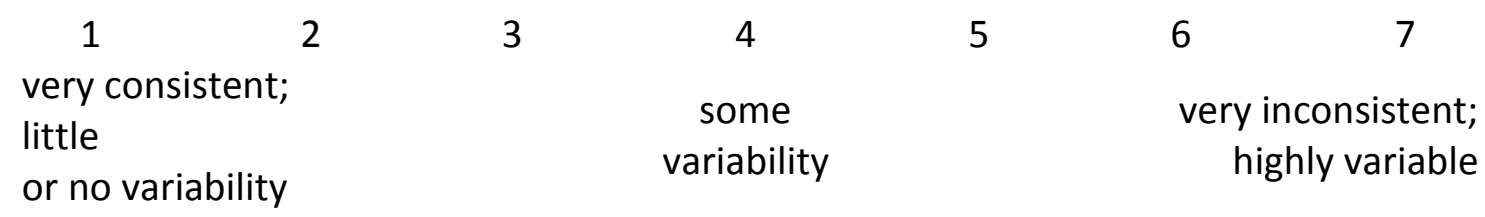

4. How easy or difficult is it for you to know what's bothering your child when he/she cries or fusses?

$\begin{array}{ccccccc}1 & 2 & 3 & \begin{array}{c}4 \\ \text { about } \\ \text { very } \\ \text { easy }\end{array} & \begin{array}{c}\text { average } \\ \text { difficult }\end{array}\end{array}$

5. How many times per day, on average, does your child get fussy and irritable - either for short or long periods of time?

\begin{tabular}{ccccccr}
1 & 2 & 3 & 4 & 5 & 6 & 7 \\
& $1-2$ & $3-4$ & $5-6$ & $7-9$ & $10-14$ & more \\
\multirow{4}{*}{ never } & times & times & times & times & times & than \\
& per & per & per & per & per & 15 \\
& day & day & day & day & day & times
\end{tabular}


6. How much does your child cry and fuss in general?

\begin{tabular}{|c|c|c|c|}
\hline 1 & 3 & 5 & 7 \\
\hline $\begin{array}{l}\text { very little; much } \\
\text { less than the } \\
\text { average child }\end{array}$ & & & $\begin{array}{c}\text { a lot; much more } \\
\text { than the average } \\
\text { child }\end{array}$ \\
\hline
\end{tabular}

7. How does your child typically respond to new playthings?

$\begin{array}{lllllll}1 & 2 & 3 & 4 & 5 & 6 & 7\end{array}$

always responds Responds favorably about half favorably always responds negatively or fearfully

8. How does your child typically respond to new foods?

1

2 3

4 5 always responds favorably

Responds favorably about half the time, or is always neutral

$6 \quad 7$ always responds negatively or fearfully

9. How does your child typically respond to a new person?

$$
1
$$

2

always responds

favorably
3

Responds favorably about half the time, or is always neutral
$6 \quad 7$

always responds negatively or fearfully

10. How does your child typically respond to being in a new place?

$\begin{array}{lllll}1 & 2 & 3 & 4 & 5\end{array}$

always responds

favorably
Responds favorably about half the time, or is always neutral
$6 \quad 7$

always responds negatively or fearfully

11. How well does your child adapt to new experiences (such as in items 7-10) eventually?

1

2

very well, always

likes it eventually
3

ends up liking it about

half the time
$6 \quad 7$ almost always dislikes it in the end 
12. How easily does your child get upset?

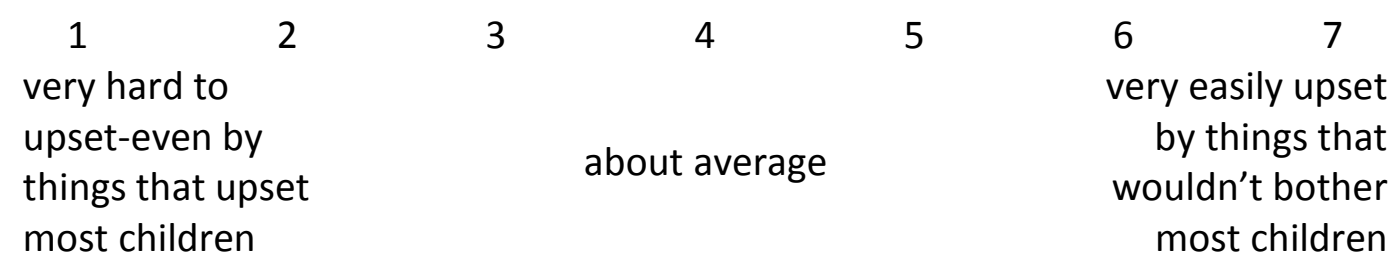

13. When your child gets upset, how vigorously or loudly does he/she cry and fuss?

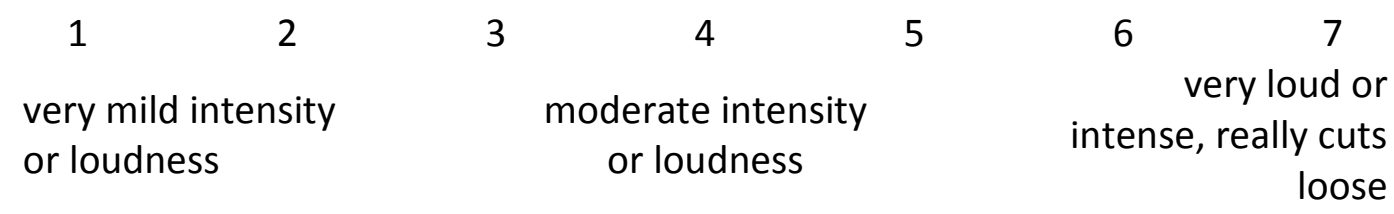

14. How does your child react when you are dressing him/her?

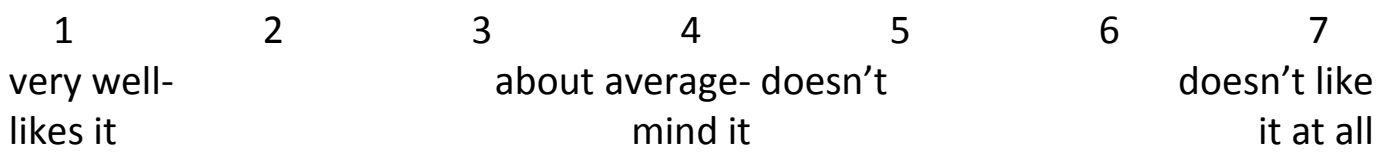

15. How active is your child in general?

$\begin{array}{ccccccc}1 & 2 & 3 & 4 & 5 & 6 & 7 \\ \begin{array}{l}\text { very calm } \\ \text { and quiet }\end{array} & & \text { average } & & & \begin{array}{r}\text { very active } \\ \text { and vigorous }\end{array}\end{array}$

16. How much does your child smile and make happy sounds?

$\begin{array}{lrrrrr}1 & 2 & 3 & 5 & 6 & 7 \\ \begin{array}{l}\text { a great deal; much } \\ \text { more than most } \\ \text { children }\end{array} & & \text { an average amount } & & \begin{array}{r}\text { very little; much } \\ \text { less than most } \\ \text { children }\end{array}\end{array}$

17. What kind of mood is your child generally in?

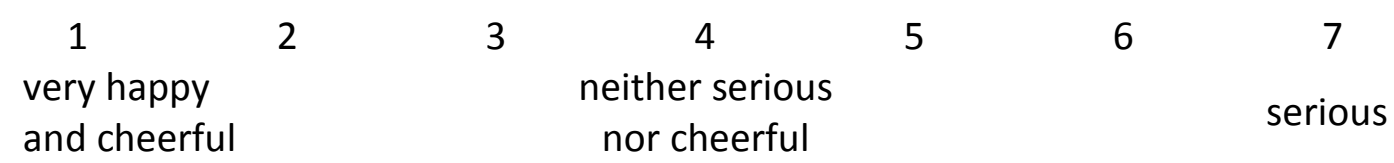


18. How much does your child enjoy playing with you?

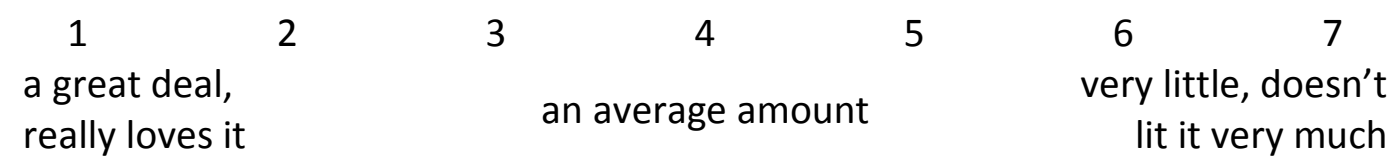

19. How much does your child want to be held?

1

2

wants to be free

most of the time
3

Sometimes wants to be held; sometimes not
5 a great deal; wants to be held almost all the time

20. How does your child respond to disruptions and changes in the everyday routine, such as when you go to church or a meeting, on trips, etc.?

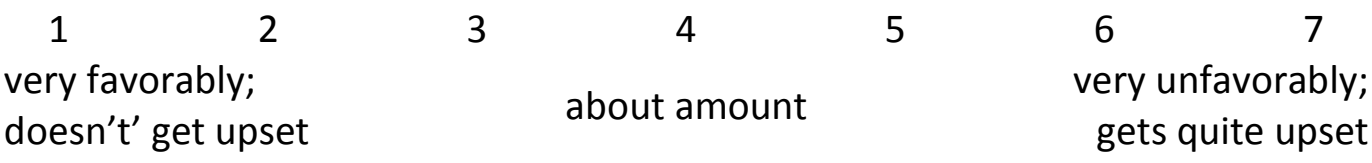

21. How changeable is your child's mood?

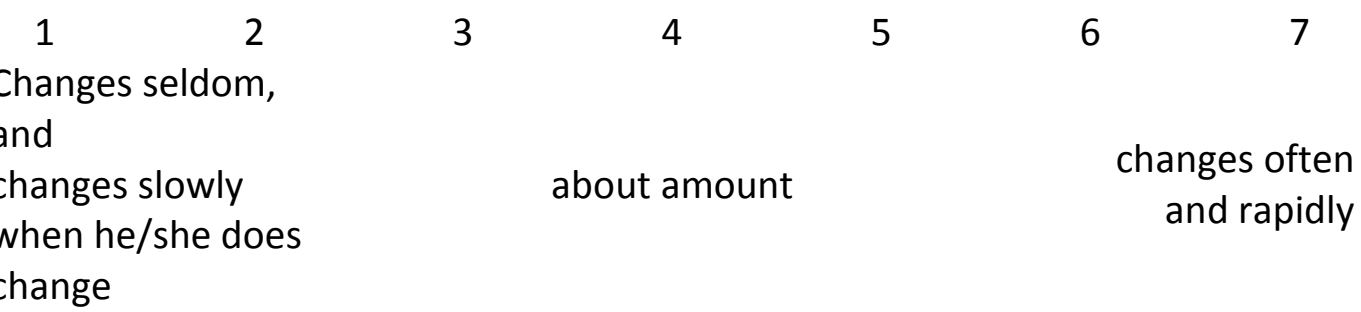

22. How excited does your child become when people play with or talk to him/her?

$\begin{array}{ccccccc}1 & 2 & 3 & 4 & 5 & 6 & 7 \\ \text { very excited } & & & \text { about average } & & & \text { not at all }\end{array}$

23. On the average, how much attention does your child require, other than for caregiving (feeding, bathing, etc.)?

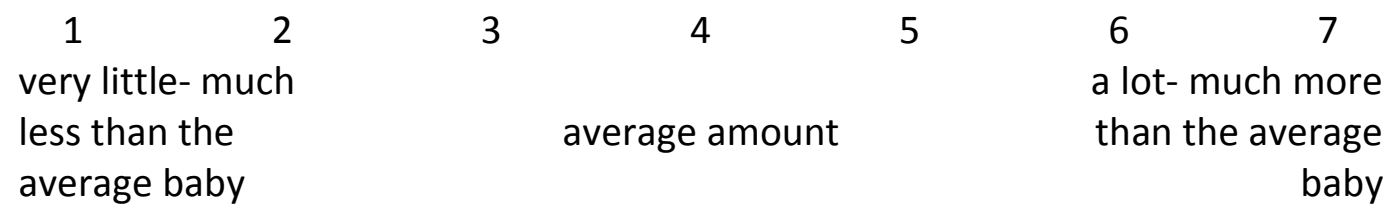


24. When left alone, your child plays well by himself/herself.

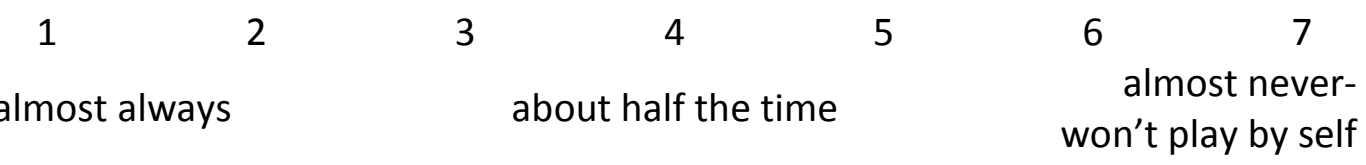

25. How does your child react to being confined (as in a carseat, bedroom, crib, etc.)?

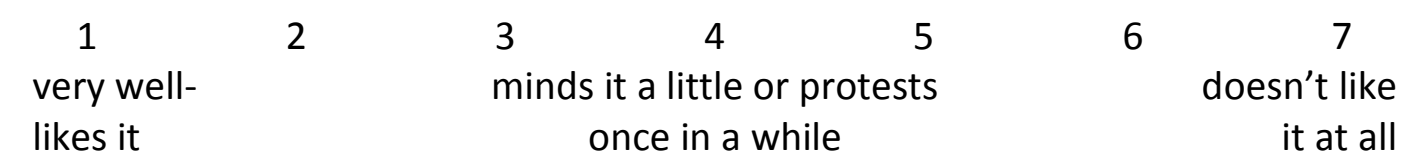

26. How much does your child cuddle and snuggle when held?

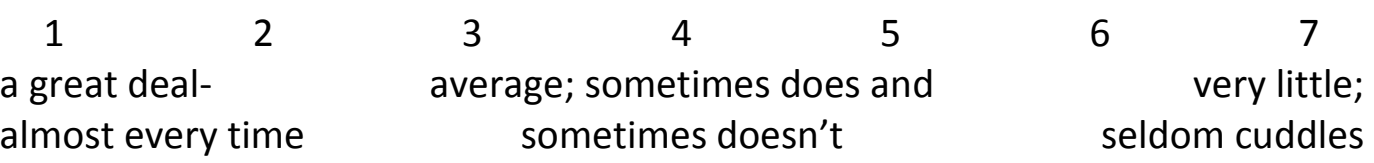

27. How easy or difficult is it to take your child places?

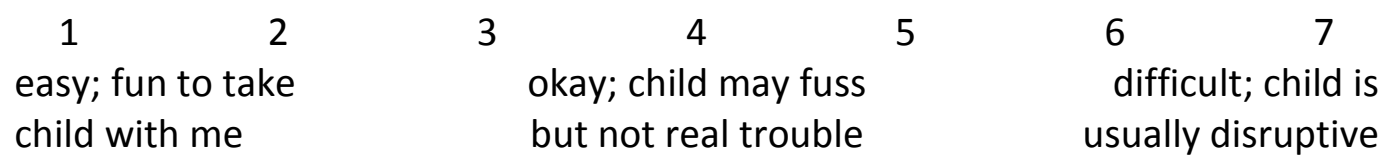

28. Does your child persist in playing with objects when he/she is told to leave them alone?

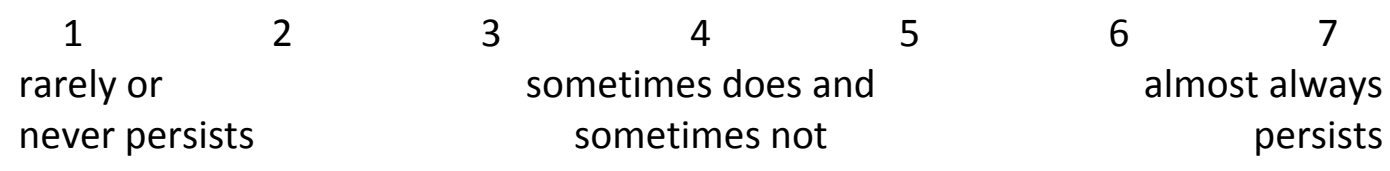

29. Does your child continue to go someplace even when told something like "stop", "come here", or "no-no"?

1

rarely or never
2
$3 \quad 4 \quad 5 \quad 6$
7
sometimes does and sometimes not
almost always


30. When removed from something he/she is interested in but should not be getting into, your child gets upset.

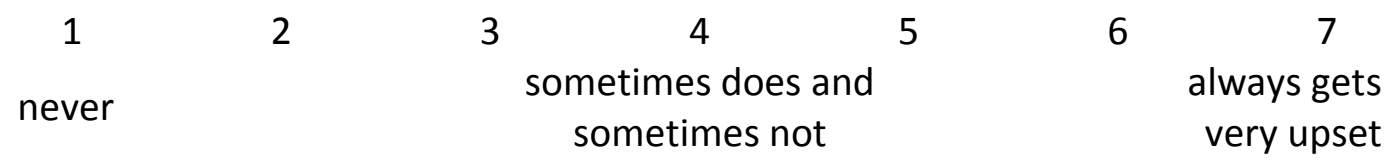

31. How persistent is your child in trying to get your attention when you are busy?

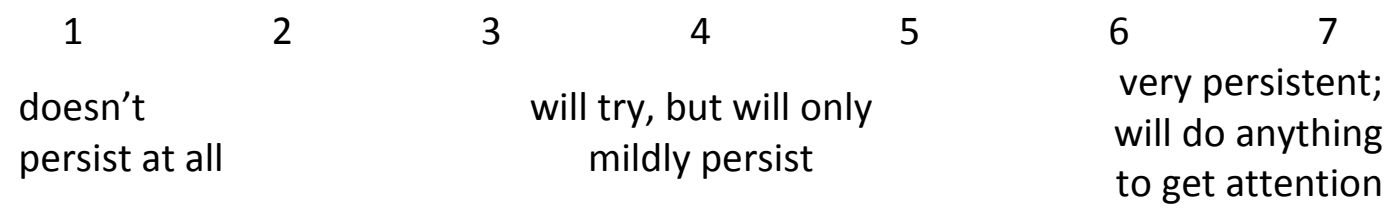

32. Please rate the overall degree of difficulty your child would present for the average mothers.

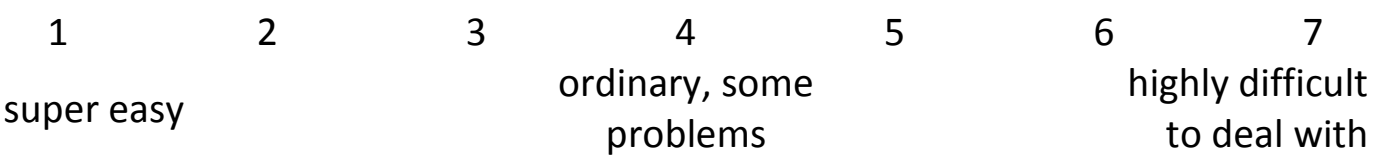




\section{Appendix D}

\section{Developmental Milestones Survey - Revised}

1. At what age do you think children should be able to use make-believe or imagination in their play?

o 21 months

2. At what age do you think children should be able to speak in simple sentences?

o 25 months

3. At what age do you think a child should be able to walk up a set of stairs?

o 21 months

4. At what age should a child be able to recognize and name different colors?

o 28 months

5. At what age should a child be able to feed himself/herself using a spoon or fork?

o 17 months

6. At what age should a child be able to clean up his/her toys when asked?

o 23 months

7. At what age do you think a child should be potty trained so he/she doesn't need diapers?

o 31 months

8. At what age do you think a child should begin to obey you when you say "no"?

o 17 months 


\section{Appendix E}

\section{Sleep and Mood Questionnaire}

Before Testing with the Bayley:

1. What time did your child go to sleep last night?

2. What time did your child wake up this morning?

3. Did your child wake up during the night? Yes No If so, when and for how long?

4. Has your child had any naps today? Yes No If so, when and for how long?

5. Approximately how much sleep did you get last night? Was your sleep interrupted? Yes No If yes, when and for how long?

6. How much sleep do you usually get each night?

7. At what time did your child last eat?

8. Has your child been ill in the last week? Yes No If yes, please describe:

9. Is your child currently ill? Yes No If yes, please describe:

10. Has anything unusual happened in your child's routine today? Yes No If yes, please describe:

11. Please rate your child's mood today: Much happier than usual Somewhat happier than usual Typical; neither happier nor more irritable than usual Somewhat more irritable than usual Much more irritable than usual 


\section{End of Bayley Administration}

1. How typical was your child's behavior? Did he/she play the way he/she usually does? Was he/he as happy or as upset as usual? As alert and active as usual? Very atypical; I never see this type of behavior Mostly atypical Somewhat typical; I see this type of behavior on some occasions Typical Very typical; I always see this type of behavior

2. Please rate your child's mood during the Bayley Administration: Much happier than usual Somewhat happier than usual Typical; neither happier nor more irritable than usual Somewhat more irritable than usual Much more irritable than usual

3. Do you think your child did as well as he/she could do? Have you seen him/her perform better or worse on the types of things we worked on? Poor indicator of child's optimal performance; child always performs much better Barely adequate Adequate; child performs as well, on average. Good Excellent; child never performs better

4. If your child was happier or more irritable during the test than usual, to what do you attribute this?

5. Why do you think your child succeeded at some items that you expected him or her to fail?

6. Why do you think your child failed as some items that you expected him or her to succeed at? 


\section{Appendix F}

\section{Bayley Expectation Questionnaires}

Ages 17-19 months Subject No.

We will be administering the items described and illustrated below from the Bayley Scales of Infant Development to your child. We are interested in your expectations concerning your child's ability to perform these items. For each item, please predict whether or not your infant will be able to do the action described. If you don't understand an item from the description, ask the test administrator for further explanation or a demonstration of the item.

1. Building a tower with one-inch blocks.

Will your child be able to build a tower that is two blocks high? YES NO Will your child be able to build a tower that is six blocks high? YES NO

2. Finding a toy hidden under a cup. Your child will be shown a toy bunny and two inverted cups. The experimenter will place the bunny under one cup, then uncover it and put it under the other cup, while your child watches.

Will your child be able to find the bunny? YES NO

3. Completing a pegboard.

Will your child be able to place six pegs in a pegboard? YES NO

Will your child be able to complete the pegboard

in 70 seconds or less?

YES NO

Will your child be able to complete the pegboard

in 25 seconds or less?

YES NO

4. Drawing with a crayon on a piece of paper.

Will your child be able to imitate drawing a line? $\quad$ YES NO

Will your child be able to imitate drawing a vertical line? $\quad$ YES NO

Will your child be able to imitate drawing a horizontal line? YES NO

Will your child be able to imitate circular scribbles?

5. Retrieving a toy. The experimenter will place a toy under a clear box that is open only on one side.

Will your child be able to get the toy? $\quad$ YES NO

6. Using a stick to get a toy. The experimenter will show your child how to move a small toy using a stick.

Will your child be able to attempt to get the toy with the stick? YES NO 
7. Naming and/or pointing to pictures of common objects. Your child will be shown pictures of the objects listed below. Which of the objects will your child be able to name correctly (with either the word listed below or one similar in meaning) and which will your child be able to point to when asked?

\section{Name Point to}

Shoe
Dog
Cup
House
Clock
Book
Fish
Star
Leaf
Car

8. Following directions with a doll. Your child will be asked to perform each of the following pretend actions with a doll and a spoon, comb, and tissue.

Will your child be able to feed the doll with the spoon?

YES NO

Will your child be able to comb the doll's hair?

YES NO

Will your child be able to blow the doll's nose?

YES NO

9. Pointing to the doll's body parts. Which of the following body parts will your child be able to point to on the doll?

$\begin{array}{lll}\text { Hair } & \text { YES } & \text { NO } \\ \text { Mouth } & \text { YES } & \text { NO } \\ \text { Ears } & \text { YES } & \text { NO } \\ \text { Hands } & \text { YES } & \text { NO } \\ \text { Eyes } & \text { YES } & \text { NO } \\ \text { Feet } & \text { YES } & \text { NO } \\ \text { Nose } & \text { YES } & \text { NO }\end{array}$

10. Naming objects. Which of the following objects will your child be able to name?

$\begin{array}{lll}\text { Ball } & \text { YES } & \text { NO } \\ \text { Book } & \text { YES } & \text { NO } \\ \text { Cup } & \text { YES } & \text { NO } \\ \text { Spoon } & \text { YES } & \text { NO } \\ \text { Pencil } & \text { YES } & \text { NO }\end{array}$


11. Completing the blue board puzzle (see picture). Your child will be handed one piece of this puzzle at a time.

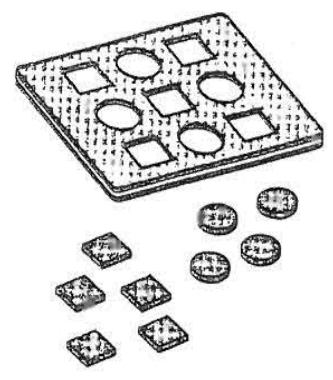

Will your child be able to correctly place at least four pieces? YES NO

12. Identifying objects in a photograph. Your child will be shown a set of objects including a toy rabbit, a bell, a block, a toy car, and a plastic triangle. After your child is shown each object, the objects will be hidden and your child will be shown a photograph of the objects.

Will your child be able to identify (by pointing) at least two of the objects in the photograph?

YES NO

13. Pointing to something in the room. The experimenter will ask your child to point to his or her shoes, or to some other item in the room.

Will your child be able to point to the named item?

YES NO

14. Speaking. Which of the following speech acts will your child likely utter during the test session?

Using a word to make his or her wants known

Using two different words appropriately

YES NO

Saying a word while gesturing (example: saying ball while pointing at or reaching for a ball)

YES NO

Saying eight different words during the exam

YES NO

Using a pronoun (such as my, me, l, you, it, mine, she, he)

YES NO

Saying a two-word utterance

YES NO

Saying a three-word utterance

YES NO

Imitating a two-word utterance said by the mother or

YES NO test administrator

YES NO 
15. Completing the pink board puzzle. The test administrator will present the pink board puzzle (see picture) with the pieces in place, and then will remove the pieces while your child watches.

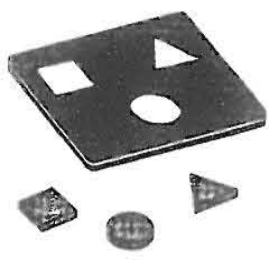

Will your child be able to put the pieces back in?

YES NO

Will your child be able to put the pieces back in after the test administrator rotates the board by 180 degrees (turns it around)?

YES NO

16. Discriminating objects. Your child will be shown three objects, a book, a block, and a key, and then asked to show each object to the test administrator.

Will your child be able to show each of these three objects to the test administrator when asked?

YES NO

17. Matching pictures. Your child will be shown four pages of pictures. On each page is a picture on the top half of the page and a set of four pictures on the bottom half of the page, one of which is the same as the picture on the top half. Your child will be asked to point to the picture on the bottom half that is the same as the picture on the top half. The pictures to be matched are an airplane, a tricycle, a tree, and a telephone.

Will your child be able to match at least three pictures?

YES NO 
18. Writing with a pencil.

Which of the methods illustrated below will your child use to hold the pencil?

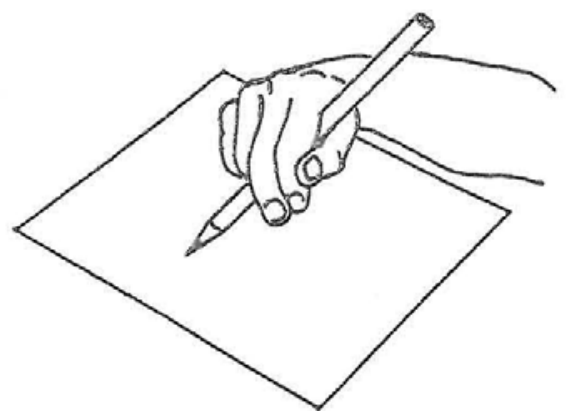

A

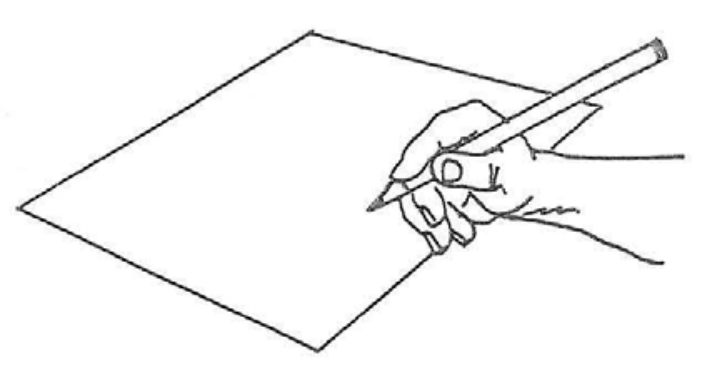

B
A or B
or OTHER

Will your child hold the paper in place with one hand while writing with the other hand?

YES NO

19. Placing pellets in a bottle.

Will your child be able to put 10 small sugar pellets

in a bottle in 60 seconds?

YES NO

20. Motor skills. Which of the following skills will your child be able to demonstrate?

Getting up from lying on his or her back without rolling over onto his or her stomach

Walking backwards

Walking sideways

Walking up stairs with some help

Walking down stairs with some help

Standing on right foot (with one hand held)

Standing alone on right foot (without help)

YES NO

YES NO

YES NO

Standing on left foot (with one hand held)

YES

YES

NO

Running

Jumping off the floor with both feet

YES NO

Walking up stairs alone, placing both feet on each step

YES NO

Walking down stairs alone, placing both feet on each step

YES

YES

Jumping from the bottom step of the stairs to the floor

YES NO

YES NO

YES NO 
We will be administering the items described and illustrated below from the Bayley Scales of Infant Development to your child. We are interested in your expectations concerning your child's ability to perform these items. For each item, please predict whether or not your infant will be able to do the action described. If you don't understand an item from the description, ask the test administrator for further explanation or a demonstration of the item.

1. Building a tower with one-inch blocks.

Will your child be able to build a tower that is two blocks high? YES NO Will your child be able to build a tower that is six blocks high? YES NO Will your child be able to build a tower that is eight blocks high? YES NO

2. Completing a pegboard.

Will your child be able to place six pegs in a pegboard?

Will your child be able to complete the pegboard in 25 seconds or less?

YES NO

YES NO

3. Drawing with a crayon on a piece of paper.

Will your child be able to imitate drawing a vertical line?

YES NO

Will your child be able to imitate drawing a horizontal line?

Will your child be able to imitate circular scribbles?

YES NO

4. Naming and/or pointing to pictures of common objects. Your child will be shown pictures of the objects listed below. Which of the objects will your child be able to name correctly (with either the word listed below or one similar in meaning) and which will your child be able to point to when asked?

\section{Name Point to}

Shoe
Dog
Cup
House
Clock
Book
Fish
Star
Leaf
Car

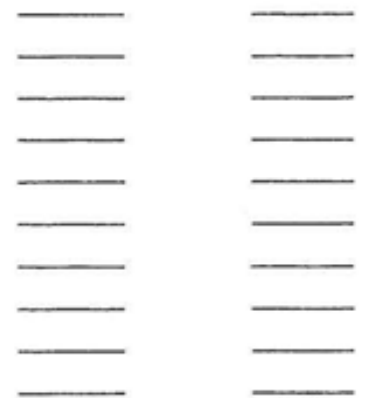


5. Following directions with a doll. Your child will be asked to perform each of the following pretend actions with a doll and a spoon, comb, and tissue.

Will your child be able to feed the doll with the spoon?

YES NO

Will your child be able to comb the doll's hair?

YES NO

Will your child be able to blow the doll's nose?

YES NO

6. Pointing to the doll's body parts. Which of the following body parts will your child be able to point to on the doll?

$\begin{array}{lll}\text { Hair } & \text { YES } & \text { NO } \\ \text { Mouth } & \text { YES } & \text { NO } \\ \text { Ears } & \text { YES } & \text { NO } \\ \text { Hands } & \text { YES } & \text { NO } \\ \text { Eyes } & \text { YES } & \text { NO } \\ \text { Feet } & \text { YES } & \text { NO } \\ \text { Nose } & \text { YES } & \text { NO }\end{array}$

7. Naming objects. Which of the following objects will your child be able to name?

$\begin{array}{lll}\text { Ball } & \text { YES } & \text { NO } \\ \text { Book } & \text { YES } & \text { NO } \\ \text { Cup } & \text { YES } & \text { NO } \\ \text { Spoon } & \text { YES } & \text { NO } \\ \text { Pencil } & \text { YES } & \text { NO }\end{array}$

8. Completing the blue board puzzle (see picture). Your child will be handed one piece of this puzzle at a time.

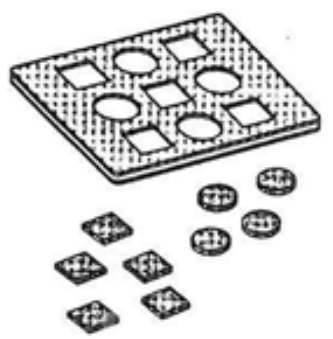

Will your child be able to correctly place at least four pieces? Will your child be able to complete the puzzle? 
9. Idenkifying objects in a photograph. Your child will be shown a set of objects including a toy rabbit, a bell, a block, a toy car, and a plastic triangle. After your child is shown each object, the objects will be hidden and your child will be shown a photograph of the objects.

Will your child be able to identify (by pointing) at least two of the objects in the photograph?

YES NO

10. Speaking. Which of the following speech acts will your child likely utter during the test session?

Saying a word while gesturing (example: saying ball while pointing at or reaching for a ball)

YES NO

Saying eight different words during the exam

YES NO

Using a pronoun (such as my, me, l, you, it, mine, she, he)

YES

NO

Saying a two-word utterance

YES NO

Saying a three-word utterance

YES NO

Imitating a two-word utterance said by the mother or test administrator

YES NO

Saying something that is a response to and elaboration of something said by the mother or test administrator

YES NO

11. Completing the pink board puzzle. The test administrator will present the pink board puzzle (see picture) with the pieces in place, and then will remove the pieces while your child watches.

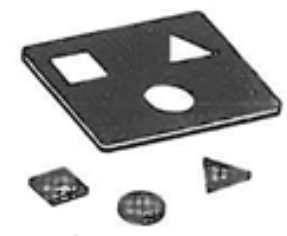

Will your child be able to put the pieces back in?

YES NO

Will your child be able to put the pieces back in after the test administrator rotates the board by 180 degrees (turns it around)?

YES NO

12. Discriminating objects. Your child will be shown three objects, a book, a block, and a key, and then asked to show each object to the test administrator.

Will your child be able to show each of these three objects to the test administrator when asked? 
13. Matching pictures. Your child will be shown four pages of pictures. On each page is a picture on the top half of the page and a set of four pictures on the bottom half of the page, one of which is the same as the picture on the top half. Your child will be asked to point to the picture on the bottom half that is the same as the picture on the top half. The pictures to be matched are an airplane, a tricycle, a tree, and a telephone.

Will your child be able to match at least three pictures?

14. Matching colors. Your child will be given three plastic circles, one red, one yellow, and one blue.

Will your child be able to put each of these circles on a circle of the same color on a printed page? $\quad$ YES NO

15. Understanding verbal descriptions. Your child will be shown several pictures of children engaging in common activities (playing ball, eating, swinging, coloring, sleeping, walking).

Will your child be able to point to at least three of these pictures when they are described by the test administrator? YES NO

16. Attending to a story. The test administrator will read a short story to your child.

Will your child be able to attend to the story? $\quad$ YES NO

17. Placing beads in a tube (see picture).

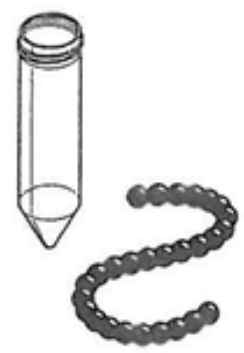

Will your child be able to put the string of beads into the plastic tube? 
18. Writing with a pencil.

Which of the methods illustrated below will your child use to hold the pencil?

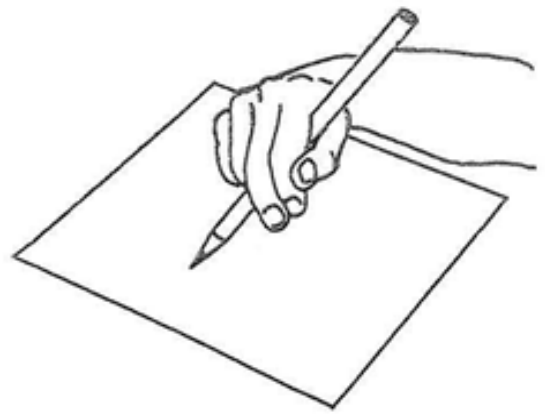

A

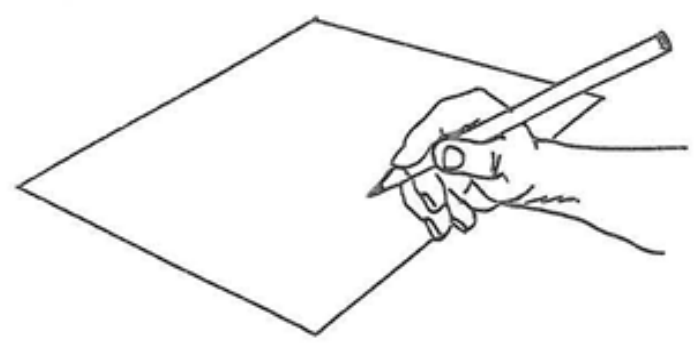

B

$$
\begin{aligned}
& \text { A or B } \\
& \text { or OTHER }
\end{aligned}
$$

Will your child hold the paper in place with one hand while writing with the other hand?

YES NO

19. Placing pellets in a bottle.

Will your child be able to put 10 small sugar pellets in a bottle in 60 seconds?

YES NO

20. Motor skills. Which of the following skills will your child be able to demonstrate?

Walking sideways

Standing on right foot (with one hand held)

Standing alone on right foot (without help)

Standing on left foot (with one hand held)

Standing alone on left foot (without help)

Running

Walking forward on a line (at least one foot on the line)

Walking backward close to a line

Trying to kick a ball (even if unsuccessful)

Jumping off the floor with both feet

Walking up stairs alone, placing both feet on each step

Walking down stairs alone, placing both feet on each step

Jumping from the bottom step of the stairs to the floor
YES NO

YES NO

YES NO

YES NO

YES NO

YES NO

YES NO

YES NO

YES NO

YES NO

YES NO

YES NO

YES NO 
We will be administering the items described and illustrated below from the Bayley Scales of Infant Development to your child. We are interested in your expectations concerning your child's ability to perform these items. For each item, please predict whether or not your infant will be able to do the action described. If you don't understand an item from the description, ask the test administrator for further explanation or a demonstration of the item.

1. Building a tower with one-inch blocks.

Will your child be able to build a tower that is six blocks high? YES NO Will your child be able to build a tower that is eight blocks high? YES NO

2. Building a train of blocks. The experimenter will demonstrate building a train of blocks with four blocks in a row and a fifth block on top of the first block in the row as an engine.

Will your child be able to put at least three blocks in a row to make his or her own train?

YES NO

3. Understanding the concept of one. The experimenter will give your child three blocks and then ask your child to give her one block.

Will your child be able to give the experimenter one, and only one, block?

YES NO

4. Completing a pegboard.

Will your child be able to place six pegs in a pegboard?

Will your child be able to complete the pegboard

in 25 seconds or less?

YES NO

YES NO

5. Drawing with a crayon on a piece of paper.

Will your child be able to imitate drawing a vertical line?

YES NO

Will your child be able to imitate drawing a horizontal line?

YES NO

Will your child be able to imitate circular scribbles?

YES NO 
6. Naming and/or pointing to pictures of common objects. Your child will be shown pictures of the objects listed below. Which of the objects will your child be able to name correctly (with either the word listed below or one similar in meaning) and which will your child be able to point to when asked?

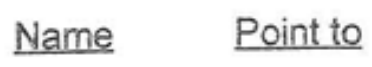
Shoe
Dog
Cup
House
Clock
Book
Fish
Star
Leaf
Car

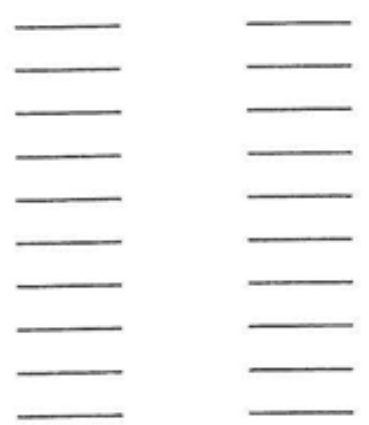

7. Naming objects. Which of the following objects will your child be able to name?

Ball
Book
Cup
Spoon
Pencil

$\begin{array}{ll}\text { YES } & \text { NO } \\ \text { YES } & \text { NO } \\ \text { YES } & \text { NO } \\ \text { YES } & \text { NO } \\ \text { YES } & \text { NO }\end{array}$

8. Completing the blue board puzzle (see picture). Your child will be handed one piece of this puzzle at a time.

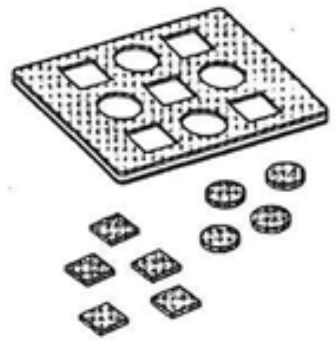

Will your child be able to complete the puzzle?

YES NO 
9. Identifying objects in a photograph. Your child will be shown a set of objects including a toy rabbit, a bell, a block, a toy car, and a plastic triangle. After your child is shown each object, the objects will be hidden and your child will be shown a photograph of the objects.

Will your child be able to identify (by pointing) at least two of the objects in the photograph?

YES NO

10. Speaking. Which of the following speech acts will your child likely utter during the test session?

Saying eight different words during the exam

Using a pronoun (such as my, me, l, you, it, mine, she, he)

Saying a two-word utterance

Saying a three-word utterance

YES NO

Imitating a two-word utterance said by the mother or test administrator

YES NO

YES NO

YES NO

Saying something that is a response to and elaboration of something said by the mother or test administrator

YES NO

Saying at least two two-word (or longer) utterances while looking at a book

Using the past tense

Asking a question

YES NO

YES NO

YES NO

YES NO

11. Completing the pink board puzzle. The test administrator will present the pink board puzzle (see picture) with the pieces in place, and then will remove the pieces while your child watches.

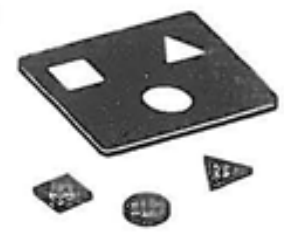

Will your child be able to put the pieces back in?

YES NO

Will your child be able to put the pieces back in after the test administrator rotates the board by 180 degrees (turns it around)?

YES NO

12. Discriminating objects. Your child will be shown three objects, a book, a block, and a key, and then asked to show each object to the test administrator.

Will your child be able to show each of these three objects to the test administrator when asked?

YES NO 
13. Matching pictures. Your child will be shown four pages of pictures. On each page is a picture on the top half of the page and a set of four pictures on the bottom half of the page, one of which is the same as the picture on the top half. Your child will be asked to point to the picture on the bottom half that is the same as the picture on the top half. The pictures to be matched are an airplane, a tricycle, a tree, and a telephone.

Will your child be able to match at least three pictures?

14. Matching colors. Your child will be given five plastic circles, one red, one yellow, one blue, one black, and one green.

Will your child be able to put three of these circles on a circle

of the same color on a printed page?
Will your child be able to put three of these circles on a circle of the same color on a printed page? $\quad$ YES NO

15. Discriminating pictures. Your child will be shown a picture of an apple, and then a picture containing an apple and several other objects. Then, your child will be shown a picture of a giraffe, followed by a picture containing a giraffe and several other objects.

Will your child be able to point to the pictures of the apple and giraffe when asked to point to the same picture they just saw?

YES NO

16. Comparing sizes. Your child will be shown a picture of three (?) different-sized trees.

Will your child be able to point to the big tree and to the little tree when asked?

YES NO

17. Understanding verbal descriptions. Your child will be shown several pictures of children engaging in common activities (playing ball, eating, swinging, coloring, sleeping, walking).

Will your child be able to point to at least three of these pictures when they are described by the test administrator? YES NO

18. Attending to a story. The test administrator will read a short story to your child.

Will your child be able to attend to the story? 
19. Placing beads in a tube (see picture).

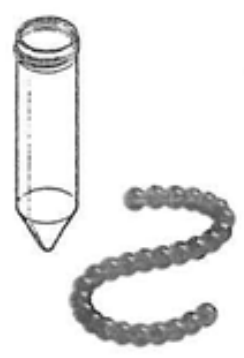

Will your child be able to put the string of beads into the plastic tube?

YES NO

20. Understanding prepositions. The experimenter will place two cups in front of your child, with one inverted. The experimenter will then ask your child to place a small toy bunny on a cup, in a cup, under a cup, and then between the cups. The experimenter will then remove the inverted cup and ask your child to put the bunny behind the cup and then in front of the cup.

Will your child be able place the bunny correctly at least twice? YES NO

21. Remembering shapes. The experimenter will show your child a plastic circle and then ask your child to point to the circle when shown a circle, square, and triangle. This procedure will then be repeated with the square and the triangle.

Will your child be able to point correctly to two of the shapes? YES NO

22. Comparing weight. Your child will be handed two boxes that differ in weight.

Will your child be able to identify the heavier box?

23. Counting. The experimenter will ask your child to count.

Will your child be able to count at least to three?

YES NO 
24. Writing with a pencil.

Will your child use the method illustrated below to hold the pencil? YES NO

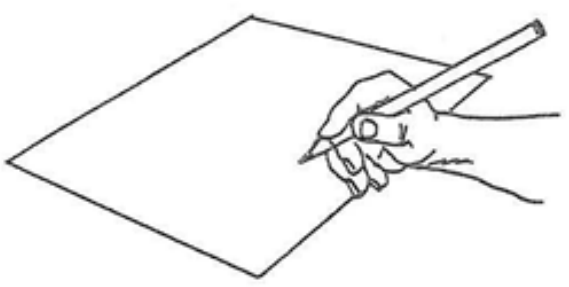

Will your child hold the paper in place with one hand while writing with the other hand?

YES NO

25. Placing pellets in a bottle.

Will your child be able to put 10 small sugar pellets

in a bottle in 60 seconds?

YES NO

26. Discriminating shapes. Your child will be given a shape (a peg, a cube, or a square) to feel, but not see.

Will your child be able to pick out which shape he or she felt? YES NO

27. Motor skills. Which of the following skills will your child be able to demonstrate?

Standing alone on right foot (without help)

Standing alone on left foot (without help)

YES NO

Walking forward on a line (at least one foot on the line)

YES NO

Walking backward close to a line

YES NO

Trying to kick a ball (even if unsuccessful)

YES NO

Jumping off the floor with both feet

YES NO

Walking up stairs alone, placing both feet on each step

YES NO

Walking down stairs alone, placing both feet on each step

YES NO

Jumping from the bottom step of the stairs to the floor

YES NO

Putting three beads on a lace

YES NO

Imitating hand movements (like clapping, making circles)

YES NO

Walking on tiptoe for four steps

YES NO

Jumping a distance of at least 4 inches

YES NO

YES NO 


\section{Appendix G}

Toddlers' Emotional Behaviors Coding Sheet

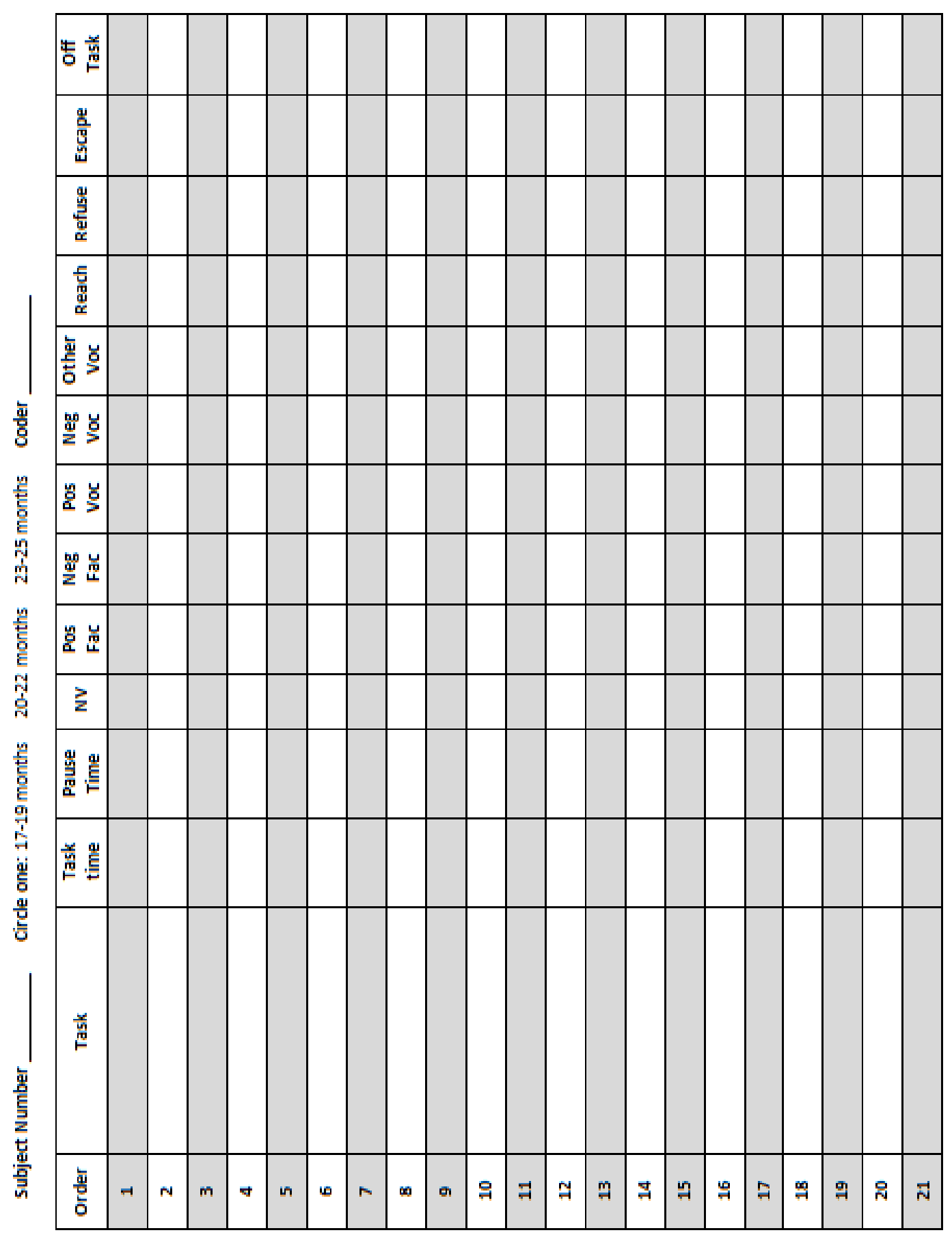



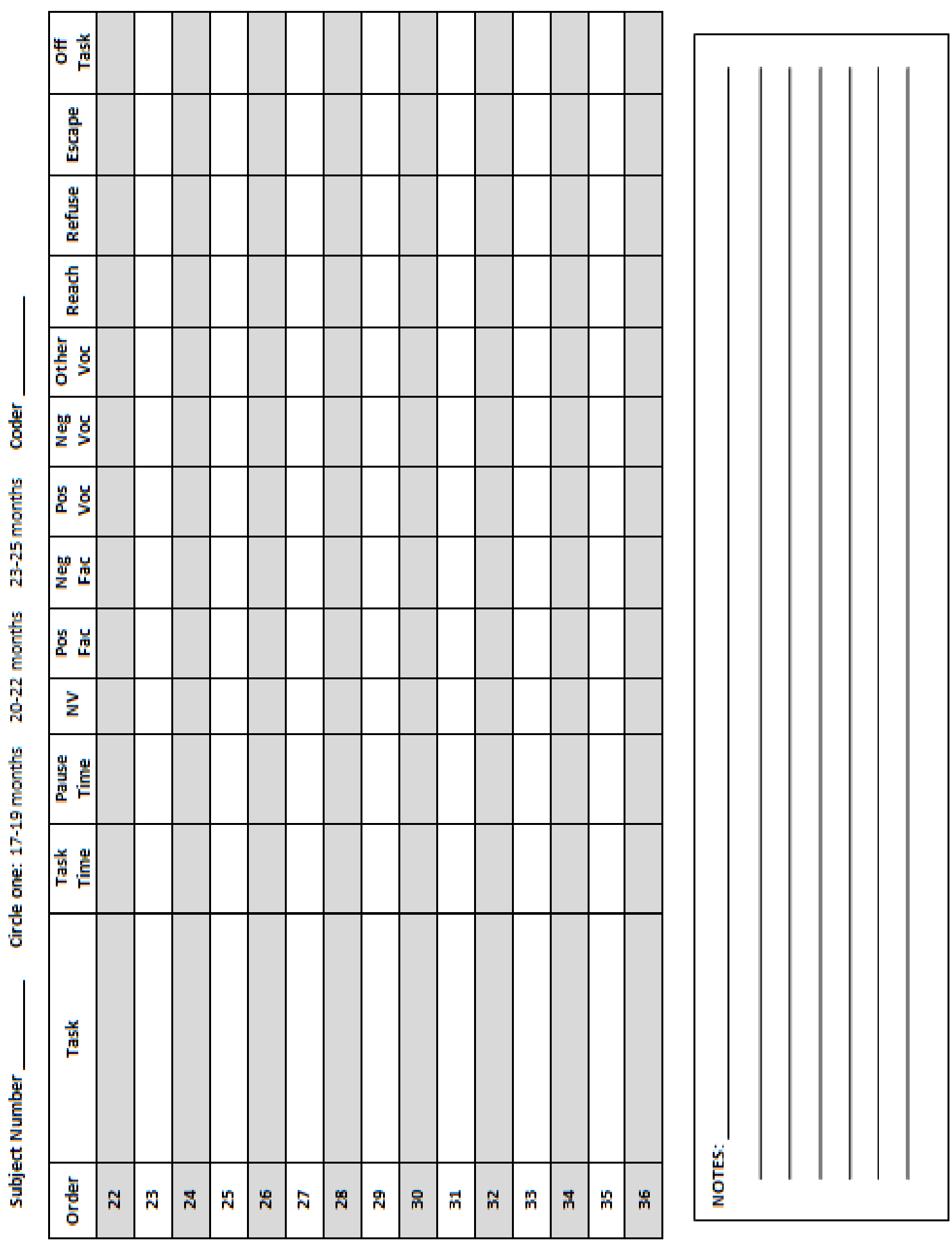


\section{Appendix $\mathrm{H}$}

\section{Coding Information}

\section{Top of coding sheet}

1. Coders were asked to write in subject number at the top left-hand corner of the coding sheet and add ".1" or ".2" depending on whether the video was from part 1 or 2 of the study.

All of the toddlers from part 1 on were small tapes that needed the adapter (ex: 5.1).

All of the toddlers from part 2 were on the larger tapes that did not need the adapter (ex 5.2).

2. Coders were told not to circle which age group the toddler was in, but rather that the researcher would do that on her coding sheets.

3. Coder put their initials at the top right-hand corner of the coding sheet (e.g. DP, JS, KK).

\section{Explanations of coding scheme}

Coders were told that the researcher was more interested in whether or not the behavior occurred during the task than how many times a behavior occurred. Therefore, for all of the coding columns, except task time and pause time, they were asked to indicate whether the behavior occurred during the task (with a $\checkmark$ ); if behaviors did not occur they were asked to leave that area blank.

\section{Explanation of coding sheet items}

1. Task - The task that was being presented to the toddler. Coders described each task using the short phrases on an additional sheet.

If task was presented more than once during test, coders were asked to make another row for that task.

2. Intra-task time - "Task time." Time during which the toddler was actively engaged in completing the desired task. Coders were asked to begin the stopwatch when administration of the task started and end it when administration ended. Typically, administration ended when task materials were put away. Coders were also reminded to reset stopwatch the stopwatch.

3. Inter-task time -“Pause time." Time between tasks toddler was not engaged in a task, typically administrator and parent were chatting or administrator was getting materials ready for the next task. Once again, coders were asked to start the stopwatch when pause time occurred and once the toddler was directed back to a task to stop the stop watch. Coders were also reminded to reset the stopwatch. 
During this time the toddler may have been presented with a task material, still have the task materials from a previous task, or have nothing at all. If the toddler was not actively engaged in completing the desired task, then the time should have been coded as pause time.

4. Not visible - "NV." When task was not visible on the screen or coders were unable to see toddler completing the task. Coders were asked not to try and code any other coded during that time, but rather start a new row when toddler came back into the camera view.

6. Positive facial expression - "Pos fac." Most commonly a smile or look of excitement with widened eyes and opened mouth (like an "oh wow" expression, not a "deer in the headlights" expression).

Due to the quality of the videos and the angle of recording, these were difficult to see.

Coders were asked only to it if they were confident that they could see that the toddler's face had a positive facial expression.

7. Negative facial expression - "Neg fac." Most commonly a frown or quivering lips with widened eyes (with body language expressing fear rather than excitement). Typically these were rare unless the toddler was about to cry or was looks scared or nervous.

Once again, due to the quality of the videos and the angle of recording, these were difficult to see. Coders were asked only to code it if they were confidence that they could see that the toddler's face had a negative facial expression.

8. Positive vocalizations - "Pos voc." Vocalizations such as laughing, saying "yay" or "yes", or a squealing with excitement would fall into this category. Positive vocalizations, both in response to the task and to parent or administrator, were coded.

9. Negative vocalizations - "Neg voc." Vocalizations such as whining, crying or saying "no" would fall into this category. Negative vocalizations, both in response to the task and to parent or administrator, were coded.

10. Other vocalizations - "Other voc." Sometimes the toddler vocalized but it was not discernible as positive or negative. These types of vocalizations, that were neutral, were coded in this column.

For example - vowel sounds were often ambiguous "eheh," "oooo," "aaaa," "uh oh," etc., or the toddler says something, understandable or not, and the coders could not categorize it as positive or negative. Coders were then asked to indicate in this column that a vocalization had occurred. 
11. Reaching - "Reach." Movement for the tasks' materials as it was presented or offered to the toddler, or as it was being taken away.

For example - using hand to reach up or out for task material or lifting up out of seat to get task (and not because s/he simply cannot reach it). Reach was not coded when a toddler reached to pick up a material during the task, such as a peg for the pegboard or puzzle piece for the puzzles.

12. Refusals - "Refuse." Movement to push the task away as it was presented or to push materials away during a task.

For example - using hand to push away task material, swat at the materials, etc.

13. Attempted escapes - "Escapes." Movement away from table or testing environment.

Escape was not coded if the toddler was getting down to pick up a dropped item or completing an item on the ground (such as kicking a ball). Escape was coded if the toddler tried to push away from the table or squirm off of mother's lap. The caveat for squirming off mother's lap was if they wanted a chair of their own; this action was not coded as escape because they were not trying to escape from the testing environment but rather seemed to want a chair of their own.

14. Off task behaviors - "Off-task". Attention to another toy, item, or task. This behavior could be for only a fraction of a second, but coders were reminded it still counted as occurring during a task.

For example, holding a blanket during the test and leaning back to cuddle with blanket in during the task, or holding food (pretend or real) and taking a "bite" during a task. Other examples included sucking his/her thumb, reaching for the balloon cut-outs on the table, and making faces in the window. Almost any behavior that indicated the toddler was not giving his or her full attention to the task at hand was coded as off task.

\section{Additional Notes}

1. Timing began when administration of the Bayley began, not when the video began.

2. It was not unusual to have to stop and start the video, and actually recommended, to ensure proper coding of behaviors as well as task and pause time.

2. Coders were asked not try to code behaviors that they could not see (thus were off-screen), but rather asked to mark as not visible. In addition, most of the gross motor tasks were completed off camera. Sometimes once the mother, toddler, and administrator left the room the video would stay on for few minutes and you could hear them in the hallway, coders were asked not to try to list or code these behaviors. Typically once they left the coding for that video 
was complete. However, if coders had only recorded a few tasks they were asked to fast forward the video to see if the participants came back into the room to try Bayley tasks once more. If they did, coders indicated on the coding sheet that there was a break and then resumed coding.

3. Often it was difficult to see the toddler's face due to the angle of the child camera to the toddler, so coding was done conservatively. The researchers preferred that the coders be absolutely confident they saw that behavior than just think that's what it was and code it.

4. Coders were also asked to use the notes section on the back as needed. Notes included comments about the possible validity of the test, if the toddler was engaging in social referencing, or if the toddler had an item during the assessment that distracted them across multiple tasks. 


\section{Appendix I}

\section{Task Names and Descriptions}

Blocks - Child is presented with set of blocks, shown how to make a tower with three blocks, and asked to build a tower as well.

Block Train - Child is presented with set of blocks, shown how to make a train with the cubes, and asked to make one as well.

Concept of one - Child is asked to hand the administrator one block.

Retrieves toy - A small toy is placed inside a clear box and the child is asked to remove the toy without moving the box.

Hidden toy - A small toy is placed inside one of two cups, cups are switched around, and then child is asked to pick the cup she/he believes the toy is under.

Stick toy - Child uses a stick-like object to move a toy toward them on the table.

Pegboard - Child is presented with yellow, rectangular pegboard and asked to place 6 yellow pegs in the holes.

Hidden objects - Child is shown a board with figurines on it, the board is then hidden by a manila folder and the child is asked to locate a certain figurine within a picture that is presented. The picture is a copy of how the board is set up.

Blue puzzle - Child is presented with a blue puzzle board that has 9 total pieces to fill in. The pieces are in the shape of circles and squares.

Doll caretaking - Child is presented with a baby doll and asked to comb the baby's hair, feed the baby, and blow the baby's nose.

Doll parts - Child is presented with a baby doll and asked to locate its body parts (e.g. fingers, toes, nose, etc).

Pink puzzle - Child is presented with a pink puzzle board that has 3 total pieces. The pieces are in the shape of a circle, a square, and a triangle.

Rotated pink puzzle - If child completes the pink puzzle taks, the administrator removes the pieces and rotates the puzzle 180 degrees for the child to complete to puzzle once more.

Drawing - Child is given a piece of paper and a crayon and asked to mimic the lines and circle drawn by the administrator.

Pencil holding - Child is given a piece of paper and a pencil and asked to draw with the pencil. 
Pellets in bottle - Child is given a small bottle and several tiny pellets and asked to put the pellets into the bottle.

Story - Administrator reads a "Thomas the Tank Engine" story to the child.

Naming pictures - Child is shown 10 pictures (4 on the first page, 6 on the second) and asked to name each one. For each one not named the administrator asks "where is the ..." and the child is expected to point to the corresponding picture.

Naming objects - Child is given several objects (e.g. ball, book, pencil, spoon, cup) and asked to name each object.

Discriminate - Child is given several objects (book, cube, and key) and asked to point to the object that the administrator names.

Match pictures - Child is shown a booklet that has one picture at the top and 4 pictures at the bottom of each page. The child is asked to match the picture at the top with one of the pictures at the bottom of the page by pointing to the corresponding picture.

Match colors - Child is shown a page with circular color splotches ( 3 or 5 ) and asked to place the same colored circles on the corresponding splotches.

Beads in tube - Child is given a string of beads, shown how to put the beads into the tube, and then asked to put the beads into the tube themselves.

Lacing beads - Child is given a string and several beads, shown how to put the beads onto the string, and then asked to string the beads themselves.

Action pictures - Child is shown several pictures of children engaging in different activities. The child is asked to point to the picture with the children engaging in the activity that is described by the administrator.

Compare masses - Child is asked to hold two cubes and identify which is heavier than the other.

Geometric forms - Child is shown a square, a triangle, and a circle. The shapes are then hidden from child's view and administrator hands the child one to look at and feel. Then it is put back with the others, all shapes are shown and the child points to the one she/he just saw and felt.

Tactile shapes - Child is asked to put hand through semi-arc in manila folder and feel a shape (peg, cube, or square) on the other side. Then child is shown objects and asked to point to the object they felt but could not see.

Prepositions - Child is given the bunny figurine and one cup. The child is asked to put the bunny on top of the cup, under the cup, behind the cup, etc. 
Discriminate pictures - Child is shown a picture of an apple and then asked to point to the apple on the next page of fruit. Child is then shown a picture of a giraffe and asked to point to the giraffe on the next page of animals.

Compare sizes - Child is shown a picture of a small tree and a large tree and asked to point to which is the larger and which is the smaller.

Counting - Child is asked to count.

Hand motions - Child is asked to mimic hand moves that the administrator (e.g. big circles on the table). 
Darcey N. Powell

Curriculum Vitae

LOCAL ADDRESS

PERMANENT ADDRESS

212 Morgan Pointe

Morgantown, WV 26505

35 Bryce Lane

Martinsburg, WV 25405

Phone: (304)671-1541

Email: Darcey.Powell@,mail.wvu.edu

\section{EDUCATION}

West Virginia University

Morgantown, WV

Program: $\quad$ Life-span Developmental Psychology

Degree: $\quad$ Ph.D. (Expected May 2013)

Academic Advisor: $\quad$ Katherine Karraker, Ph.D.

West Virginia University

Program: $\quad$ Life-span Developmental Psychology

Degree: $\quad$ Ph.D. (Expected December 2011)

Academic Advisor: Katherine Karraker, Ph.D.

Cumulative GPA: $\quad 4.00$

West Virginia University

Program: $\quad$ Psychology

Degree: $\quad$ B.S. May 2009

Institutional honors: Summa Cum Laude

University Honors Scholar

Academic Advisor: $\quad$ Kevin Larkin, Ph.D.

Cumulative GPA: $\quad 3.82$

Psychology GPA: $\quad 4.00$

\section{RESEARCH INTERESTS}

Parent-Child Relationship

Transition to parenting, knowledge of child development, parenting self-efficacy, and facilitation of social development

\section{Children}

Infants (birth to 24 months) and toddlers (24 months to 3 years)

$\underline{\text { Assessment }}$ 
Infant, toddler, and preschool developmental assessments

\section{SCHOLARSHIPS, HONORS, \& AWARDS}

Scholarships:

HERF Supplementary Fellowship

AmeriCorps Educational Stipend

Mountaineer Scholarship

Promise Scholarship

Honors:

Phi Beta Kappa

Psi Chi - Psychology Honorary

Chimes - Junior Honorary

WVU Honors College

Awards:

WV Academy of Science

-Best poster presentation

Presidential Volunteer Service Award West Virginia University
$2009-2010$

$2009-2010$

$2005-2009$

$2005-2009$

West Virginia University

West Virginia University

West Virginia University

West Virginia University

2009 - Present

2007 - Present

$2007-2008$

$2005-2009$

April 2010

West Virginia University

$2007-2008$

\section{TEACHING EXPERIENCE}

Graduate Teaching Assistant:

Class:

Duties:

Faculty Supervisor:

Institution:

Graduate Teaching Assistant:

Class:

Duties:

Faculty Supervisor:

Institution:

Co-mentor:

Class:

Duties:

Faculty Supervisor:

Institution:
Fall 2010 to Spring 2011

Introduction to Human Development

Lecture to, grade assignments, and proctor exams for approximately 120 students each semester.

Aaron Metzger, $\mathrm{Ph}$. D.

West Virginia University

Fall 2009 to Spring 2010

Introduction to Psychology

Lecture to, grade assignments, and proctor exams

for approximately 115 students each semester.

Constance Toffle, Ph.D. and Julie Patrick, Ph. D.

West Virginia University

Fall 2006 and Fall 2007

Honors Orientation for incoming freshmen

Developed syllabus and lesson plans for the

semester. Oriented incoming freshmen to WVU and the Honors College.

Keith Garbutt, Ph.D. and undergraduate Lauren

Dembeck

West Virginia University 


\section{RESEARCH EXPERIENCE}

Teaching Project:

Title:

Authors:

Institution:

Literature Review:

Graduate Research Assistant: Laboratory Training:

Duties:

Faculty Supervisor: Institution:

\section{Master's Thesis:}

Title:

Authors:

Institution:

Literature Review:

Graduate Research Assistant: Laboratory Training:

Duties:

Faculty Supervisor:
Fall 2010 to Spring 2011

Effect of Self-Explanations on Student Performance Darcey N. Powell, Kaitlyn A. Ferris, Aaron Metzger, Ph.D., \& Katherine, Karraker, Ph.D.. West Virginia University Improving performance on assignments in Psychology courses by having students explain why they selected a particular answer as correct.

Fall 2010 to Spring 2011

Adolescent Development Laboratory - assisted with data collection for civic study and preliminary data collection for adolescent-parent communication study.

Traveled to recruit and collect data from middle and high school students, discussed conceptualization of measures for adolescent-parent communication study, and aided in the preliminary collection of videotaped discussions on a set of topics.

Aaron Metzger, Ph.D.

West Virginia University

Spring 2010 to Fall 2011

Mothers' Accuracy and Bias in Predicting Their Toddlers' Performance on the Bayley Scales of Infant Development

Darcey N. Powell, Katherine Karraker, Ph.D., \& Priscilla Coleman, Ph.D.

West Virginia University

Mothers' knowledge of child development, and their biased predictions of their own children's behavior.

Fall 2009 to Present

Infant Social Development Laboratory - assisted with social interaction study and study on correlates of parenting attitudes and knowledge, as well as provided guidance to undergraduate assistants. Helped during the toddler play groups and interviewed mothers for social interaction study, discussed conceptualization of and online setup of study on correlates of parenting attitudes and knowledge, and provided guidance to and feedback on submissions to undergraduate research assistants. Katherine Karraker, Ph.D. 
Institution: $\quad$ West Virginia University

Honor's Thesis and Investigation: Spring 2008 to Fall 2009

Title:

Authors:

Institution:

Literature Review:

Undergrad Research Assistant:

Laboratory Training:

Duties:

Faculty Supervisor:

Institution:

\section{WORK EXPERIENCE}

Pre-Psychology Advisor

Duties:

Supervisor:

Institution:

SONA systems Administrator Duties:

Supervisor:

Institution:

Assessment Administrator:

Duties:
Adults' Preferences for and Stereotypes Associated with Infant Names

Darcey N. Powell, Katherine Karraker, Ph.D., Marion Young, M.S., \& Jessica Stoltzfus, M.S. West Virginia University

Factors that influence adults' liking and choice of names, and stereotypes associated with different names.

Fall 2007 to Spring 2009

Infant Social Development Laboratory - assisted with prematurity stereotyping study.

Set-up study on online database, data collection, data entry, and presentations

Katherine Karraker, Ph.D.

West Virginia University

July 2011 to Present

Meet with $\sim 500$ undergraduates each semester to discuss their current status as a Pre-psyc major and make suggestions for future classes, as well as answer any additional questions they may have over the course of the year.

Amy Fiske, Ph.D.

West Virginia University

July 2011 to Present

Handle any issues that arise with the online database that the Psychology Department uses to collect data, as well as answer questions from undergraduates, graduate students, and faculty about the system.

Dr. Amy Fiske, Ph.D.

West Virginia University

May 2011

Provided methodological and conceptual suggestions for the assessment, distributed assessment and conducted interview with the students (ranging from kindergarten to $12^{\text {th }}$ grade), and served as a liaison between Helianthus LLC and 
Supervisor:

Institution:

Engineering Psychologist Intern:

Duties:

Supervisor:

Institution:

College-level Tutor:

Duties:

Supervisor:

Institution:

Energy Express Mentor:

Duties:

Supervisor:

Institution:

Resource Teacher:

Duties:

Supervisor:

Institution:

Nursery Attendant

Duties:

Supervisor:

Institution:
PATCH (an afterschool program in western West Virginia seeking evaluation for external funding). Bob Dunkerley

Helianthus LLC

May 2010 to August 2010

Determined the age appropriateness of consumer products, coded large data sets, and completed office-related tasks.

Robert Oschman, Ph.D.

U.S. Consumer Product Safety Commission

August 2008 to August 2009

Tutored student athletes in various subjects for academic improvement.

Paul Downey

West Virginia University

June 2007 to August 2007

Taught and supervised a group of 8 children with a focus on reading, writing, art, and nutrition. Kella Zicafoose, M.Ed. AmeriCorps

May 2006 to May 2009

Assisted teachers with infant and toddler daily activities and learning; worked at the front desk to aid managers with administrative tasks.

Sandy Panrell

WVU Child Development Center

Sept 2003 to June 2005

Supervised the children in the church nursery while their parents attended the weekly church service.

Carried out activities with groups of children ranging in age from 6 weeks to 7 years old.

Tanya Cole

Trinity Episcopal Church

\section{CONFERENCES}

\section{Attended:}

Association for Psychological Science Annual Convention 
Association for Psychological Science - Society for the Teaching of Psychology

Teaching Institute

Washington, DC

Research Horizons

Morgantown, WV

Science and Technology in Society

Morgantown, WV
May, 2011

April, 2011

April, 2011

Society for Research in Child Development

Montreal, Canada April, 2011

Society for Research in Child Development Developmental Science Teaching Institute

Montreal, Canada $\quad$ March, 2011

Research Horizons

Morgantown, WV April, 2010

WV Academy of Science

Morgantown, WV

April, 2010

International Conference on Infancy Studies

Baltimore, MD

April, 2010

Society for Research in Child Development

Denver, CO

April, 2009

Tristate Undergraduate Conference

Morgantown, WV April 2009

Eastern Psychological Associations

Pittsburgh, PA

March, 2009

International Society for Psychobiology

Washington, DC

November, 2008

Second Annual Professional Development Conference for Undergraduates

Interested in Graduate Training in Family and Child Sciences

Arizona State University

September, 2008

Undergraduate Research Day

West Virginia University $\quad$ February, 2006

\section{Presented:}

Karraker, K., Powell, D. N., Coleman, P. (2011, May). Maternal Expectations Related to Toddler Performance on the Bayley. Poster presented at APS Annual Convention, Washington, DC.

Powell, D. N., Karraker K. (2011, May). Adults’ Perceptions of Infants are Differentially Impacted by Names and Photographs. Poster presented at APS Annual Convention, Washington, DC.

Powell, D. N., Ferris, K., Metzger, A., \& Karraker, K. (2011, May). Self-Explanation of an Answer Choice is Beneficial to Student Performance. Poster presented at APS - STP Annual Convention Teaching Institute, Washington, DC. 
Powell, D. N., Karraker, K., \& Coleman, P. (2011, April). Maternal Expectations Related to Toddler Performance on the Bayley Scales of Infant Development. Poster presented at Science and Technology in Society: Effective Communication Strategies, Morgantown, WV.

- Also presented at Research Horizons (2011, April), Morgantown, WV.

Powell, D. N., Ferris, K., Metzger, A., \& Karraker, K. (2011, March). Effects of Requiring Students to Provide Explanations for Answers to Homework Questions. Poster presented at SRCD Developmental Teaching Institute, Montreal, Canada.

Powell, D., Karraker, K., Young, M., \& Stoltzfus, J. (2010, March). Adults' Liking of Names. Poster presented at the International Conference on Infant Studies, Baltimore, MD.

- Presented at Research Horizons (2010, April), Morgantown, WV.

- Presented at WV Academy of Science (2010, April), Morgantown, WV.

Powell, D., Karraker, K., Young, M., \& Stoltzfus, J. (2010, March). Adults’ Perceptions of Infants Depicted through Names and Photographs. Poster presented at the International Conference on Infant Studies, Baltimore, MD.

- Presented at Research Horizons (2010, April), Morgantown, WV.

- Presented at WV Academy of Science (2010, April), Morgantown, WV.

0 Won award for best poster presentation by a graduate student

Powell, D., Karraker, K., Young, M., \& Stoltzfus, J. (2009, April). Adults’ Preferences for and Stereotypes Associated with Infant Names. Poster presented at the Tristate Undergraduate Conference, Morgantown, WV.

\section{PROFESSIONAL MEMBERSHIP}

2001

2011

2011

2010 - Present

2010

2009

2009

2009

2009

$2008-2009$

$2006-2009$
International Society of Infant Studies

Association for Psychological Science

Society for Research in Child Development

Society for the Teaching of Psychology

International Society of Infant Studies

Eastern Psychological Association membership

International Society of Development Psychobiology

Society for Research in Child Development

Vice President of Silver Wings

Professional development and community service organization

Service co-chair for Psychology Club and Psi Chi

National Exemplary Students in Service

Community service organization

\section{OTHER EXPERIENCES}

Fall 2011 Guest presenter in Psyc 201: Psychology as a Profession. 
Fall 2011 Guest Panelist during the Graduate Teaching Assistant Orientation.

Spring 2011 Attended a workshop on writing effective conference abstracts.

Spring 2011 Attended a creative course design workshop.

Fall $2010 \quad$ Attended a guest lecture by Cameron Camp, Ph.D.

Spring 2010 Invited presenter on senior honor's thesis at the Advisory Board Dinner.

Spring 2010 Attended a workshop on how to find and apply for academic jobs.

Fall 2009

Attended a curriculum vitae and cover letter workshop.

Fall 2009

Attended a teaching portfolio workshop.

Fall 2008

Enrolled in graduate level course work as an undergraduate.

Fall 2008 Invited presenter on undergraduate research experience to college recruits.

Spring 2008 Invited for an honors luncheon with Laurie Santos, Ph.D.

Spring 2008 Attended a research designs guest lecture by Salvatore Insana.

2007-2008 Advising assistant for pre-psychology majors.

Fall 2007 Tutored Psychology 101 students as a member of Psi Chi. 